The Effects of Age on Stress and The Biomechanics of Slips and Falls

\author{
Thomas W. Davis
}

Masters Thesis submitted to the Faculty of Virginia Polytechnic Institute and State University in partial fulfillment of the requirements for the degree of

\author{
Master of Science
}

In

Industrial and Systems Engineering

Dr. Thurmon E. Lockhart, Chair

Dr. Tonya L. Smith-Jackson

Dr. Karen A. Roberto

August 15, 2002

Blacksburg, Virginia

Keywords: Required Coefficient of Friction, Heel Contact Velocity, Step Length, Anxiety, Stress 


\section{The Effects of Age and Anxiety on The Biomechanics of Slips and Falls}

by

Thomas W. Davis

\section{(ABSTRACT)}

Research has shown that older adults who have experienced a previous fall are $60-70 \%$ more likely to suffer future falls. A study was conducted to investigate if stress and anxiety associated with a fear of falling contributes to the increased incidents of falls among older adults. The investigation compared physiological parameters, with biomechanical parameters of walking for twenty-eight participants in two age groups: (18-35) and (65 or older). Both age groups were evaluated while walking over dry and slippery floor surfaces. Biomechanical parameters included: step length, required coefficient of friction (RCOF), slip distance, and heel contact velocity. Physiological parameters included: stress and anxiety.

Overall, the results indicated that there were differences between older and younger adult's biomechanical parameters of walking, and their physiological stress and anxiety associated with an inadvertent slip. Younger adult's normal RCOF was higher and their normal step length was longer compared to older adults. Older adult's stress level after a slip was significantly higher than younger adults. However, younger and older adult's anxiety scores were not significantly different. Furthermore, younger and older adults modified their step length differently to avoid slipping, when walking over the slippery floor surface. It was concluded that some anxiety and stress may be beneficial in reducing the occurrence of inadvertent slips and falls due to an increased awareness of one's external environment. 


\section{DEDICATION}

I would like to dedicate this thesis to my parents who have always encouraged my siblings and I to reach for our dreams. They have made enormous sacrifices in their life to provide and care for six children. Their love and support has inspired me to accomplishments things I never imagined. I thank them for being great parents and good role models. I love you and no matter how high I go in life; I will always look up to you.

Your Eldest Child,

Thomas Wayne 


\section{ACKNOWLEDGEMENTS}

First, I would like to thank God for continuously blessing me with the presence of mind, health, and faith to complete my Masters Degree. Next, I would like to thank Dr. Robin Keesee, Director of the Army Research Laboratory's Human Research and Engineering Directorate, for believing in me, and for giving me this opportunity.

To my Committee: I would like to thank my advisor, Dr. Thurmon E. Lockhart for his guidance through the thesis process. Additionally, I would like to thank Dr. Tonya L. Smith-Jackson and Dr. Karen A. Roberto for their great suggestions and valuable input.

Special thanks: To Lenita Daniels for the many hours she spent proof reading documents for me. To my colleagues, Linda Fatkin, Debbie Patton, and Jeannie Breitenbach, for their support and technical expertise. To Ryan Urquhart thank you for the laughs when I needed it, and the early morning and late night brainstorming sessions. To Ms. Lovedia Cole who always greeted me with a smile and went out of her way to help me with administrative matters. To the Locomotion Research Laboratory Team: Tanavadee Khuvasanont, Jeremy Spaulding, and Sukwon Kim, it was great working with you for the last 14 months. To Chuck Perala, Kayenda Johnson, LaTanya Martin, Charneta Samms, Kim Myles, and Ella Carter for their friendship and support.

Finally, to the Davis family, I would like to thank you for your prayers, encouragement, and support. 


\section{TABLE OF CONTENTS}

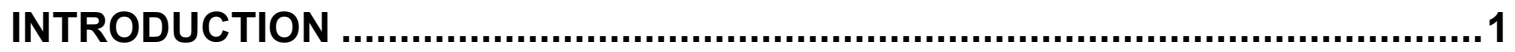

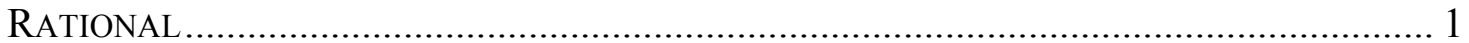

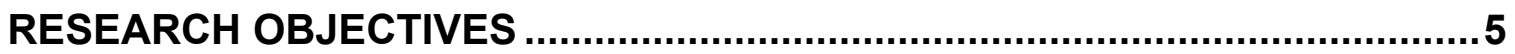

RESEARCH HYPOTHESIS .....................................................................

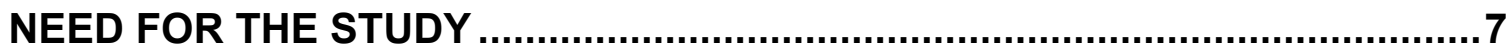

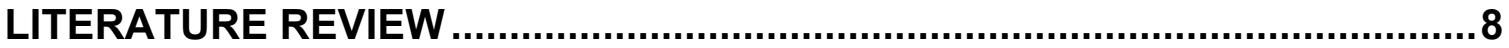

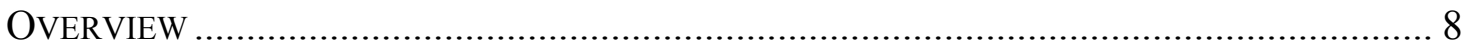

EPIDEMIOLOGY OF SLIP, TRIP AND FALL ACCIDENTS ………...................................... 8

PSYCHOPHYSICAL APPROACH........................................................................... 15

Function of Psychophysics........................................................................ 15

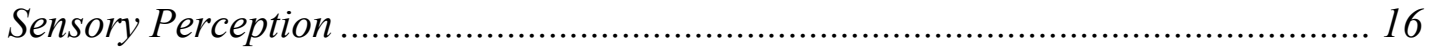

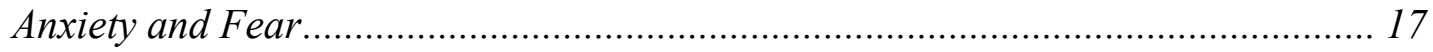

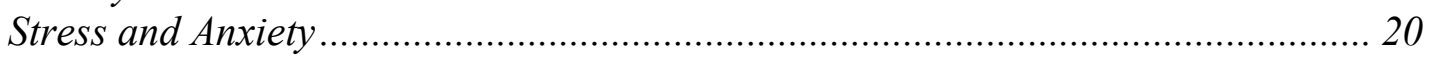

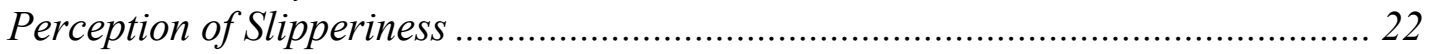

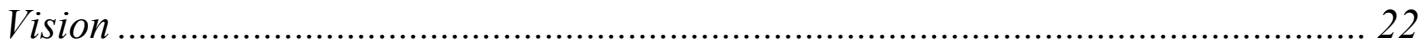

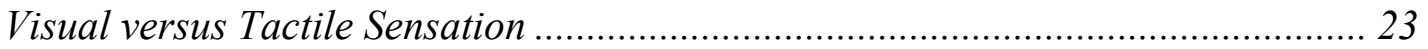

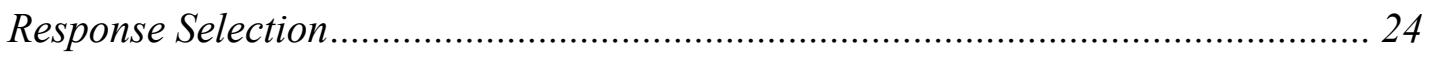

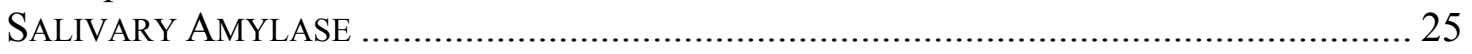

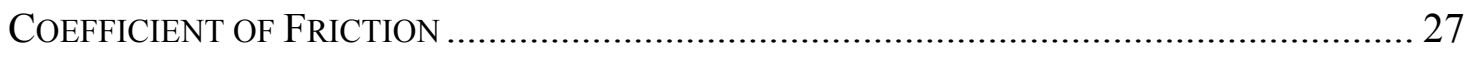

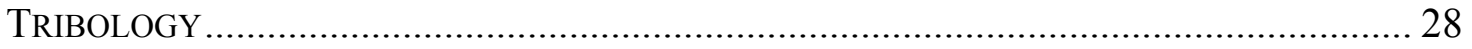

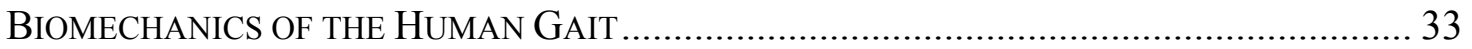

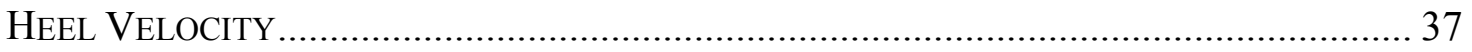

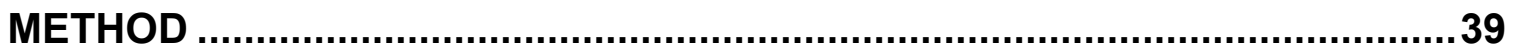

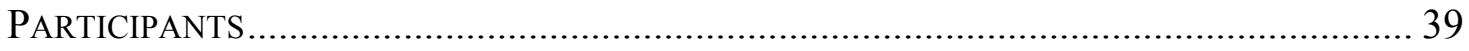

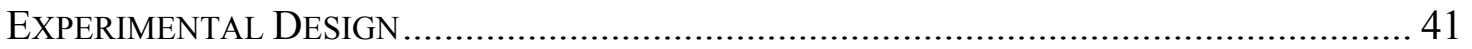

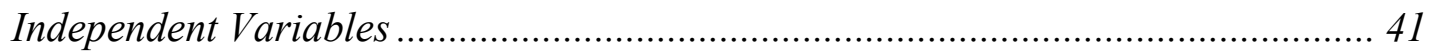

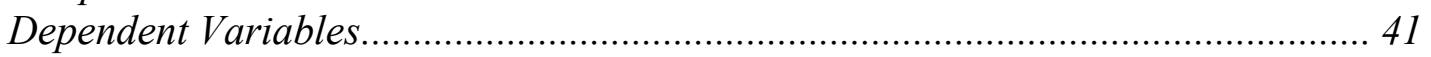

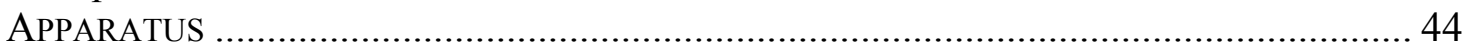

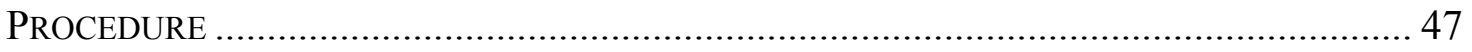

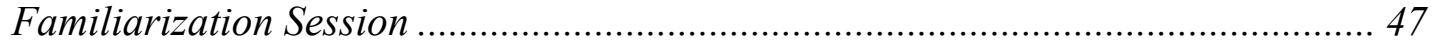

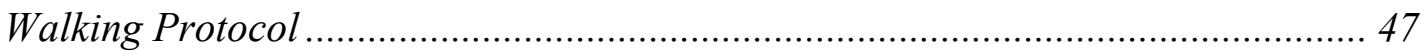

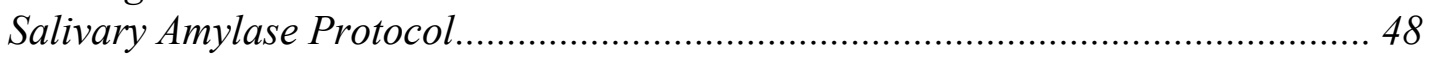

Multiple Affects Adjective Checklist (MAACL) Protocol........................................ 49

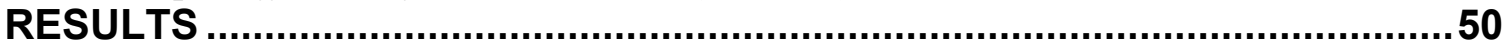

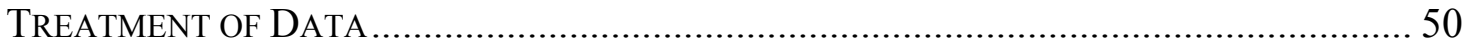

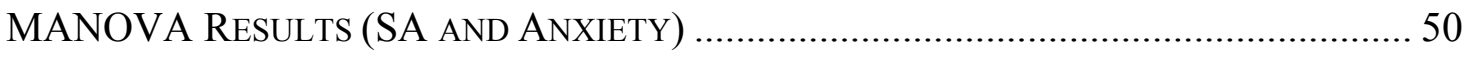

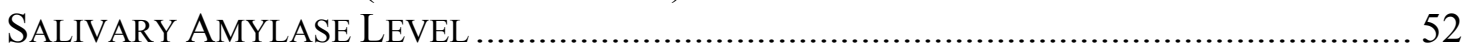

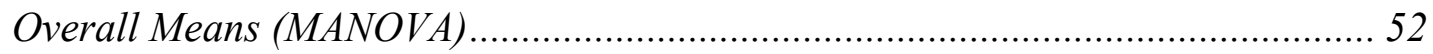

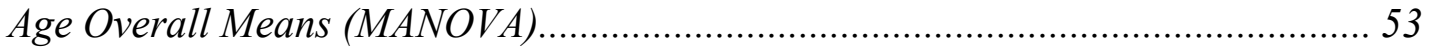

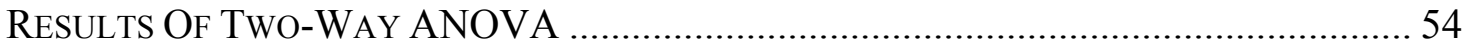

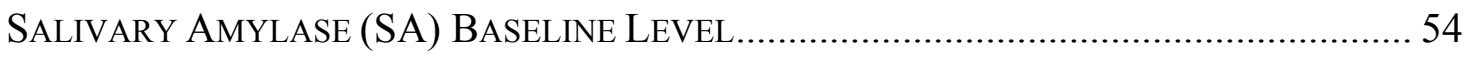

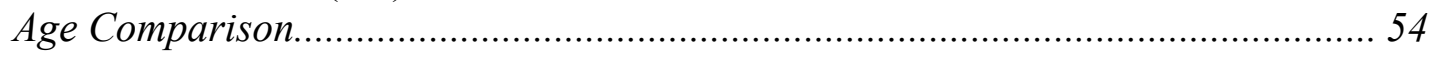

SALIVARY AMYLASE (SA) PRE-SLIP LeVEL ……………......................................... 54

Age Comparison.................................................................................. 54

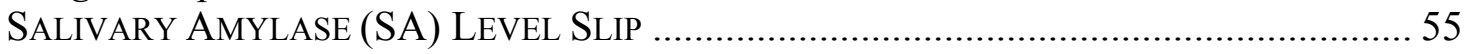




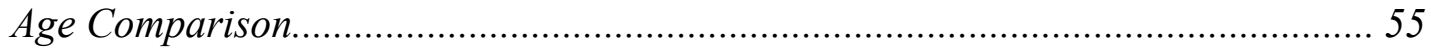

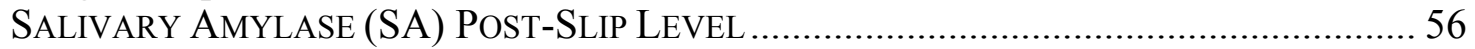

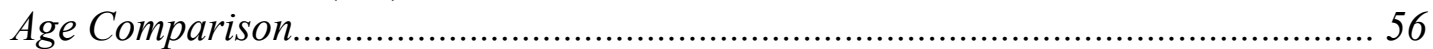

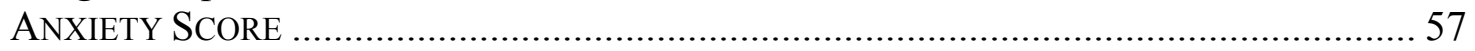

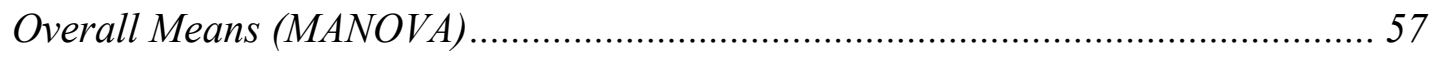

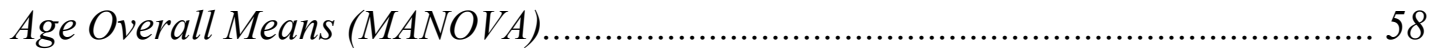

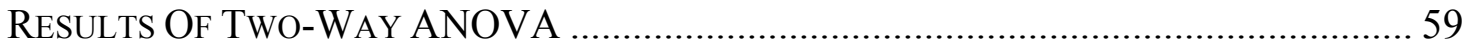

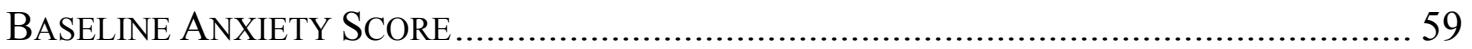

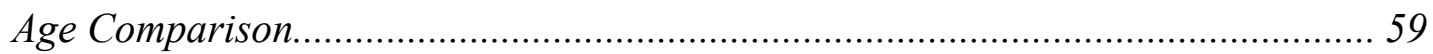

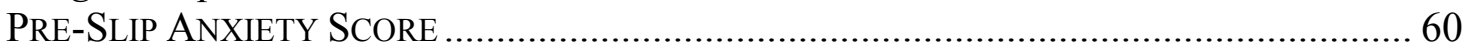

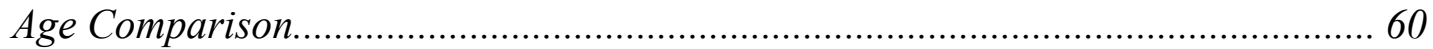

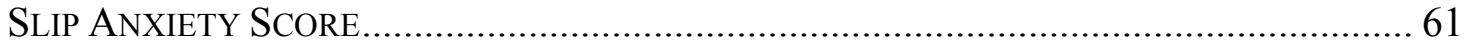

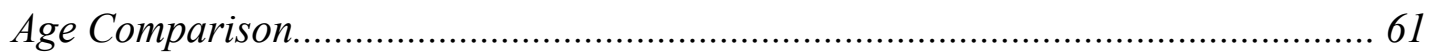

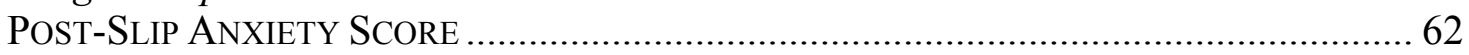

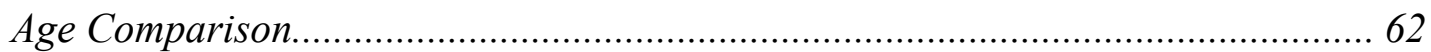

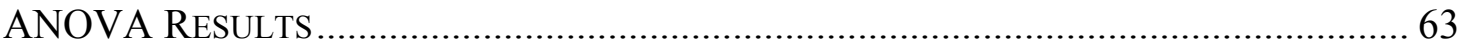

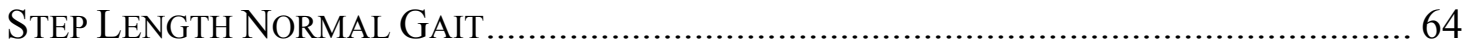

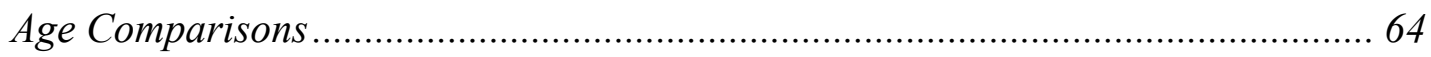

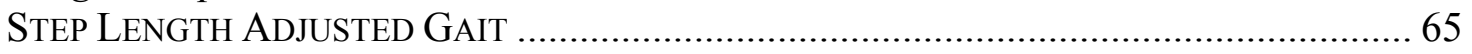

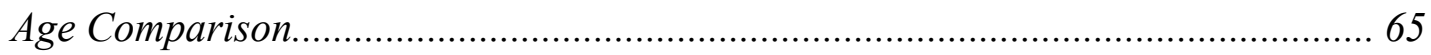

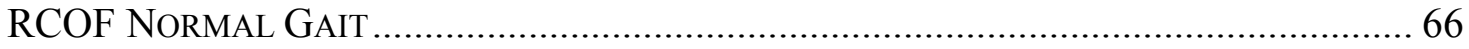

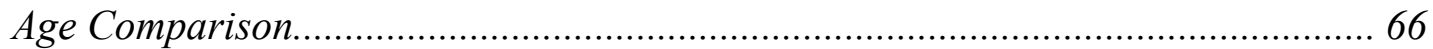

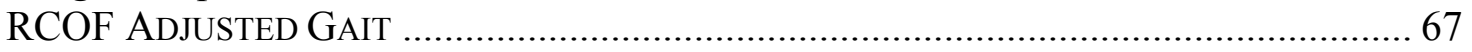

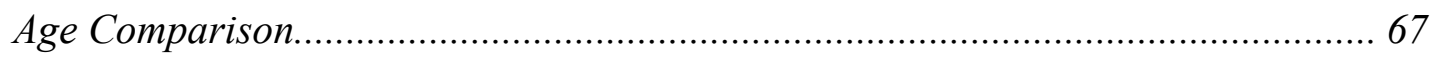

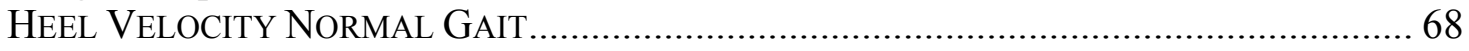

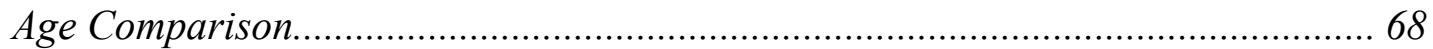

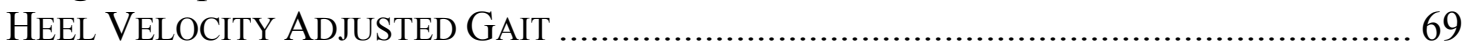

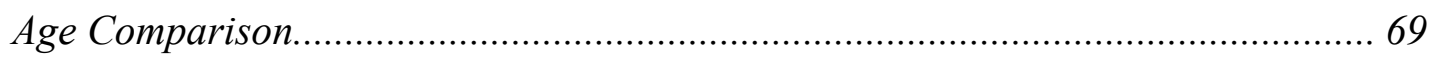

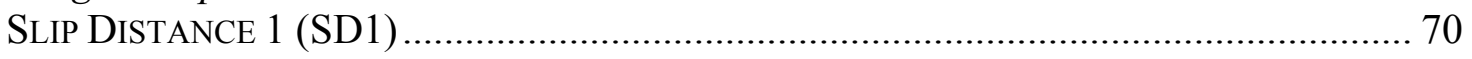

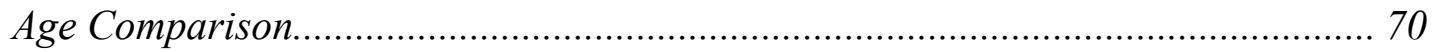

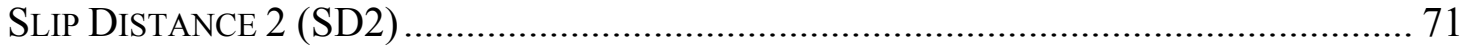

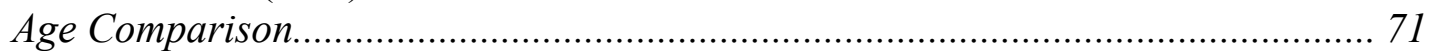

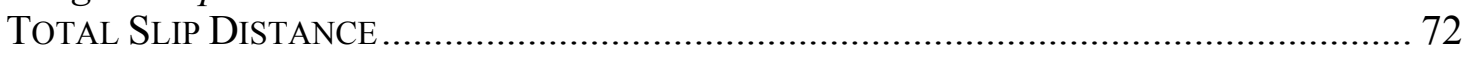

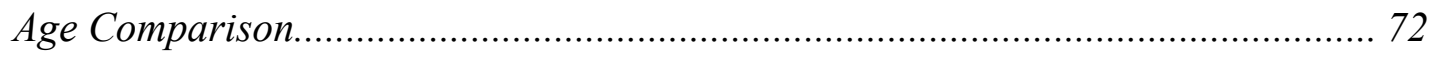

OldER AdUlts Normal AND AdJUSTED GAIT COMPARISONS ................................. 73

Older Adults Normal and Adjusted Step Length.................................................. 73

Older Adults Normal and Adjusted Step Length............................................... 74

Older Adults Normal and Adjusted RCOF ................................................... 75

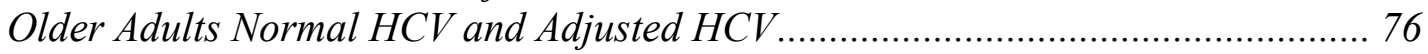

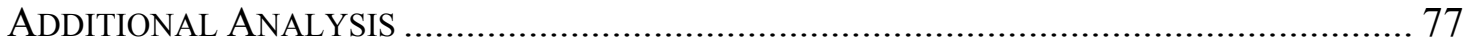

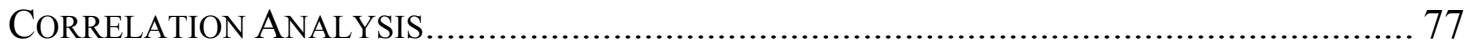

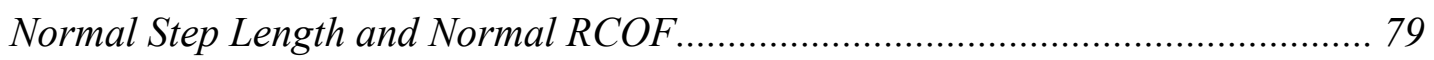

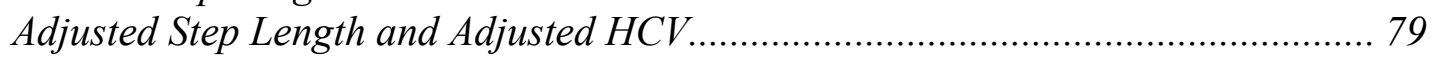

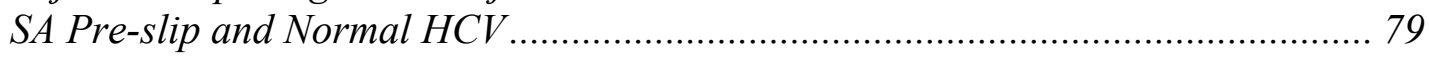

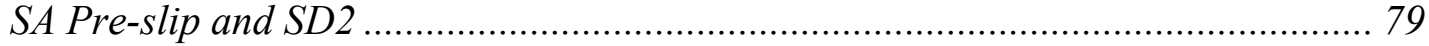

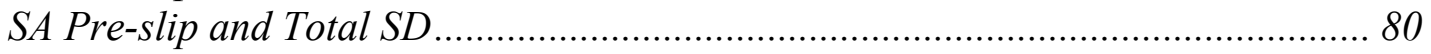




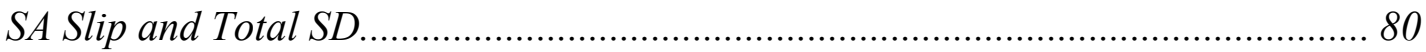

SA Post-slip and SD1 ............................................................................ 80

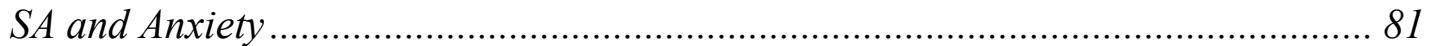

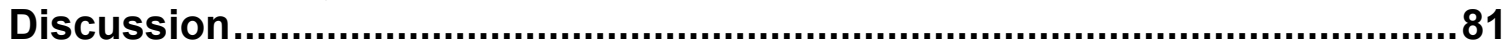

HYPOTHESIS AND EXPERIMENTAL FINDINGS: ......................................................... 81

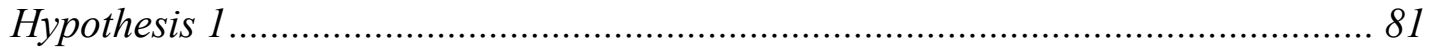

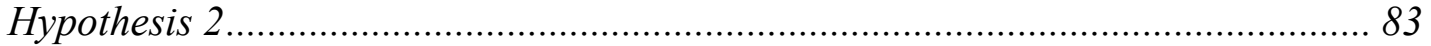

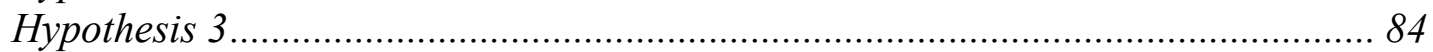

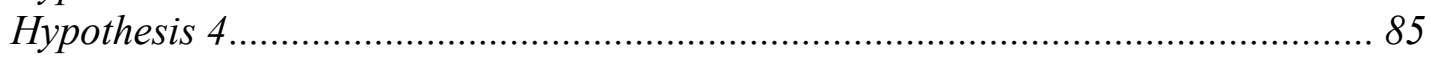

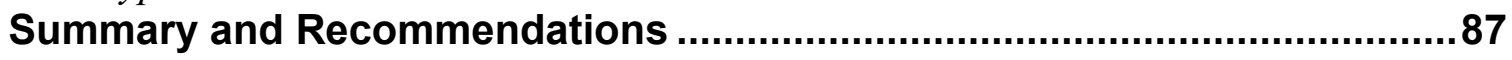

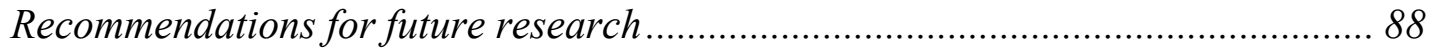

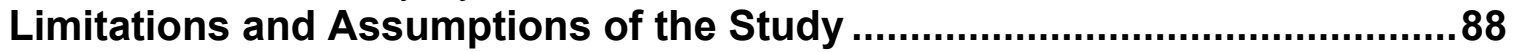

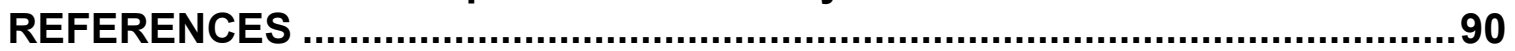

APPENDIX A: Informed Consent Form …............................................95

APPENDIX B: Personal Data and Medical History ......................................98

APPENDIX C: Multiple Affects Adjective Check List (MAACL) ...................100

VITA 


\section{LIST OF FIGURES}

Figure 1. Frictional $(\mathrm{F})$ and normal force $(\mathrm{FN})$ force vectors vs. horizontal $(\mathrm{FH})$ and vertical (FV) force vectors applied by the foot during the heel contact phase in normal level walking (adapted from Lockhart, 2000).

Figure 2. Number of persons in millions age 65 and older, from the year $1900-$ 2030 (adapted from the Administration on Aging, 2000)....

Figure 3. Deaths per 100,000 population by age in 1977 (Baker Harvey, 1996).

Figure 4. Fall injury rates per 100,000 persons. $0=$ females; $X=$ males

Figure 5. Beck's cognitive model of threat response (Adapted from Michelson \& Ascher, 1987).

Figure 6. Typical required coefficient of friction values for walking without slipping are represented by the bold curve and the thin line represents a micro- slip recovery (adapted from Lockhart 2000).

igure 7. Gait phases in normal level walking conditions with typical horizontal and vertical ratio for one step (adapted from Perkins, 1978).....31

Figure 8. Comparison of RCOF between young and older adults on four floor levels and cadence levels (adopted from Lockhart, 2000)...........34

Figure 9. Body Kinematics at heel contact for a typical walking trial...................38

Figure 10. Adjusted gait kinematic profile data. .........................................42

Figure 11. Field layout of the experiment including; Fall Arresting System, Infrared cameras (6), Linear Slide Floor Changer (LSFC) with force plate (F2) and hidden oily and non-oily test floor surfaces, fixed force plate (F1), Optoelectric Switch, and workstations. ...................................................46

Figure 12. Overall means of salivary amylase levels. ................................52

Figure 13. Age effect on overall SA means............................................53

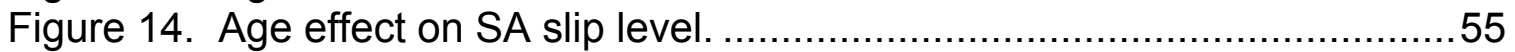

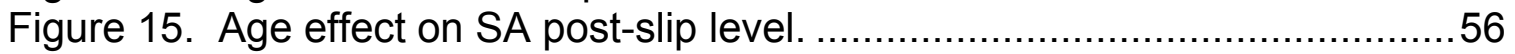

Figure 16. Overall means of anxiety scores............................................57

Figure 17. Age effect on overall anxiety score means. ..............................58

Figure 18. Age effect on baseline anxiety score.....................................59

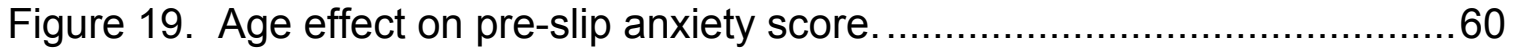

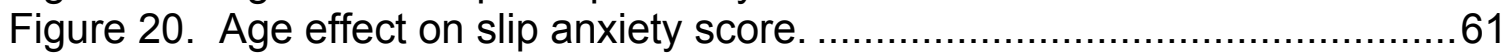

Figure 21. Age effect on post-slip anxiety score ...................................62

Figure 22. Age effect on step length normal gait......................................64

Figure 23. Age effect on step length adjusted gait...................................65

Figure 24. Age effect on RCOF normal gait.............................................6

Figure 25. Age effect on RCOF adjusted gait. ..........................................67

Figure 26. Age effect on heel velocity normal gait. ....................................68

Figure 27. Age effect on heel velocity adjusted gait...................................69

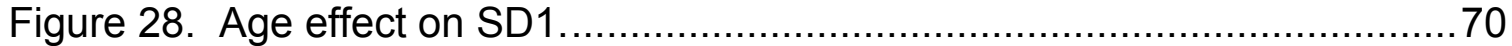

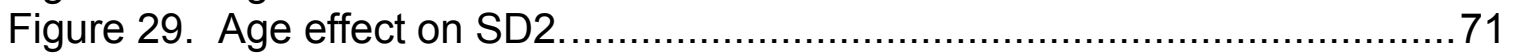

Figure 30. Age effect on total slip distance. ...........................................72

Figure 31. Comparison of older adults normal and adjusted gait Step Length...73

Figure 32. Comparison of older adults normal and adjusted gait Step Length...74

Figure 33. Comparison of older adults normal and adjusted gait RCOF...........75 
Figure 34. Comparison of older adults normal and adjusted gait HCV 


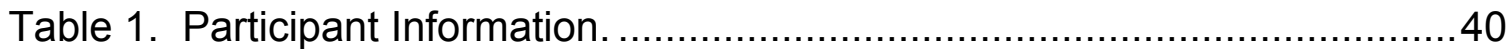

Table 2. Summary of MANOVA Means and Standard Deviations. ..................51

Table 3. Overall means and standard deviations for SA Level. ......................52

Table 4. Summary of overall SA mean levels for main effect age......................53

Table 5. Descriptive summary of SA baseline level on main effect age.............54

Table 6. Descriptive summary of SA pre-slip level on main effect age. .............54

Table 7. Descriptive summary of SA level after a slip on main effect age..........55

Table 8. Descriptive summary of SA level after a slip on main effect age..........56

Table 9. Summary of overall anxiety level means.......................................57

Table 10. Summary of overall anxiety means for main effect age ....................58

Table 11. Descriptive summary of anxiety baseline score on main effect age...59

Table 12. Descriptive summary of anxiety pre-slip score on main effect age. ...60

Table 13. Descriptive summary of anxiety score after slip on main effect age...61

Table 14. Descriptive summary of post-slip anxiety score on main effect age...62

Table 15. Summary of ANOVA Means and Standard Deviations. ....................63

Table 16. Descriptive summary of normal gait step length on main effect age. .64

Table 17. Descriptive summary of adjusted gait step length on main effect age.

Table 18. Descriptive summary of normal gait RCOF on main effect age. ........66

Table 19. Descriptive summary of adjusted gait RCOF on main effect age.......67

Table 20. Descriptive summary of normal gait heel velocity on main effect age.

Table 21. Descriptive summary of adjusted gait heel velocity on main effect age.

Table 22. Descriptive summary of SD1 on main effect age. ..........................70

Table 23. Descriptive summary of SD2 on main effect age...........................71

Table 24. Descriptive summary of total slip distance on main effect age...........72

Table 25 Summary of Correlation Analysis ................................................78 


\section{INTRODUCTION}

\section{Rational}

Injuries associated with slip and fall accidents continue to pose a significant problem to society, both in terms of human suffering and economic losses. The Center for Disease Control (2000) reported that older adults are hospitalized for fall-related injuries five times more often than they are for injuries from other causes. Moreover, of those older adults who fall, approximately $20 \%-30 \%$ suffer moderate to severe injuries that reduce mobility and independence, and increase the risk of premature death (Center for Disease Control, 2000). In addition, research has shown that the populations of older adults who have experienced a previous fall are $60-70 \%$ more likely to suffer future falls versus those who have not fallen previously (Carpenter, Frank, Silcher, and Peysar, 2001). This observation highlights the relationship between fear of falling and balance control. According to Tinetti et al. (1988), approximately $50 \%$ of older adults who have reported falling previously admitted to fear of falling. Fear of falling may be a result of deteriorated balance capabilities and decreased balance confidence (Carpenter, Frank, Silcher, and Peysar, 2001). Alternatively, fear of falling may influence changes in strategy or execution of postural control, which could be indirectly related to decreased postural performance and gait characteristics that can negatively impact slip induced falls (Carpenter, Frank, Silcher, and Peysar, 2001).

Gait changes associated with aging may affect the outcome of slip and fall accidents. A review of the biomechanical literature indicates that there are several differences in the gait characteristics of older and younger people. Older adults tend to walk slower, have a shorter step length, and a broader walking base. This results in a gait 
cycle with a longer stance or double support time (Lockhart, Woldstad, and Smith, 2001a). On slippery floor surfaces, people of all ages tend to shorten their step length to reduce horizontal foot forces to reduce the likelihood of slipping (Cooper and Glaslow, 1963; Llewellyn and Nevola, 1992).

Most slips that lead to falls occur when the frictional force ( $\mathrm{F} \mu$ ) opposing the movement of the foot is less than the shear force $\left(F_{h}\right)$ of the foot immediately after the heel contacts the floor (Perkins and Wilson, 1983). Particularly, at the heel contact phase of the gait cycle, there is a forward thrust component of force on the swing foot against the floor. This results in a forward horizontal shear force $\left(\mathrm{F}_{\mathrm{h}}\right)$ of the ground against the heel. Moreover, a vertical force $\left(\mathrm{F}_{\mathrm{v}}\right)$ results as the body weight and the downward momentum of the swing foot (and leg) make contact against the ground (Lockhart et al., 2001a). Perkins (1978), identified six peak forces in a normal gait cycle by observing ground reaction forces exerted between the shoe and ground, and calculated the ratio of horizontal to vertical forces $\left(\mathrm{F}_{\mathrm{h}} / \mathrm{F}_{\mathrm{v}}\right)$. This ratio $\left(\mathrm{F}_{\mathrm{h}} / \mathrm{F}_{\mathrm{v}}\right)$ has been used to identify where in the gait cycle a slip is most likely to occur (slip initiation). Analyzing this ratio, Perkins found that dangerous forward slips were most likely to occur shortly after $(<50-100 \mathrm{~ms})$ the heel contact phase of the gait cycle (peak 3$)$. This ratio $\left(\mathrm{F}_{\mathrm{h}} / \mathrm{F}_{\mathrm{v}}\right.$ at peak 3$)$ is termed the "Required coefficient of Friction (RCOF)" because this is believed to represent the general friction demand (minimum coefficient of friction that must be available) at the shoe-floor interface to prevent initiation of forward slipping (Lockhart et al., 2001b). The number of slip and fall events increased as the difference between the friction demand (RCOF) and available dynamic COF of the floor surface increased (Hanson, Redfern, and Mazumdar, 1999). Lockhart (1997) found that elderly individuals had difficulty 
adjusting their gait to reduce the RCOF on very slippery floor surfaces (oily vinyl tile). The RCOF has been related to the tangent of the angle between the leg and a line perpendicular to the floor as illustrated in Figure 1 (Gronqvist, 1989). As a result, increasing the step length will, in general, increase RCOF (Perkins, 1978). However, many studies indicate that younger participants stride length were longer than older participants. These findings suggest that there might be other factors contributing to older individuals higher RCOF. Winter et al. (1990) and Lockhart (1997) reported that the horizontal heel velocity during the heel contact phase of the gait cycle was significantly higher for elderly individuals than younger individuals even though the walking velocity of older participants was slower. This increase in horizontal heel velocity during a critical time of weight transfer might increase the potential for slipinduced falls if the friction between the heel and the floor is reduced due to contamination of the floor surface. Thus, general gait instability among older individuals, and specifically, higher horizontal heel contact velocity during the critical phase of the gait cycle may increase the RCOF and thereby, increase the likelihood of slip and fall accidents.

However, one may ask, why are older adults who have fallen previously more likely to fall again? Research indicates that older adults who fell previously modify their gait patterns (shorter step lengths, slower heel contact velocity, and reduced RCOF) in an attempt not to fall (Lockhart, 1997). This change in gait characteristics suggests that older adults who have previously fallen should be less likely to fall. However, fear of falling was not assessed in these studies. Additionally, epidemiology findings clearly indicate that this is not the case. Therefore, the relationship between older adults who 


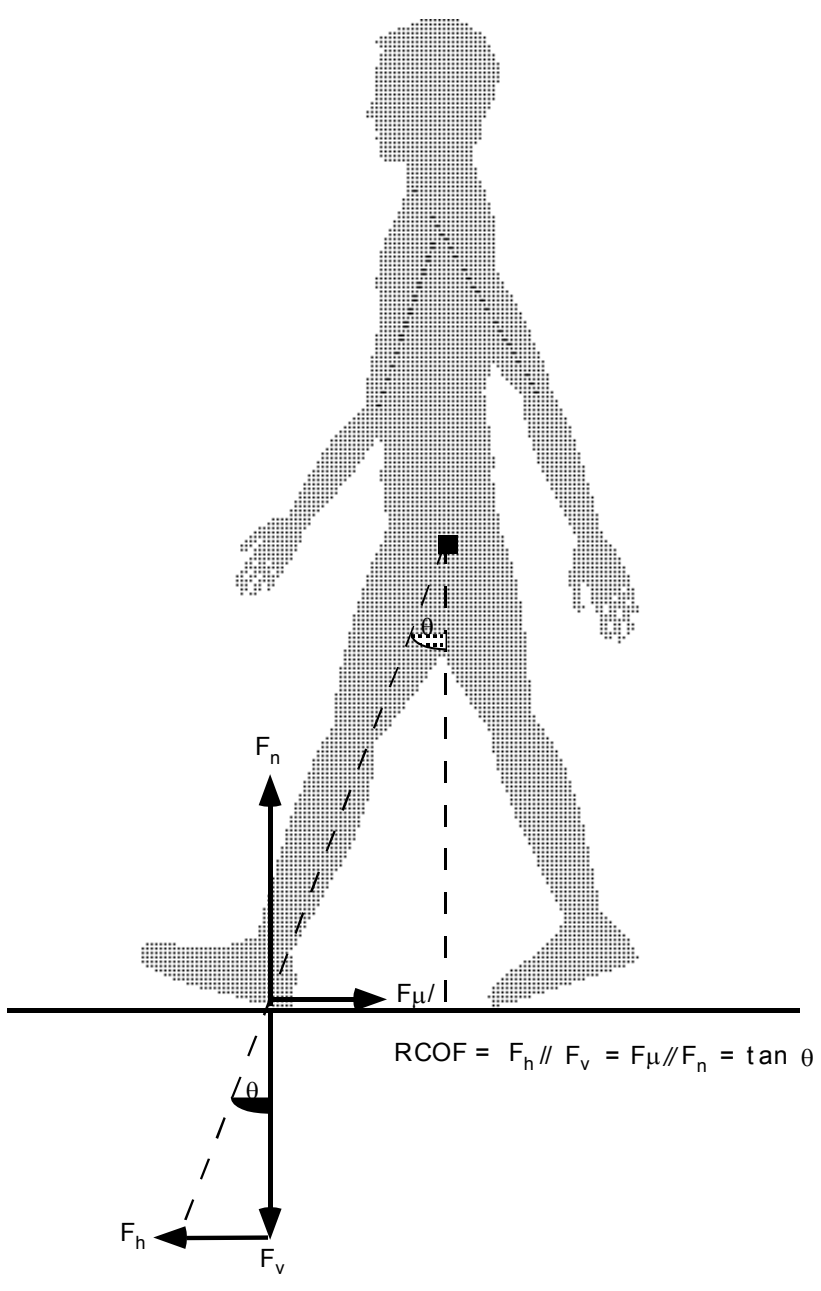

Figure 1. Frictional (F) and normal force (FN) force vectors vs. horizontal $(\mathrm{FH})$ and vertical (FV) force vectors applied by the foot during the heel contact phase in normal level walking (adapted from Lockhart, 2000). 
have fallen versus older adults who have not fallen needs to be examined. Moreover, the effects of anxiety associated with a fear of falling needs to be investigated to identify if anxiety is a factor that contributes to older adults who have fallen being more likely to fall again. Therefore, in order to effectively reduce slip and fall accidents in society and industry, there is a need to examine the behavior and psychological characteristics of humans walking on a slippery floor surface to ascertain if there is a relationship between anxiety, stress, biomechanics of the gait, and the occurrence of slips and falls.

\section{RESEARCH OBJECTIVES}

Research indicates that falls are prevalent for older adults, but there are no empirical studies that address whether the effect of stress level contributes to the occurrence of repeated falls. The specific objectives of this research are:

1. Investigate if older adults stress level and anxiety associated with a fear of slips and falls affects biomechanical parameters of gait patterns (e.g., step length, heel contact velocity, required coefficient of friction).

2. Explore the differences in gait characteristics between younger and older adults by comparing step length, heel contact velocity, and required coefficient of friction.

3. Determine if older and younger adults pre-slip gait characteristics will differ from that of post-slip gait characteristics (e.g., step length, heel contact velocity, required coefficient of friction).

4. Examine the relationship between stress levels and gait patterns for both younger and older adults to ascertain if stress level could be used as a screening tool to determine if a person is at risk of falling. 


\section{RESEARCH HYPOTHESIS}

The primary objectives of the research presented in this thesis are encapsulated in the following hypotheses:

Hypothesis 1: Stress level and anxiety score for the older age group will be higher than their younger counterparts after a fall, as measured by a salivary amylase test.

Hypothesis 2: The younger age group and older age group pre-slip step length will be longer, required coefficient of friction will be higher, and heel contact velocity will be faster than that of post-slip.

Hypothesis 3: Older adults who slipped after walking condition 1 (Pre-slip) will have a higher level of stress as measured by salivary amylase test when standing still on the track looking at the floor surface prior to starting walking condition 2 (Post-slip) than their younger counterpart.

Hypothesis 4: Older adults who slipped in walking condition 1 will have a higher level of stress as measured by Salivary Amylase test, and will modify their gait characteristics in a way that will adversely affect slipinduced falls (i.e., higher heel contact velocity and higher RCOF). 


\section{NEED FOR THE STUDY}

This research will provide a better understanding of the relationship between stress level and gait patterns in older and younger adults as they walk across a dry and

slippery floor surface. Also, it will help to determine if individuals with high stress levels are more likely to fall. This information can be used in industry to screen employees and/or potential employees for certain jobs that may have a higher probability of a fall related injury (e.g., working on a scaffold). Additionally, medical personnel could potentially use this information to develop an assessment tool to identify older adults who are at risk of suffering a fall related injury. 


\section{LITERATURE REVIEW}

\section{Overview}

The following section provides background information gathered during a literature review covering several areas of knowledge relevant to this study. It begins with a discussion of epidemiological data about slips and falls, and continues with a detailed discussion of psychophysics, salivary amylase, tribology, biomechanics of the human gait, and heel velocity.

\section{Epidemiology of Slip, Trip and Fall Accidents}

The epidemiological approach is concerned with the presence of an injury or disease-causing agent within a population. The Administration On Aging (2000) indicated that, in 1999, there were 34.5 million persons age 65 or older and that they represent $12.7 \%$ of the United States population. They estimate that the number of older Americans increased by 3.3 million (10\%) since 1990 compared to $9.1 \%$ for Americans less than 65 years of age. The percentage of Americans age 65 or older has more than tripled from 4.1 percent in 1900 to 12.7 percent in 1999, and the number of Americans age 65 or older has increased 11 times from 3.1 million to 34.5 million (Administration on Aging, 2000). The older population itself is getting older. In 1999, the number of Americans age 65-74 was 18.2 million, which is eight times larger than in 1900, but the number of Americans age 75-84 was 12.1 million, which is 16 times larger, and the Americans age 85 and older were 4.2 million which is 34 times larger (Administration on Aging, 2000). As illustrated in Figure 2, by the year 2030, there will be about 70 million older adults, which is more than double that of the year 1999. And, people age 65 and 


\section{Total number of persons age 65 or older, by age group, 1900 to 2050 , in millions}

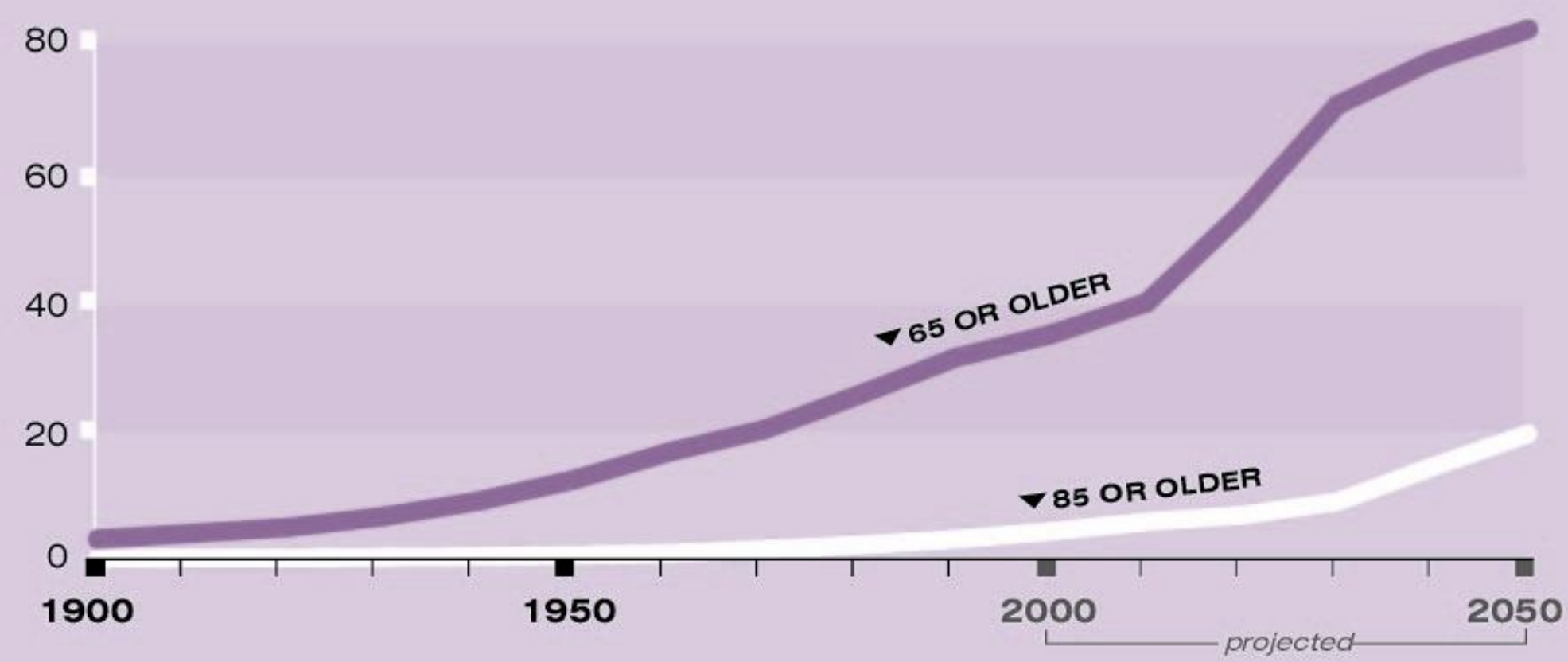

Note: Data for the years 2000 to 2050 are middle-series projections of the population.

Reference population: These data refer to the resident population.

Source: U.S. Census Bureau, Decennial Census Data and Population Projections.

Figure 2. Number of persons in millions age 65 and older, from the year $1900-2030$ (adapted from the Administration on Aging, 2000). 
over will represent almost 13 percent of the population in the year 2000 and is expected to be 20 percent of the population by 2030 (Administration on Aging, 2000).

The Center for Disease Control (2000) reported that falls are the leading cause of injury-related deaths among people age 65 and older, and the death rate rises sharply with an increase in age. In 1997, almost 9,000 people age 65 and older died as a result of falls. Persons age 75 and older account for $82 \%$ of all fall related deaths among older adults, and the number of fall related deaths are higher among men than among women (Center for Disease Control, 2000). The Center for Disease Control (2000) also reported that $60 \%$ of fatal falls for older adults occur in the home, $30 \%$ in public places, and $10 \%$ in institutions. Additionally, there are an estimated 300,000 disabling injuries each year in the American workforce, resulting in 1,400 worker deaths. Slips, trips, and falls account for 15 to 20 percent of all workers' compensation cost.

The cost of fall-related injuries are enormous, in 1994, the average direct cost for a fall injury was $\$ 1,400$ for a person over the age of 65 . And, the total direct cost of all fall related injuries for people age 65 and older in 1994 was $\$ 20.2$ billion. Moreover, by 2020 , the cost of fall injuries is expected to reach $\$ 32.4$ billion (National Center for Injury Prevention and Control, 2000; Center for Disease Control, 2000). Hip fractures are the most serious fall related injury and with the American population aging, the problem of hip fractures will likely increase substantially over the next four decades. In 2000, the number of hip fractures was 300,000 , and by 2040 , the number is expected to exceed 500,000 (Center for Disease Control, 2000).

In addition, slips, trips and falls accounted for 26 percent of worker injuries in the United Kingdom requiring three or more days off from work; second only to lifting and 
handling activities that accounted for 33 percent of reported injuries (Kidd et al., 1992). The cost associated with injuries due to slips, trips and falls are very costly in terms of medical treatment, health or company insurance, lost production, temporary labor to replace injured worker, and personal suffering (Kidd et al., 1992).

Underfoot accidents represent a major concern for society due to the monetary cost, pain and suffering, and death associated with a fall. Manning (1983), as sited in Ergonomics, (1983), conducted an epidemiological investigation (deaths and injuries caused by slipping, tripping and falling) describing the accidental events that caused injury to his patients on floors, stairs, roofs and scaffolding, etc. He characterized these types of accidents as "underfoot accidents". Some of the events in the underfoot accidents were as follows: (1) slipping of one or both feet when friction between the shoe and underfoot surface is low or when the surface is contaminated with water, ice, oil, food scraps or small objects. (2) tripping or stumbling that causes a sudden arrest of movement of a foot with continued motion of the body, (3) twisting of the foot or ankle on an object or uneven surface or edge of a surface, and (4) moving of the underfoot surface, for example a slide of a doormat. Manning (1983) indicated that these events would result in complete loss of balance and a fall against some object or the underfoot surface, thereby causing injury. He further stated that at any stage in these accident injuries could cause overstressing joints, bones and ligaments or from violent muscular attempts to correct balance. Additionally, Baker and Harvey (1996) stated that injuries are the sixth leading cause of death for older Americans age 75 and older, with falls being the primary source of injury- related deaths. Figure 3 shows the deaths per 100,000 populations by age in 1977. Amazingly, for each fall-related death for older adults, there 
are 20 fall-related hip fractures (Baker and Harvey, 1996). There are approximately 200,000 hip fractures per year with 172,000 (84\%) occurring in the population age 65 and older with an average hospital stay of 21 days (Baker and Harvey, 1996). In females age 75 to 84 , the death rate from falls is almost five times higher than at the age of 65 to 74 as shown in Figure 4. In males, there is a similar increase in death rate (Baker and Harvey, 1996). 


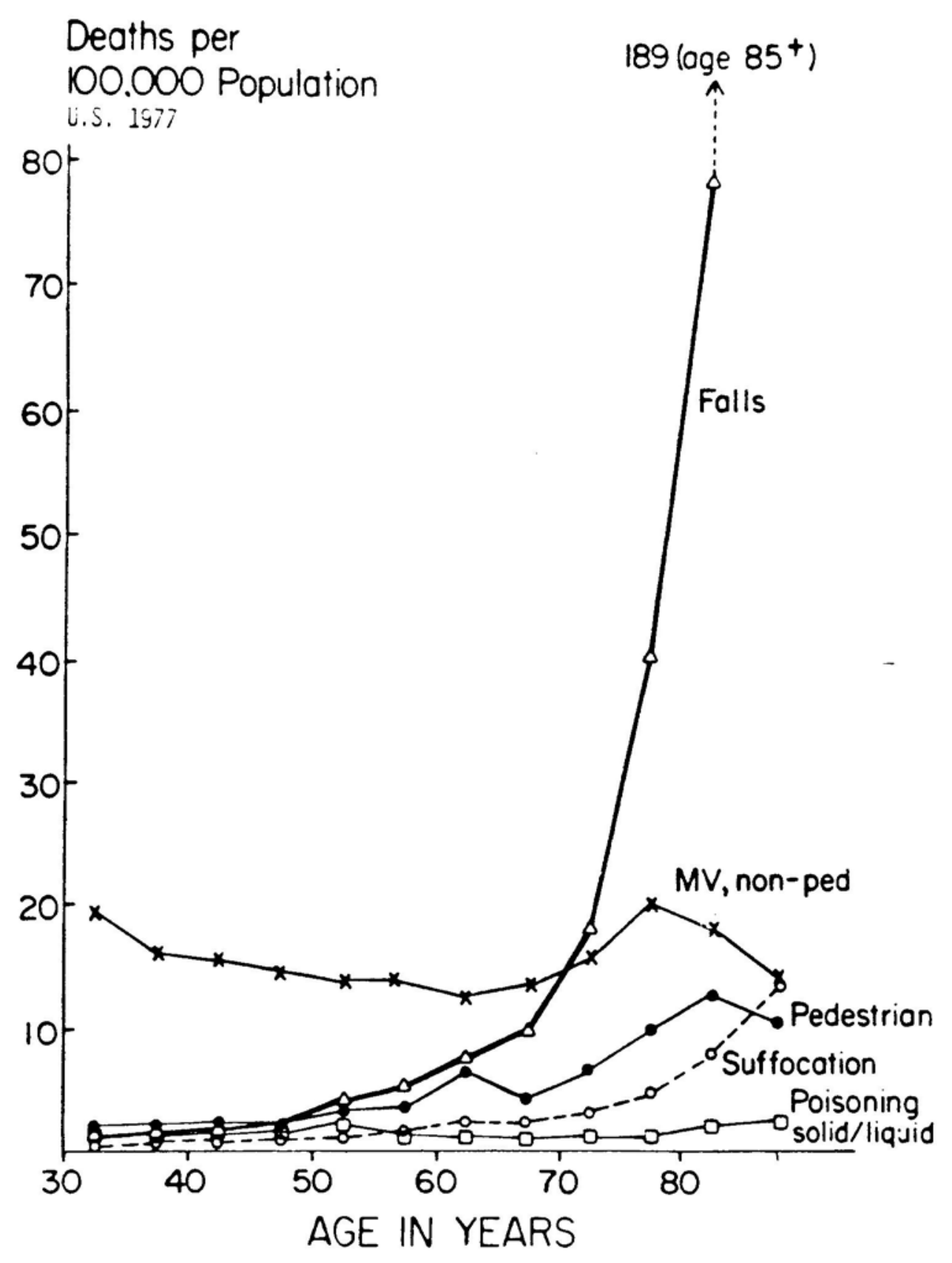

Figure 3. Deaths per 100,000 population by age in 1977 (Baker Harvey, 1996). 


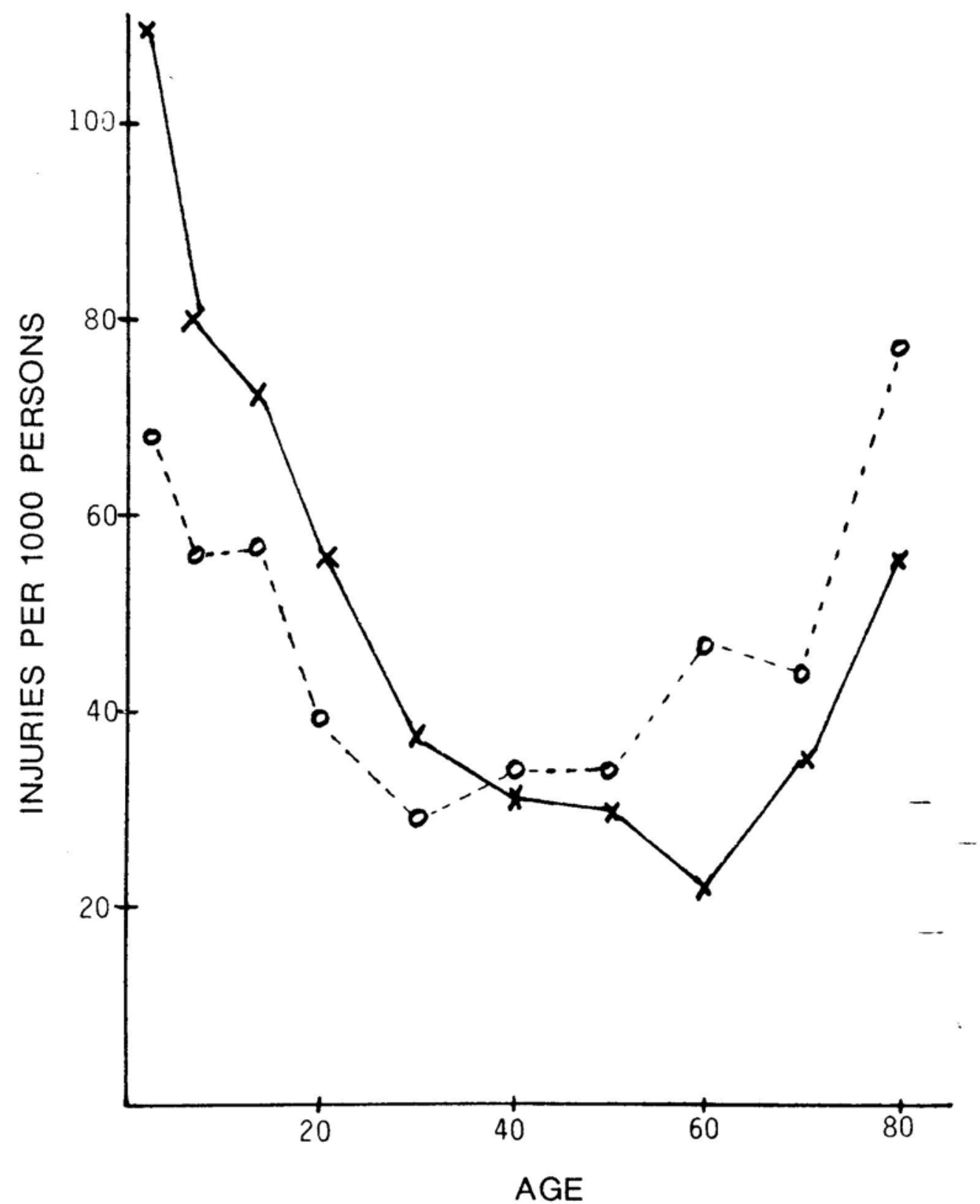

Figure 4 . Fall injury rates per 100,000 persons. $0=$ females; $X=$ males. 


\section{Psychophysical Approach}

\section{$\underline{\text { Function of Psychophysics }}$}

Psychophysics as a discipline was started by a physicist, name G. T. Fechner, in the 1860's. Fechner's works focused on the idea that mind and matter are equal and are merely two alternative ways of regarding the universe (Gescheider, 1985). His work has helped to shape modern day concepts of the field of psychophysics. The classical definition of psychophysics as it relates to risk perception is: Psychophysics is a part of psychology that focuses on the effects of physical responses related to the intensity of the stimulation to mental processes. The underlying goal of the study of psychophysics is to investigate the relationship between sensations in the psychological domain and stimuli in the physical domain (Gescheider, 1985). The study of psychophysics provides information in two basic areas, descriptive psychophysics and analytical psychophysics.

Descriptive psychophysics involves the study of thresholds and the sensitivity of the sensory system in a quantitative manner (Gescheider, 1985). The study of thresholds is important to determine the levels of stimulus required to produce a response or interfere with a response using the visual, auditory, or proprioceptive systems.

The study of analytical psychophysics involves the comparison of different stimuli and various responses. Analytical psychophysics is a second study of psychophysics concerned with the nature of sensory information used to carry out a physiological or biomechanical response.

Studies involving analytical psychophysical parameters have shown that there is a mental component directly involved in the gait cycle (Adkins et al. 2000; Carpenter et al., 2001; Cohen and Cohen 1994a\&b; Zohar, 1978). These studies examine the perception 
of slipperiness and how vision is involved to detect hazards that may lead to a fall. It is also stated that the input of such visual information into the brain can alter the subject's gait.

In the following subsections, the relationship of psychophysics to physiology is further explained. Additionally, the relationship of psychophysical parameters to psychological behavior is examined.

\section{Sensory Perception}

Sensory perception can be defined as the interpretation and organization of all information provided to the brain by the senses. Interpretation suggests that some meaning has been attached to the information and that a value judgment, no matter how primitive, has been made as to whether an event is positively regarded as safe or pleasant, or negatively regarded as unsafe or unpleasant (Rice, 1987). Risk perception is the interpretation of potentially hazardous situations or environments, which could ultimately lead to physical harm. Studies show that people tend to perceive their surroundings in various ways. For example, studies show that some people, this author included, while in their car at a traffic stop light, and a larger automobile (bus, etc) beside them moves slowly up or back, perceive the motion of the larger automobile as backward motion of their own vehicle, and frantically attempts to stop their car from moving by pressing firmly on the brake pedal. This perceived motion causes the person to exert a biomechanical response, and elevates the person's anxiety level, even though the car was not actually moving (Balaban and Thayer, 2001). This situation was used to help describe and relate a momentary departure from a spatially stable, non-moving frame of 
mind with anxiety and fear. In addition, this theory involves sensory perception and stimulation input in the brain based on this perception. Sensory perception is very important for deciphering the external environment and inputting information for the body to act upon. Another consideration is the impact of Anxiety and fear on one's responses to a given situation.

\section{$\underline{\text { Anxiety and Fear }}$}

Anxiety can be defined or characterized as the apprehension caused by a threat to a human's existence as a person. The threat may be to physical life, or to psychological existence, such as, the loss of freedom. Or the threat may be to some value, which one identifies with one's existence (May, 1979 as sited in Barlow, 1988). Beck and Emery (1985) define anxiety as the person's preoccupation with and response to danger.

Anxiety may be distinguished from fear in that anxiety is an emotional process while fear is a cognitive one. Fear involves the intellectual appraisal of a threatening stimulus; anxiety involves the emotional response to that appraisal (Beck and Emery, 1985). For example, when a person says he fears something; he is generally referring to a set of circumstances that are not present but may occur at some point in the future. When a person has anxiety he or she experiences a subjectively unpleasant emotional state characterized by unpleasant feelings, such as tension or nervousness, and physiological symptoms like heart palpitations and nausea. A fear is activated when a person is exposed, either physically or psychologically; to the stimulus situation he or she considers threatening. When fear becomes activated, people experience anxiety. 
Therefore, fear is the appraisal of danger, and anxiety is the unpleasant feeling state evoked when fear is stimulated (Beck \& Emery, 1979).

Furthermore, Beck and Emery (1985); Beck (1976) as sited in Michelson and Ascher (1987), describes the subjective feeling of anxiety as one aspect of an archaic survival mechanism that consist of an interplay of the cognitive, behavioral, physiological, and affective systems. The cognitive content focuses on threat to one's domain, and the person's emergency response to the threat, real or perceived, is psychological and biological. Once the emergency response has begun, the person's awareness is cleared to make room for information about the danger and possible coping mechanisms. The person selectively enhances what is relevant to the perceived danger and suppresses what is incongruent with it. The emergency response's cognitive appraisal activates the autonomic nervous system is illustrated in Figure 5. This includes the automatic, primal response strategies: fight, flight, freeze, and faint; as well as, the subjective anxiety to trigger coping strategies. Two behavioral systems are activated separately or simultaneously: the energic, tonic sympathetic nervous system and the anergic, atonic parasympathetic nervous system. The energic system's active strategies fight, flight, and so on, mobilize when the person feels threatened, whereas the anergic system demobilizes, for example, the person faints due to feeling helpless. Both are complete psychobiological reactions of the cognitive, motor, somatic, and affective systems. The energic and anergic reactions are part of a larger psychophysiological reaction that activates the subjective feeling of anxiety and causes the increase or decrease in muscle tone. The two self- protective mechanisms are: (1) the primal, 


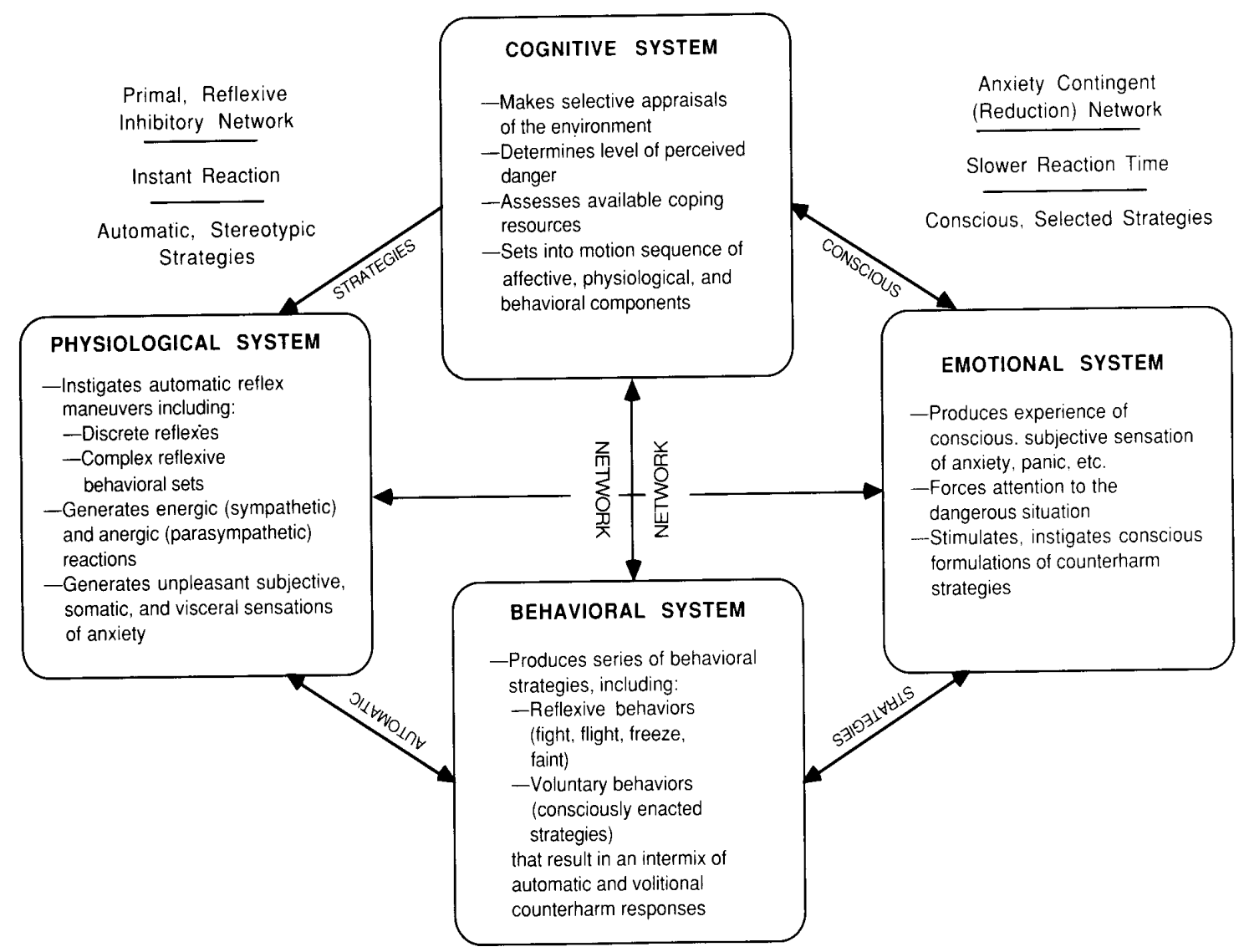

Figure 5. Beck's cognitive model of threat response (Adapted from Michelson \& Ascher, 1987). 
reflective inhibitory network, which reacts instantly with automatic, stereotypic strategies, and (2) the voluntary anxiety-contingent network that is slower and uses more complete information processing and strategy selection. Both mechanisms are activated congruently. The slower contingent system follows the reflective autonomic strategies. The reflexive system has a limited repertoire of stereotypic behavior responses, whereas the contingent system focuses attention on ways to reduce the danger (Beck \& Emery, 1985). Also, the effects of stress and anxiety on one's mental and physical processes must be considered.

\section{Stress and Anxiety}

The word stress is used constantly in connection with emotional states; it appears almost as often as the word anxiety. The word stress is well implanted in scientific literature and cannot be ignored in any systematic treatment of anxiety (Levitt, 1967). In scientific literature, stress is used in three distinct ways. It is used first to refer to an event or to any environmental stimulus that causes a person to feel tense or aroused. In this sense, stress is something external to the person. Second, it is used to refer to a subjective response to what is going on. In this sense, stress is the internal mental state of tension or arousal. Third, it is viewed as a physical reaction of the body to demand or damaging intrusions (Rice, 1987).

Stress can be characterized as something that threatens our well-being and survival; people instinctly react in some programmed way to protect themselves from harm. Therefore, when a threat to the self is perceived, that causes anxiety, we react instinctly and rev up the body's defenses (physical) to be ready to take some (physical) 
action should the need arises. The anxiety caused by the threat excites (arouses) the muscles, the cardiovascular and respiratory systems and affects other body functions in appropriate ways so that the body is physically ready to defend against or escape the coming assault. Experts suggest that stress illness is due to these physical reflexes or distress (Brown, 1984). Distress (negative stress) refers to the negative aspects of the body's reactions to stress, such as depression, anxiety, anger, and exhaustion. A common notion is that a stressor is an affect that is perceived as stressful by an individual, so that what is distressful for one person may not be so for another (McGuigan, 1999).

When one perceives negative stressful events, a number of complex internal processes follow: First, the entire body is activated in the startle reaction where neural impulses reverberate between the striated muscles and the brain; later the autonomic nervous system becomes involved (increased heart rate, blood pressure, blood volume, and respiration rate, and changes in electrical skin resistance). The pituitary gland releases hormones, principally adrenocorticotropic hormone $(\mathrm{ACTH})$, which acts on the cortex of the adrenal glands to release corticosteroids. Distress has been linked with coronary heart disease, the speeding up of aging through hormonal imbalance, nervous conditions, and the development of degenerative diseases. How a person reacts to a particular stressors depends on many factors: the characteristics of the stressor; the individual's range of coping techniques; how he or she perceives the situation in light of previous experiences; his or her capacity to tolerate anxiety; and so forth (McGuigan, 1999; Monat and Lazarus, 1991). Based on this discussion, one's perception of a floor surface as being hazardous may influence how he or she reacts when walking across it as discussed in the next section. 


\section{$\underline{\text { Perception of Slipperiness }}$}

Attempts have been made to determine factors that influence people when they are walking. Carlsoo (1962) has studied human gait and whether or not different floor hardness can cause different patterns of walking with different muscle coordination and muscle-load. The results suggest that differences in muscle activities exist for floors of different hardness. In addition, when potentially hazardous conditions are perceived through visual and tactile sensation, or expected to exist in walking person's perceptual field, one's walking gait is adjusted accordingly (Ekkebus and Kelly, 1973; Swensen et al., 1992). The length of stride is shortened, which consequently produces low foot velocities and smaller foot shear forces, as the body's center-of-gravity is better maintained. The ground reaction force during the heel strike and the toe-off phases is also significantly reduced to diminish the likelihood of slipping. In addition, vision can be instrumental in recognizing hazards that may lead to slip and fall accidents.

\section{$\underline{\text { Vision }}$}

The visual field is an important psychophysiological parameter involved in gait regulation. Studies of the human visual mechanism have indicated that the visual field of a walking person is dynamically changing and only a small part of the effective visual field is attended to. In other words, the attention is divided in such a way that the first priority is given to objects falling within the effective visual field. Therefore, if a slippery condition is not detected within one's effective visual field (usually 10-15 feet ahead), the likelihood of fall accidents is significantly increased (Zohar, 1978). 
The optic flow field effect (Lishman, 1981) provides an explanation of how an individual's judgment of velocity and displacement of surrounding objects (during walking) can affect perception of tripping hazards. For example, if one is trying to catch a ball thrown toward oneself, the apparent diameter of the ball increases, since the size of the retinal image is also increased, and the brain seems to calculate the time of arrival of the ball from the rate of change in size of the retinal image. Thus, utilizing the optic flow field effect, judgment of the velocity and distance of approaching objects are effectively managed. However, judgment will be altered if a finite object is not in view (such as, an infinitely long corridor which has uniformly painted walls and ceiling, and an unpaterned carpet on the floor). In this situation, if there is a tripping hazard such as a step in the corridor, or someone has dropped something, then judgment of its (tripping hazard) distance can be hampered, resulting in potential danger of tripping and falling accidents. Based on the previous discussion, it is evident that other factors besides vision are important in slips and falls. One such factor is the interaction between visual and tactile sensation.

\section{$\underline{\text { Visual versus Tactile Sensation }}$}

Recently, Cohen and Cohen (1994a) further explored the perceptual and cognitive factors involved in the perception of floor tile surface slipperiness. The results of this study also demonstrated that tactile cues are most sensitive to physical measurement of dynamic COF. A follow-up field study (Cohen and Cohen, 1994b) of the psychophysical assessment of the perceived slipperiness of floor tile surfaces concluded that people tended to make predictions about the slipperiness of walking surfaces and verified these expectations as they crossed them. The results suggest that visual cues to slipperiness are 
inferior to tactile sensation. They also suggested that in real-world conditions, the perception of walking surface slipperiness is probably the result of tactile cues, with visual impressions being confirmatory. Thus, in unfamiliar conditions, people may rely on the primary but inferior visual information about a surface's traction until they actually walk on it. The potential for an accident can be created due to misjudgment of slipperiness based on initial visual sensing and the limited time available to make immediate adjustments in gait to accommodate for the hazardous condition. Additionally, research indicates that response selection will impact one's ability to avoid a fall when a slippery surface is encountered.

\section{$\underline{\text { Response Selection }}$}

Simple reaction time (RT) is increased with age (Clarkson, 1978; Gottsdanker, 1980; Kroll and Clarkson, 1978; Loveless, 1980). These findings suggested that older adults have difficulty in fully preparing a response and maintaining that preparation (Gottsdanker, 1980). Response selection must be both accurate and timely. If postural instability goes uncorrected, a critical time boundary is soon exceeded, beyond which balance is irrecoverable. This time boundary period is about $300 \mathrm{~ms}$ for producing a step forward in response to an unexpected fall (Do, Breniere, and Brenguier, 1982). If aging has the effect of even a moderate slowing of response selection, then a large increase in the number of falls could result (Stelmach and Worringham, 1985). One important aspect of this proposed research is to ascertain if stress affects locomotion parameters. Therefore, participant's stress level will be measured by salivary amylase, which is generated in their saliva when a stressor is encountered. 


\section{Salivary Amylase}

The U. S. Army Research Laboratory (ARL), Human Research and Engineering Directorate (HRED), has utilized salivary amylase essay test kits to assess the stress level of soldiers for more than 15 years. For example, in 1990, soldiers, Marines, and Army and Air National Guard forces, were deployed to help battle the wildfires that spread through Yellowstone National Park, destroying a million of the 2.2 million acres. Soldiers $(\mathrm{n}=855)$ from the $9^{\text {th }}$ Infantry Division (Motorized) and supporting units were tested for stress by HRED scientists. The results of the stress battery test showed that some soldier's stress and anxiety levels were comparable to that of what might be expected on the battlefield because they faced real hazards, real dangers, and real consequences in a real world setting (Fatkin, King and Hudgens, 1990).

Amylase is an enzyme that hydrolyzes starch to oligosaccharides and then slowly to maltose and glucose. Salivary amylase concentrations are predictive of plasma catecholamine levels and can be used as a measure of stress (Chatterton, Vogelsong, Lu, Ellman, \& Hudgens, 1996). Measurement of amylase concentration in saliva includes the observation of chemical color changes according to standard photometric procedures developed by Northwestern (Chatterton et al., 1996). The concentration of amylase is then determined from a table of values relating time and temperature to amylase activity. Typical procedure is as follows: Saliva samples (50-microliter) are mixed into vials with pre-measured, buffered saline. The saliva-saline mixture is transferred to the reagent, and the time for the sample to reach the color of the yellow liquid reference vial is recorded using a stopwatch. Next, the time recorded for the color change is found in the conversion table and the amylase level (Kilo-Units per liter $(\mathrm{KU} / \mathrm{L}))$ is recorded. For 
example, a time of one minute and fifty-eight seconds based on the conversion table would equal $400 \mathrm{KU} / \mathrm{L}$. This value would be compared to the baseline measure to establish if stress level has increased. This technique allows researchers to assess the effects of different stressors on a target population. Because salivary amylase provides a relative measure as opposed to an absolute measure of stress, there are no set criteria that can be applied to the whole population.

Chatterton et al. (1996) conducted an investigation to evaluate the production rates and concentrations of salivary amylase as a measure of adrenergic activity during conditions of physical and psychological stress in humans. Saliva and blood samples were simultaneously collected, and significant associations between the concentrations of salivary amylase and plasma levels of catecholamincs were found, suggesting that the same stimuli that increase the concentration of plasma catecholamines may activate sympathetic input into the salivary glands. In addition to psychological stress and physical exercise, responses from heat and cold stress conditions were also measured. The experience of heat stress resulted in increases in salivary amylase and heart rate that were expected from studies of catecholamine responses to heat. Heart rate responded more rapidly in the thermal chamber than did amylase concentrations; however, amylase remained elevated for a full 15 minutes after the subjects left the chamber. This continuing response may be similar to that observed after a critical exam and may indicate a psychological component, as reflected by the high anxiety levels reported at that time.

A clear dichotomy was demonstrated between heart rate and salivary amylase secretion during a cold stress condition and indicated a more complex response of the 
heart. Although cold is a potent stimulus for catecholamine secretion, the heart has compensatory mechanisms that limit the response during conditions when body temperature must be conserved. Chatterton et al. (1996) surmised that salivary amylase is a less complex and therefore a more direct measure of catecholamine levels than heart rate. The following discussions will focus on physical phenomenon that leads to slips and falls. One such phenomenon is coefficient of friction.

\section{Coefficient of Friction}

The coefficient of friction (COF) is defined as the ratio of the foot's horizontal shear force divided by the foot's vertical normal force (Chaffin, Woldstad, and Trujillo, 1992). COF is generally used to describe the amount of traction between the shoe sole and the underfoot-surface materials, and varies based on individual and task-related factors. As previously stated the coefficient of friction is the horizontal force required to cause motion divided by the vertical force:

$$
\begin{aligned}
& \mathrm{F}_{\mathrm{v}}=\mathrm{F}_{\mathrm{L}} \cos \theta \\
& \mathrm{F}_{\mathrm{H}}=\mathrm{F}_{\mathrm{L}} \sin \theta
\end{aligned}
$$

therefore, $\mathrm{COF}=\mathrm{F}_{\mathrm{H}} / \mathrm{F}_{\mathrm{V}}=\mathrm{F}_{\mathrm{L}} \sin \theta / \mathrm{F}_{\mathrm{L}} \cos \theta=\tan \theta$.

(The angle $\theta$ is determined by the length of the leg (L) and the 1 step length.) Given the first law of friction: $\mathrm{F}=\mu \mathrm{F}_{\mathrm{N}}$, and safe walking condition when COF is greater than the ratio of the horizontal force components applied to the floor (Lockhart, 2000): $\mu>\mathrm{F}_{\mathrm{H}} /$ $F_{V}$, by combining two formulas the latter can be expressed; $F / F_{N}>F_{H} / F_{V}$.

Therefore, if the magnitude of the $\mathrm{F}_{\mathrm{H}}$ and $\mathrm{F}_{\mathrm{V}}$, and the $\mathrm{COF}(\mu)$ for the actual shoelubricant-flooring combination are known, it is possible to evaluate whether this 
combination presents the risk of falling (Gronqvist, Roine, Jaroinen, and Korhonen, 1989). During normal level walking COF values shown in (Figure 6) are typical, and the minimum requirements for the COF (normal, level walking) is $0.15-0.30$ (Lockhart, 2000). If walking at a faster pace than normal speed (stride length is longer and $\theta$ increases therefore, required COF increases to about 0.40 (Lockhart, 2000). Based on the previous discussion, friction utilization is instrumental in slips and falls accidents. One key parameter in assessing friction is tribology.

\section{Tribology}

Tribology focuses on friction, wear, and lubrication of interacting surfaces in relative motion (Stachowiak and Batchelor, 2001). According to Adler \& Piermen (1979) the National Safety Council reported that slips and falls are the major building related cause of accidental death and injury. In 1976, over 8 million falls resulted in 1.6 million disabling injuries and 14,896 deaths. Adults over 65 experienced $20 \%$ of the fatalities. In more than half of the falls, slippery surfaces were identified as a major contributing factor. Slip resistance shoe soles and the underfoot surface are important for human locomotion and pedestrian safety. There must be sufficient frictional force to prevent slipping and tripping. Slip resistance is defined as the "frictional force opposing the movement of and object across a surface" (ASTM, 1975). This encompasses opposing forces of movement in both the static and dynamic phases of foot contact. The fundamental idea of slip resistance is that a slip will occur whenever the frictional force 


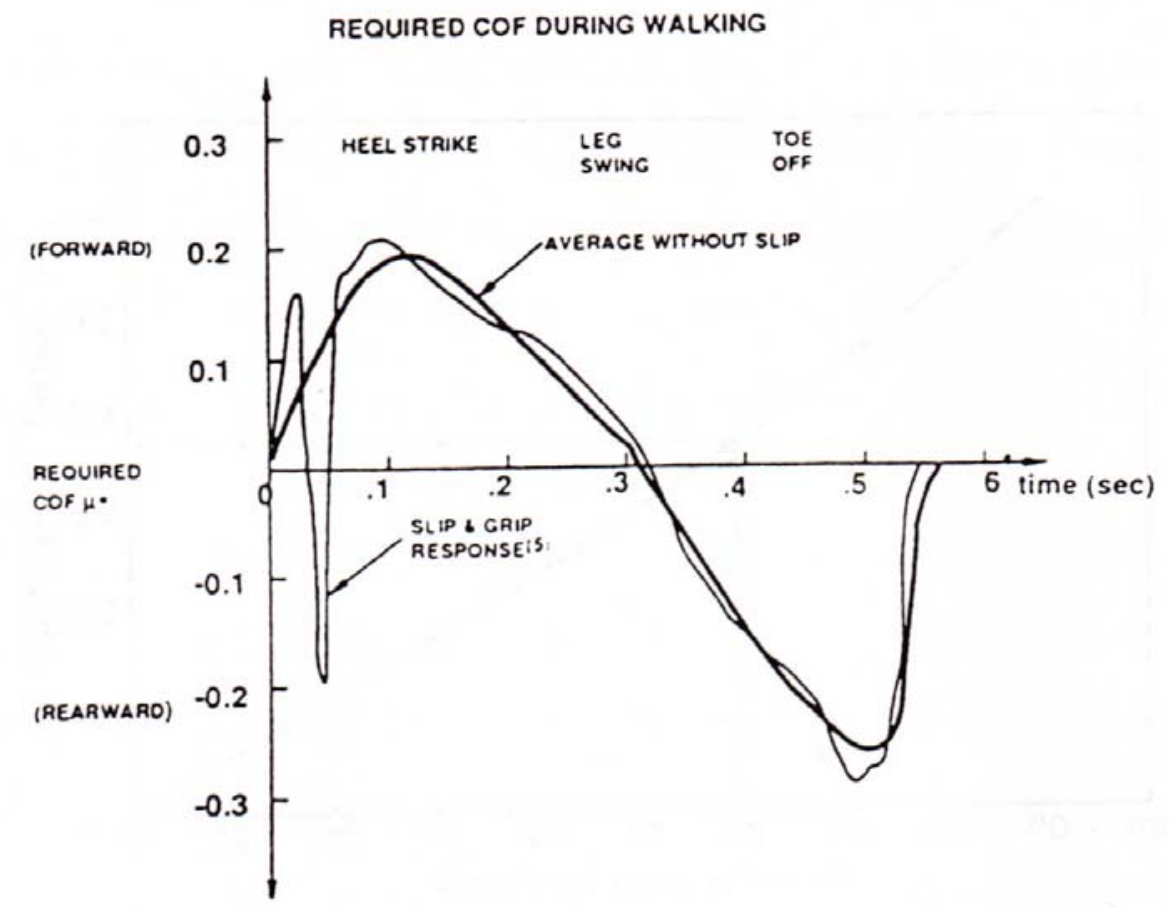

Figure 6. Typical required coefficient of friction values for walking without slipping are represented by the bold curve and the thin line represents a micro- slip recovery (adapted from Lockhart 2000). 
opposing the movement of an object is less than the shear force of the foot (Lockhart, 2000). The tribological approach focuses on the surface dissipative processes in terms of hydrodynamics of contaminants between the shoe and the floor and viscoelastic characteristics of the shoe heel and sole materials (Anders and O'Connor, 1992). The tribological approach to fall accident prevention has focused on the static and dynamic coefficient of friction between the shoes and underfoot surface (Lockhart, 2000). The required coefficient of friction represents the minimum coefficient of friction needed at the shoe and floor contact point to avoid forward slipping at heel contact (Lockhart, 2000).

Perkins, (1978) used a force platform to measure the horizontal $\left(\mathrm{F}_{\mathrm{H}}\right)$ and the vertical $\left(\mathrm{F}_{\mathrm{v}}\right)$ components of the force exerted between the shoe and under-foot surface during normal walking. An analogue divider calculated the ratio of horizontal to vertical forces $\left(\mathrm{F}_{\mathrm{H}} / \mathrm{F}_{\mathrm{V}}\right)$ and displayed this on an oscillograph as a function of time (Figure 7). $\mathrm{He}$ identified six peak forces in the normal gait cycle. The first four peaks occurred during the landing phase and the remaining two peaks occurred during the take off phase. A forward force causes peaks 1,3 , and 4 , where a backward force on the force platform causes peaks 2,5 , and 6 .

Peak 1 is caused by the force impact of the heel tip against the force platform and has a forward direction as a result of the approach angle of the heel to the ground. However, peak 1 can be inconsistent due to the low vertical force during this phase. Peak 2 is caused by a backward force exerted on the heel of the shoe shortly after contact. Several investigators have noted this force (Perkins, 1978; Lanshammar and strandberg, 1981), however, no reason has been suggested why this force occurs. 
right foot in stance phase

- left foot in stance phase

$\square$ foot in swing phase

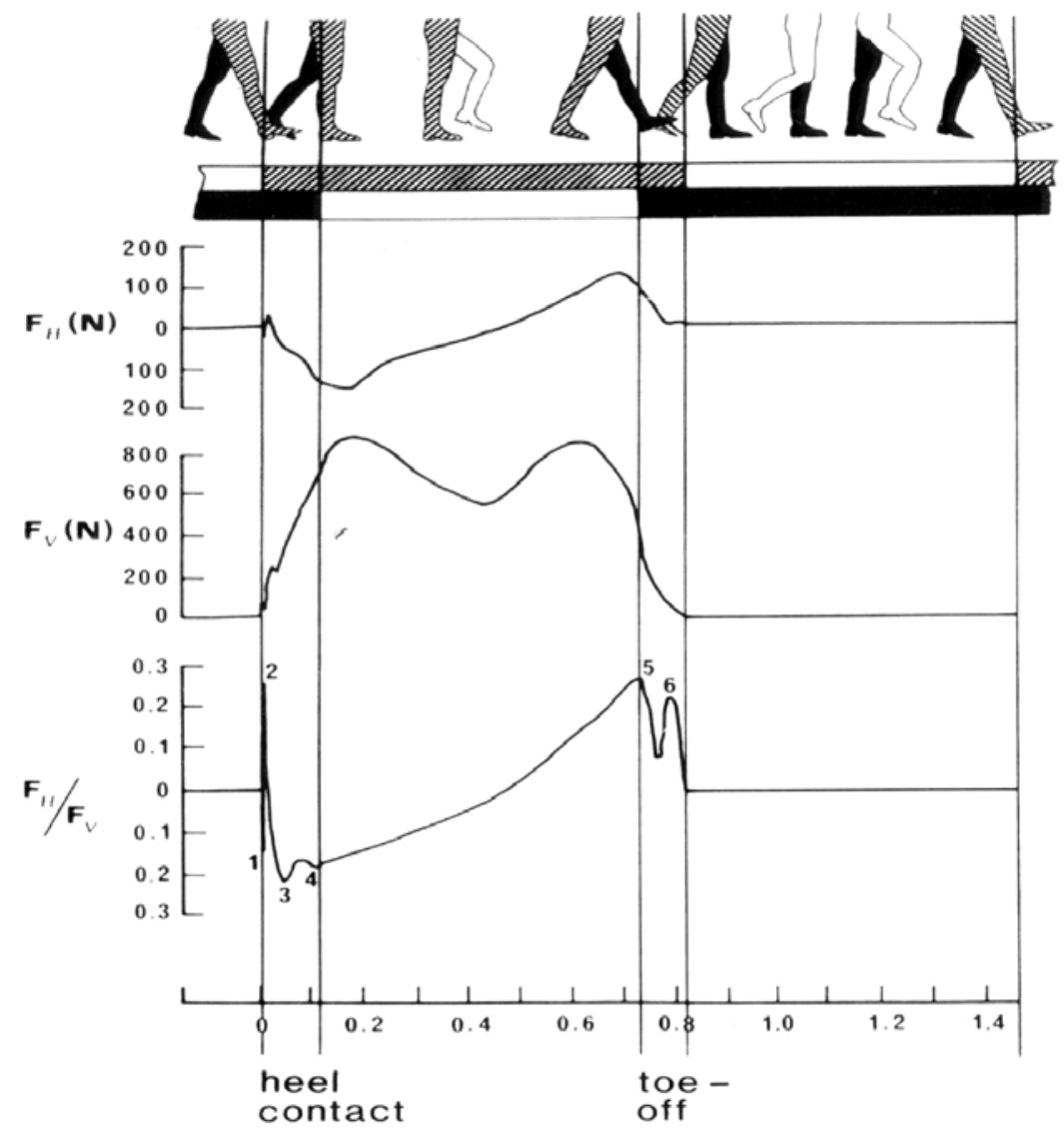

Time after heel contact, seconds

Figure 7. Gait phases in normal level walking conditions with typical horizontal and vertical ratio for one step (adapted from Perkins, 1978). 
Peak 3 and 4 are caused by the main forward force that retards the motion of the body and leg. During peaks 3 and 4, the vertical force increases and a significant proportion of the body weight is being applied through the heel tip (Less than .1s after heel contact). Therefore, the error in $F_{H} / F_{V}$ ratio is relatively small (Perkins, 1978). Subsequently, as the body's weight is progressively transferred to the striking foot, the center- of-gravity of the body moves over the now stationary foot and the forward force causing Peak 4 decreases. During the take-off phase, the $\mathrm{F}_{\mathrm{H}} / \mathrm{F}_{\mathrm{V}}$ increases again due to the force (Peaks 5 and 6 in figure 7) exerted by the foot propelling the body forward. The importance of the ratio $\left(\mathrm{F}_{\mathrm{H}} / \mathrm{F}_{\mathrm{V}}\right)$ is that it indicates where in the walking step a slip is most likely to occur. If the magnitude of $\mathrm{FH} / \mathrm{F}_{\mathrm{V}}$ exceeds the coefficient of friction (COF) between the two surfaces at a particular moment in time, a slip will occur (Perkins and Wilson, 1983).

The two critical gait phases in normal walking from a slipping perspective (Perkins, 1978; Strandberg and Lanshammar, 1981) are:

1. Shortly after heel contact-when only the back edge of the heel is in contact with the underfoot surface (Peaks 3 and 4 in Figure 7). Peaks 1 and 2 are not considered hazardous because $\mathrm{F}_{\mathrm{V}}$ is quite small at Peak 1 and $\mathrm{F}_{\mathrm{H}}$ is directed backwards at Peak 2. 2. At the point of toe-off-when only the forepart of the shoe is in contact with the underfoot surface (Peaks 5 and 6 in Figure 7).

According to Perkins and Wilson (1983), in theory, the forward slip at Peaks 3 and 4 during landing is more hazardous since the forward momentum of the body will continue to apply the body's weight on the slipping foot. Conversely, backward slip at 
Peaks 5 and 6 is less likely to be hazardous, as most of the body weight has been transferred forward from the slipping foot to the opposite leading foot. Backward slip at Peak 2 shortly after landing appears to be hazardous, but the likelihood of slip continuing in a backwards direction is small since the force rapidly changes direction.

According to Lockhart (2000), floor slipperiness and cadence appear to have a significant effect on RCOF. The floor effect was compared utilizing measured RCOF for each floor level across both age groups and cadence levels, and the results indicated statistically significant RCOF differences between four floor slipperiness levels. The RCOF decreased with decreasing Available Dynamic Coefficient of Friction (ADCOF), which was measured using a horizontal slipmeter. Also, the RCOF values were significantly higher as the cadence increased. Finally, the overall means of RCOF of the age group and floor levels indicated that older adults could not adjust their RCOF to ADCOF on a very slippery floor (oily vinyl tile floor) surface. Figure 8 illustrates this concept. The RCOF was adjusted well below the ADCOF of the stainless steel, ceramic tile, and oily plywood floor surface for both younger and older adults, however, for the oily vinyl tile floor, the older adults could not adjust their RCOF to ADCOF during moderate to very fast cadence levels. People will vary to some degree in the required friction needed to avoid slip and fall accidents based on their gait as discussed below.

\section{Biomechanics of the Human Gait}

Walking can be defined as a "method" of locomotion utilizing the use of two legs, alternately, to provide both support and propulsion (Lockhart, 2000). Gait can be 

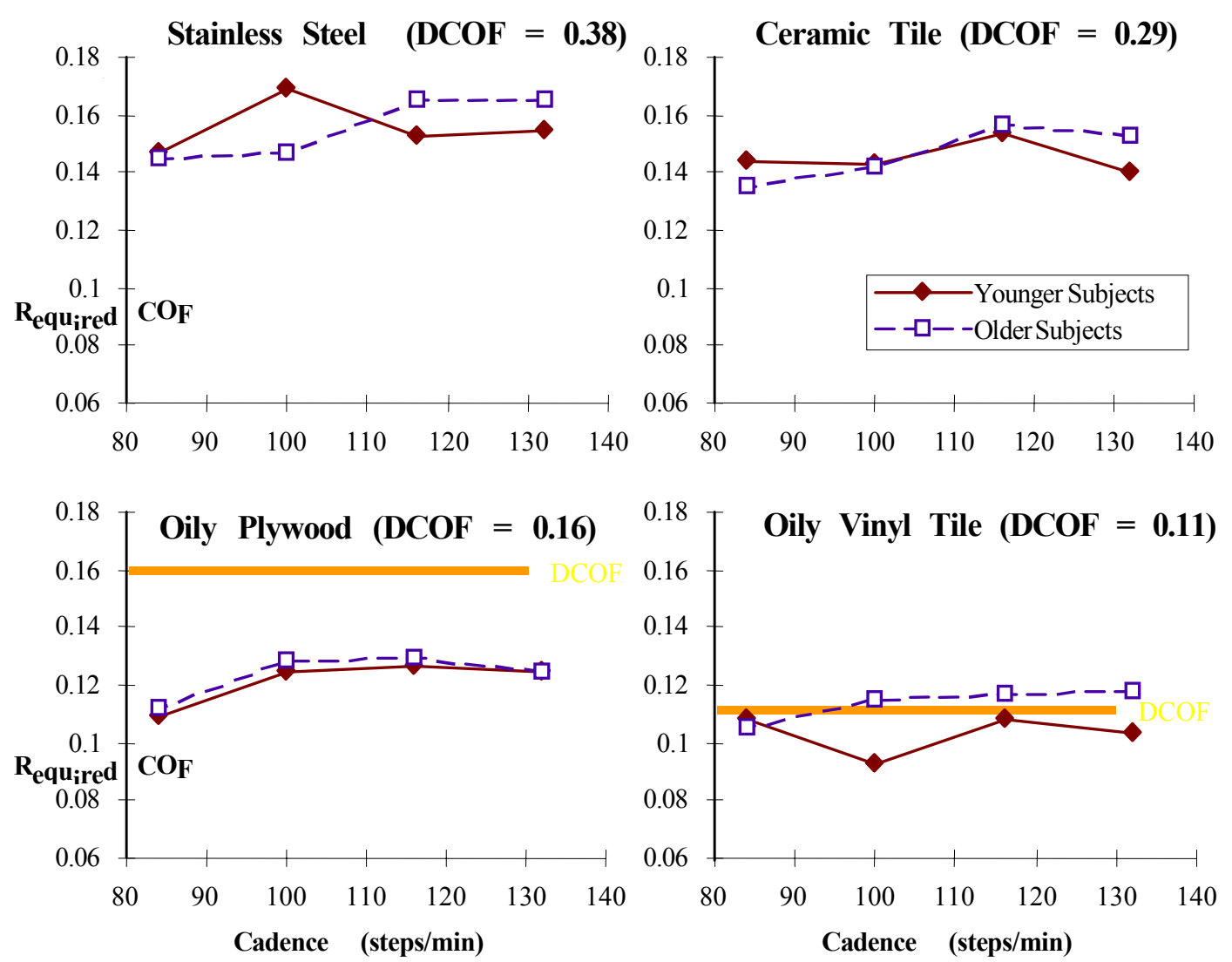

Figure 8. Comparison of RCOF between young and older adults on four floor levels and cadence levels (adopted from Lockhart, 2000). 
described as the characteristic of a person's walking pattern. The mastering of the erect bipedal type of locomotion appears to be a learned process and a relatively long one. The characteristic patterns of walking seen in adults are not achieved until the child reaches age 7 or 9 years (Popova, 1935). Before this age, Inman et al. (1981) concluded that the child modifies the displacements that occur in various segments with changes in bodily proportions, and develops improved neural control.

According to Lockhart (2000), if walking is a learned activity, then each of us portray certain personal peculiarities superimposed on the basic pattern of erect bipedal locomotion. Thus, it is possible to recognize a person at a distance by a glimpse of their gait. However, under normal conditions, walking involves the integrated activity of muscles acting across many joints. Because of the synergistic and antagonistic nature of many of these muscles, the sequence and type of movement of different body parts are essentially the same in all individuals. Therefore, in order to analyze principles of body stability and the mechanisms of slips and falls, it is necessary to understand dynamic principles of each body segment in locomotion and the translation of the body as a whole (center-of-gravity) through space.

Gait parameters such as stride length, heel velocity, slip distance, and Required Coefficient of Friction (COF) have been objectively assessed during walking under normal and abnormal conditions by many investigators (Crowinshields et al., 1978; Herman et al., 1976; Perkins 1978; Winter, 1991). Stride length is defined as the linear displacement in the direction of progression between successive points of foot-to-floor contact of the same foot (Murray, Kory, and Clarkson, 1966). Stride length has played a key role in gait analysis (Ohmichi and Miyashita, 1983). Many researchers have 
observed that on slippery floor surfaces, participants tended to shorten their stride length in order to keep the body's center-of-mass within a smaller region, so that a greater stability could be achieved (Lockhart, 2000).

Literature suggests that natural cadence varies from 101 to 122 steps/min for adults younger than age 65. Winter (1991), recorded 60-university students (aged 18-32 years) natural cadence, and reported them to have a cadence of $107 \mathrm{steps} / \mathrm{min}$ (with $S D=$ 8.8 steps/min). Du Chatinier et al. (1970) study revealed that females walked slightly faster than males (116 vs. 122 steps/min) for a population of 72 males and 57 females. Also, Finley and Cody (1970) reported a higher natural cadence for females (116 steps $/ \mathrm{min}, S D=11.7, \mathrm{~N}=472)$ than for males (110 steps $/ \mathrm{min}, S D=10.0, \mathrm{~N}=434)$. A study of walking patterns in healthy older men age 65 to 87 years showed a decrease in the average cadence and stride length (Murray, et al., 1969). Meserlian (1995), reported that the average cadence for older adults to be about $100 \mathrm{steps} / \mathrm{min}$. However, (Winter et al., 1990) after screening older participants for both fitness and walking-related problems, found that there was no decrease in cadence (110 vs. 111 steps/min), but there was a significant decrease in stride length. Lockhart (1997) also reported significant difference in stride length. For the most part, younger participants had longer stride length $(131.04 \mathrm{~cm})$ than older participants $(115.29 \mathrm{~cm})$ when compared with the normalized height index. Stride length was also significantly affected by the level of slipperiness of the floor surface (stride length increased with an increase in ADCOF of the floor surface). Another characteristic of the human gait that affects the occurrence of slips and falls is heel velocity. 


\section{Heel Velocity}

Winter (1991) characterized the control of the foot during swing as essentially a ballistic and positional task. Horizontal velocity gradually builds up after heel - off and reaches a maximum velocity late in the swing phase and drops rapidly to almost zero just prior to Heel Contact (HC). The vertical trajectory during mid and late swing phase drops rapidly, but just $10 \%$ before $\mathrm{HC}$ (based on stride period), the vertical drop is arrested about $1 \mathrm{~cm}$ above ground level (Lockhart, 2000). During the last 10\% of swing, the heel is lowered carefully to the surface as horizontal velocity decreases rapidly to almost zero. Figure 9 shows the body kinematics at HC for a typical trial (Lockhart, 2000). It can be observed that the forward velocity of the body's center-of-gravity was $1.6 \mathrm{~m} / \mathrm{s}$ and the heel velocity was reduced to $0.4 \mathrm{~m} / \mathrm{s}$ horizontally and $0.05 \mathrm{~m} / \mathrm{s}$ vertically.

The implication of the heel velocity before the $\mathrm{HC}$ is that at the end of the swing phase the heel velocity must be minimized so that a dangerous slip does not occur. According to Winter (1990), heel contact velocity in the horizontal direction was significantly higher for older adults compared to their younger counter-part even though walking velocity was slower for older adults compared to younger adults. He also noted that friction between the heel and floor surface reduced heel velocity to zero, and cautioned against low COF floor surfaces. He concluded that the only way to reduce the forward velocity of the foot prior to $\mathrm{HC}$ is through increased or earlier activation of the hamstring muscles. 


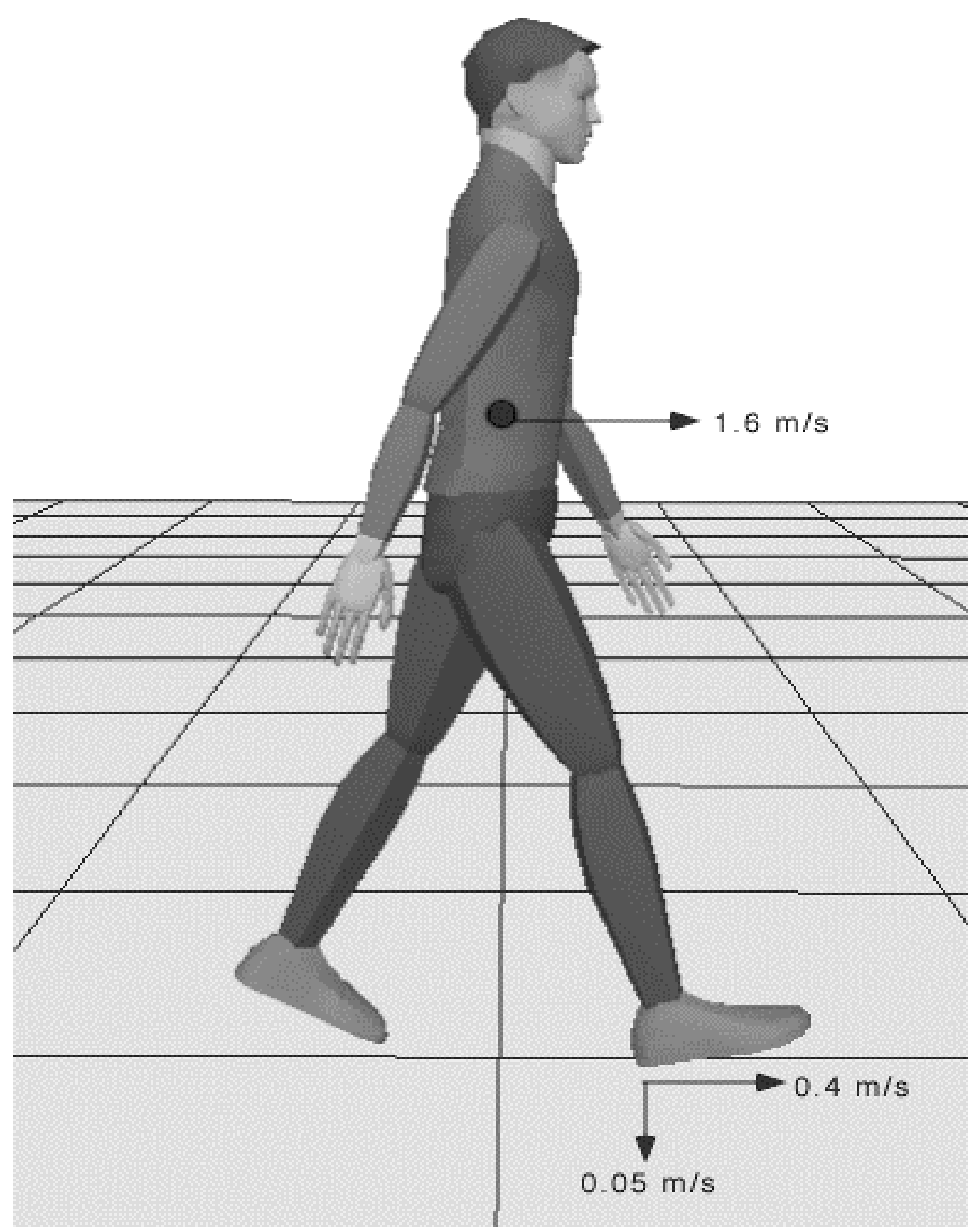

Figure 9. Body Kinematics at heel contact for a typical walking trial. 


\section{METHOD}

\section{Participants}

Fourteen younger (18-35 years old) adults ( 7 male and 7 female), and fourteen older ( 65 and older) adults ( 7 male and 7 female) participated in this experiment (Table 1). The younger adults were recruited from the general student population at Virginia Tech and the older adults were recruited from the local community. All participants were compensated for their time and effort. Participants were recruited by word of mouth and newspaper advertisements from the general population in Blacksburg, Virginia. All participants were required to have had a recent medical exam. Younger adults were required to have had a medical exam within the past year to participate in this study. Older adults were required to have had a medical exam within the past 6 months. The exam had to indicate no restrictions to physical activity. Participants were excluded from the study, if they indicated any physical problems, which may lead to further injury from participation in the study. Each participant completed an informed consent procedure approved by the Virginia Tech Internal Review Board (Appendix A), and a medical screening form (Appendix B). No other criterion was used in the selection process. 
Table 1. Participant Information.

\begin{tabular}{|c|c|c|c|c|}
\hline & \multicolumn{2}{|c|}{$\begin{array}{l}\text { Younger Adults (18-35 yrs) } \\
\text { Mean }\end{array}$} & \multicolumn{2}{|c|}{$\begin{array}{l}\text { Older Adults (65 and UP) } \\
\text { Mean } \\
\end{array}$} \\
\hline Age (yrs) & 23.36 & 4.29 & 72.64 & 4.36 \\
\hline Height (cm) & 172.81 & 11.34 & 168.49 & 9.10 \\
\hline Weight (Kg) & 72.52 & 12.31 & 72.59 & 16.31 \\
\hline
\end{tabular}




\section{Experimental Design}

$\underline{\text { Independent Variables }}$

Age Groups (Between Subjects): For this study, there were two age groups, 1835 and 65 and older.

Floor Surfaces (Within Subjects): For this study, two types of floor surfaces (dry and slippery) were examined where appropriate.

\section{Dependent Variables}

The processed coordinate data from the Motion Analysis system, and data collected from the force plates were used to calculate the following dependent variables from the kinematic and kinetic profiles associated with slips. Additionally, the salivary amylase (SA) level and anxiety score were assessed.

Step Length (SL):

Normal step length was calculated from the linear distance in the direction of progression between successive points of foot-to-floor contact of the same foot was measured. The step length was calculated using the distance formula from the difference between consecutive positions of the heel contacting the floor (resultant).

Adjusted step length was calculated by graphing the kinematic profiles utilizing Microsoft Excel. Force profiles in the $\mathrm{Z}$ and $\mathrm{X}$ direction for force plate one and two were graphed along with the left and right heel contact in the X direction. Step length was calculated using the distance formula from the linear distance between successive points of contact from force plate one to force plate two (Figure 10). 


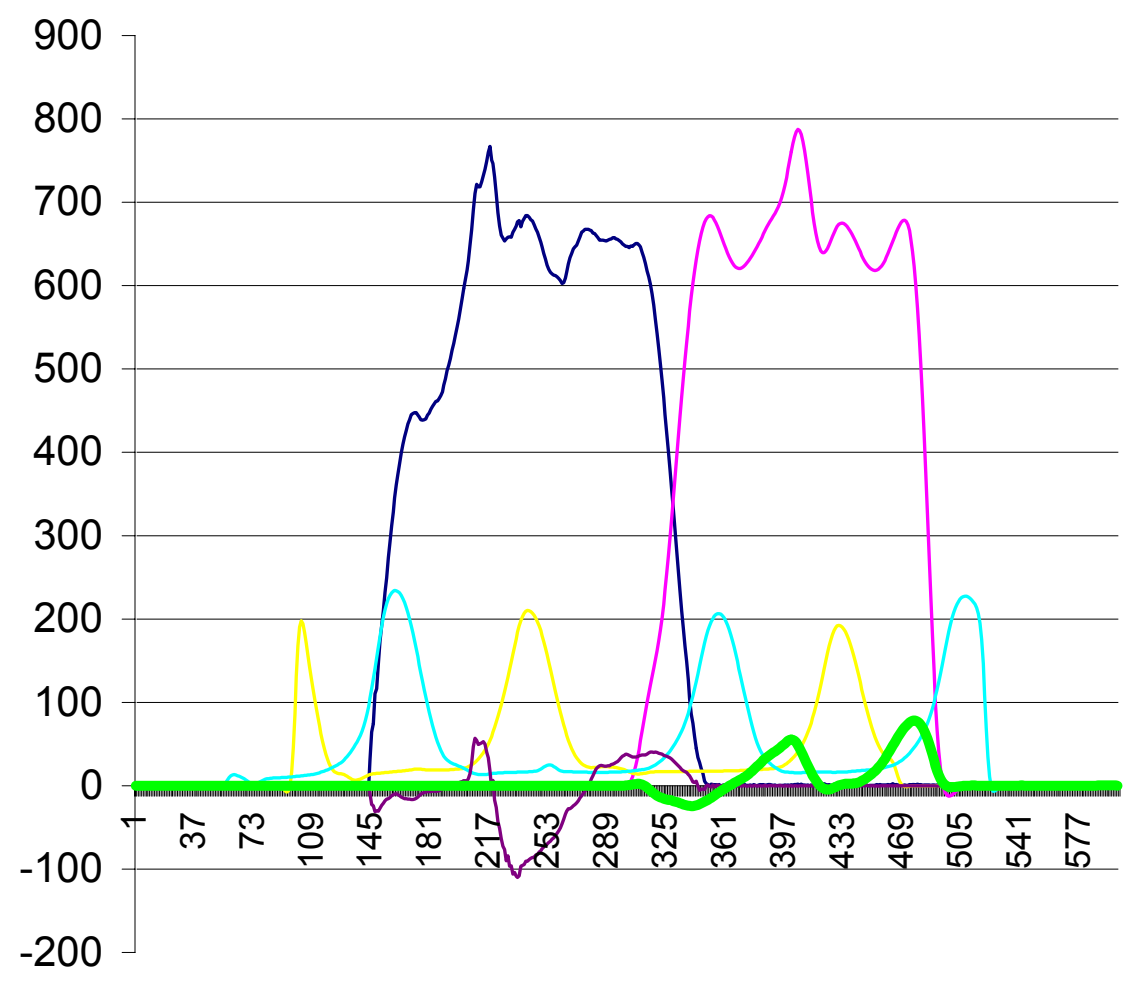

\begin{tabular}{|c|}
\hline FP1 \\
FP2 \\
Right Heel \\
Left Heel \\
\hline Fx FP1 \\
Fx FP2
\end{tabular}

Figure 10. Adjusted gait kinematic profile data. 


\section{Heel Velocity $\left(\mathrm{V}_{\mathrm{x}}\right)$ :}

Normal heel contact velocity and adjusted heel contact were calculated as follows: The horizontal velocity $(\mathrm{x})$ of the heel before the heel contacts the floor was measured. The position data was used to calculate the heel velocity. $V_{x}$ of a sequence of data was obtained using the finite difference method. The linear finite difference equation is using the difference of the foot displacements of last 1/120 second $(\Delta t)$ before and after the heel contact divided by the elapsed time $(2 \Delta t)$ using the following formula.

$$
\begin{aligned}
& \mathrm{V}=\Delta \mathrm{x} / \Delta \mathrm{t} \\
& \mathrm{V}_{\mathrm{xi}}=\left(\mathrm{X}_{\mathrm{i}+1}-\mathrm{X}_{\mathrm{i}-1}\right) / 2 \Delta \mathrm{t}
\end{aligned}
$$

Required Coefficient of Friction (RCOF):

Normal RCOF was calculated from the ratio between the horizontal and vertical ground reaction force $\left(\mathrm{F}_{\mathrm{h}} / \mathrm{F}_{\mathrm{v}}\right)$ was calculated at peak 3 (Perkins, 1978) on the non-oily vinyl floor surface with the LabView data collection software system. This ratio indicates where in the walking step a slip is most likely to occur (slip initiation).

Adjusted RCOF was calculated from the graphed kinematic data (Figure 10). The $\left(F_{x}\right.$ for force plate two was used to determine the point of heel contact, and based on this point of contact, the relationship between the horizontal and vertical ground reaction forces were calculated by the ratio $\left(\mathrm{F}_{\mathrm{x}} / \mathrm{F}_{\mathrm{z}}\right)$ for force plate two.

Slip Distance (SD):

The horizontal distance traveled by the foot after contact with the floor was measured utilizing the Lab View data collection software system. 
Anxiety Score:

The Multiple Affects Adjective Check List (MAACL) was administered to participants to capture their initial baseline score before testing began; just before changing to the slippery floor surface; after they slipped on the slippery floor surface; and when standing on the track looking at the slippery floor surface they previously slipped on. A Macro-program developed by the U.S. Army Research Laboratory - Human Research and Engineering Directorate was utilized to score the MAACLs.

Salivary Amylase Level (i.e., stress level):

Saliva samples were collected from participants to capture their initial baseline level before testing began; just before changing to the slippery floor surface; after they slipped on the slippery floor surface; and when standing on the track looking at the slippery surface they previously slipped on. Saliva samples were sent to the Department of $\mathrm{Ob} / \mathrm{GYN}$ at Northwestern University to be analyzed.

\section{Apparatus}

Walking trials were conducted in the Locomotion Research Laboratory at Virginia Tech. A baseline linear floor surface was mounted on the linear walking track (1.5 m x $15.5 \mathrm{~m})$. A commonly used vinyl tile (Armstrong) material was used in this experiment to represent a realistic environmental setting. The vinyl tile surface was covered with soap and water (53\% soap and $47 \%$ water) to reduce the coefficient of friction (COF). The available dynamic COF (ADCOF) for each surface was measured utilizing a standard $4.54 \mathrm{Kg}(10 \mathrm{lb}$.) horizontal pull slip-meter with a rubber sole material on the force platform. Walking trials were conducted on a linear walking track using an 
overhead fall arresting harness system (Figure 11). A manual sliding floor changer was used to change the test surface conditions. The overall function of the system was to control the experimental conditions without the participants being aware of any floor surface change. The arresting rig was used to protect participants from falling during the experiment, and was designed to permit the participants to slip approximately $10 \mathrm{~cm}$ (dampened by a spring break) before arresting the fall, and stopping any forward motion. A six-camera ProReflex Qualysis system (infra-red passive marker system) was used to collect the three-dimensional posture data of the participants as they walked over the test surface. Posture data was sampled and recorded at a rate of $120 \mathrm{~Hz}$. Ground reaction forces of the participants walking over the test surfaces were measured using two force plates (Bertec Corporation) and sampled at a rate of $1200 \mathrm{~Hz}$. Force profiles were collected using an analogue-to-digital converter and microcomputer. Psychophysical stress level was measured through Salivary Amylase (SA). SA samples was collected and stored in a cold storage chest, which was sent to Department of $\mathrm{Ob} / \mathrm{GYN}$ at Northwestern University Medical School for further analysis. 


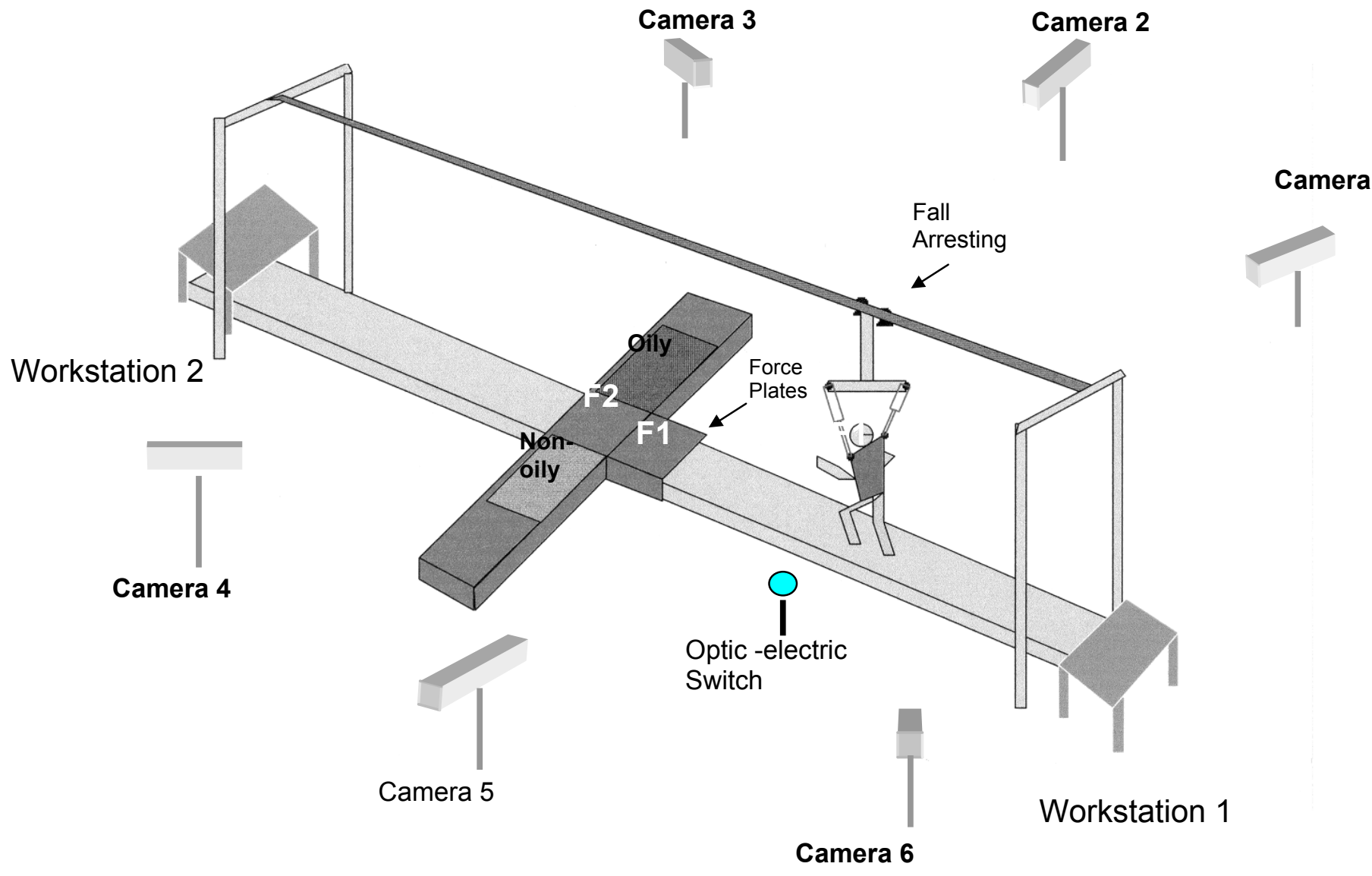

Figure 11. Field layout of the experiment including; Fall Arresting System, Infra-red cameras (6), Linear Slide Floor Changer (LSFC) with force plate (F2) and hidden oily and non-oily test floor surfaces, fixed force plate (F1), Optoelectric Switch, and workstations. 


\section{Procedure}

\section{$\underline{\text { Familiarization Session }}$}

The participants attended a familiarization session before the scheduling of the experiments (data collection). This session familiarized the participants with the fall arresting rig system and the walking conditions (natural cadence). The participants tested the fall arresting rig to assure themselves that the system (fall arresting rig) would arrest potential falls. Anthropometrics data (such as body weight and height) was collected at this time.

\section{$\underline{\text { Walking Protocol }}$}

The biomechanical parameters of walking were collected during the second session of the experiment. Prior to performing the walking experiment, participants were fitted with standardized walking shoes in order to minimize possible variations due to footwear. In addition, infrared passive markers were attached to the anatomically significant body positions (toe, heel, knee, and hip). All participants wore a full-body safety harness suspended with multiple cables from a single overhead track. The length of the harness suspension cable was adjusted for each participant so that his or her hands would not contact the floor surface in the event of a failure to regain balance. The full body harness did not interfere with upper or lower extremity motions, and all support cables were attached to the shoulders out of the participant's field of vision. Investigators have worked with a similar harness in previous studies testing 98 participants total, and 
have experienced no injuries associated with this procedure (Bunterngchit et al., 1999; Lockhart, 1997; and Lockhart et al., 2000a and b).

During the experiment, participants walked (natural cadence) across the dry vinyl floor surface (base line floor) for 15-30 minutes. Within a subsequent 10-minute session, slippery conditions were randomly introduced by changing the floor surface utilizing a manual floor changer. The participant's posture, ground reaction forces, MAACL, and SA data were collected. The second trial was used (for data analysis) only if the first trial was not acceptable (e.g., stepping on the edge of the force platform). While walking, participants were instructed to focus their eyes on a television monitor screen located approximately 2 meters above and 3 meters away from the testing area to ensure that they did not look at the test floor surface. Participants performed a secondary task that required them to count a specified shape and color (i.e., number of blue circles). This task was used to maintain attentional focus away from the floor. Participants were supplied with a Walkman-compact disc player, and listened to old comedy routines during the walking experiment to conceal any sound of the floor changer.

At least two graduate research assistants and the principal investigator were present during all testing periods. Staff members running the tests strongly emphasized, in both spoken and written instructions, that participants are free to discontinue participation at any time.

\section{$\underline{\text { Salivary Amylase Protocol }}$}

Psychophysical parameters of walking were collected utilizing a noninvasive physiological measure of stress (salivary amylase). Four samples were collected as follows: (1) baseline: stress level was collected prior to performing the walking 
experiment, (2) pre-slip: prior to changing the floor surface from dry to oily to assess the participant's stress level just before slipping, (3) slip: immediately after the participant slipped for comparison to baseline and pre slip stress levels, (4) post-slip: while the participants stood on the track looking at the slippery floor surface after they slipped. For each sample, participants were given a cotton swab and plastic vial annotated with their participant number, the date and time, and the researcher's initials (researchers were wearing rubber gloves). Participants were asked to place the cotton swab in their mouth and move it around until moist with saliva and to remove the moisten swab from their mouth and place it in the plastic vial (researcher did not come into contact with the moisten swab). The sealed vials were placed in a cold storage chest. At the conclusion of the experiment, the sealed vials were sent to the Department of $\mathrm{Ob} / \mathrm{GYN}$ at Northwestern University Medical School, Chicago, IL to be analyzed.

\section{Multiple Affects Adjective Checklist (MAACL) Protocol}

Anxiety was assessed utilizing the MAACL during the walking portion of the experiment. Four samples were collected as follows: (1) baseline: anxiety level was collected prior to performing the walking experiment, (2) pre-slip: prior to changing the floor surface from dry to oily to assess the participant's anxiety level just before slipping, (3) slip: immediately after the participant slipped for comparison to baseline and pre slip anxiety levels, (4) post-slip: while the participants stood on the track looking at the slippery floor surface after they slipped. For each sample, participants were given the MAACL and asked to check all adjectives that described how they felt at that time. The MAACls were sent to the Army Research Laboratory to be analyzed. 


\section{RESULTS}

\section{Treatment of Data}

The salivary amylase levels (SA) and anxiety scores were analyzed using a 2x2 two-way (age x gender) multivariate analysis of variance (MANOVA). Additionally, separate ANOVA was performed on all significant variables. In addition, dependent measures (e.g., heel contact velocity, RCOF, slip distance, step length) were analyzed by $2 \times 2$ two-way (age x gender) repeated measures analyses of variance (ANOVA). Bivariate correlation analyses were performed to describe the relationships between independent and dependent variables. Post-hoc means separation test (Tukey-Kramer Least Significant Difference) was performed on all significant differences (age, gender, interactions). The statistical package, JMP, was utilized for all data analyses. Results were considered significant at $\alpha \leq 0.05$.

\section{MANOVA Results (SA and Anxiety)}

The findings from the MANOVA analysis are summarized under the following headings: overall means and age comparison. Salivary amylase levels and anxiety scores were analyzed in four categories: baseline, pre-slip, slip and post-slip. Post-hoc means separation test (Tukey-Kramer Least Significant Difference) was performed on all significant differences (age, gender, interactions). Summary of the MANOVA results for age effect are listed in Table 2. 
Table 2. Summary of MANOVA Means and Standard Deviations.

\begin{tabular}{lcc}
\hline $\begin{array}{l}\text { Variables } \\
\text { (unit) }\end{array}$ & $\begin{array}{c}\text { Young } \\
\text { Mean (SD) }\end{array}$ & $\begin{array}{c}\text { Old } \\
\text { Mean (SD) }\end{array}$ \\
\hline Salivary Amylase Baseline (level) & $157.17(61.49)$ & $204.66(89.78)$ \\
Salivary Amylase Pre-slip (level) & $172.24(145.63)$ & $194.48(71.24)$ \\
*Salivary Amylase Slip (level) & $193.95(135.28)$ & $306.00(107.18)$ \\
*Salivary Amylase Post-slip (level) & $181.92(90.43)$ & $283.67(118.92)$ \\
Anxiety Baseline (score) & $46.15(5.75)$ & $43.00(3.91)$ \\
Anxiety Pre-slip (score) & $47.31(5.78)$ & $46.69(9.01)$ \\
Anxiety Slip (score) & $67.69(24.26)$ & $61.69(29.86)$ \\
Anxiety Post-slip (score) & $58.31(18.67)$ & $57.85(25.82)$ \\
\hline
\end{tabular}

*Denotes significant differences between age groups 


\section{Salivary Amylase Level}

\section{$\underline{\text { Overall Means (MANOVA) }}$}

The results indicated a statistically significant difference $\left(\mathrm{F}_{3,106}=3.3997, \mathrm{p}=\right.$ 0.0205) between each level: baseline, pre-slip, slip, and post-slip. (Figure 12 and Table 3). Furthermore, Tukey-Kramer post-hoc test indicated a significant difference between baseline mean level and slip mean level $(\mathrm{p} \leq 0.0005)$. SA mean level was significantly higher than baseline SA mean level. No differences were found for all other levels.

Table 3. Overall means and standard deviations for SA Level.

\begin{tabular}{|c|c|c|}
\hline SA Level & Mean $(\mathrm{U} / \mathrm{mL})$ & Std. Dev. \\
\hline Baseline & 180.91 & 97.33 \\
\hline Pre-slip & 183.36 & 95.81 \\
\hline Slip & 249.97 & 131.31 \\
\hline Post-slip & 232.80 & 118.92 \\
\hline
\end{tabular}

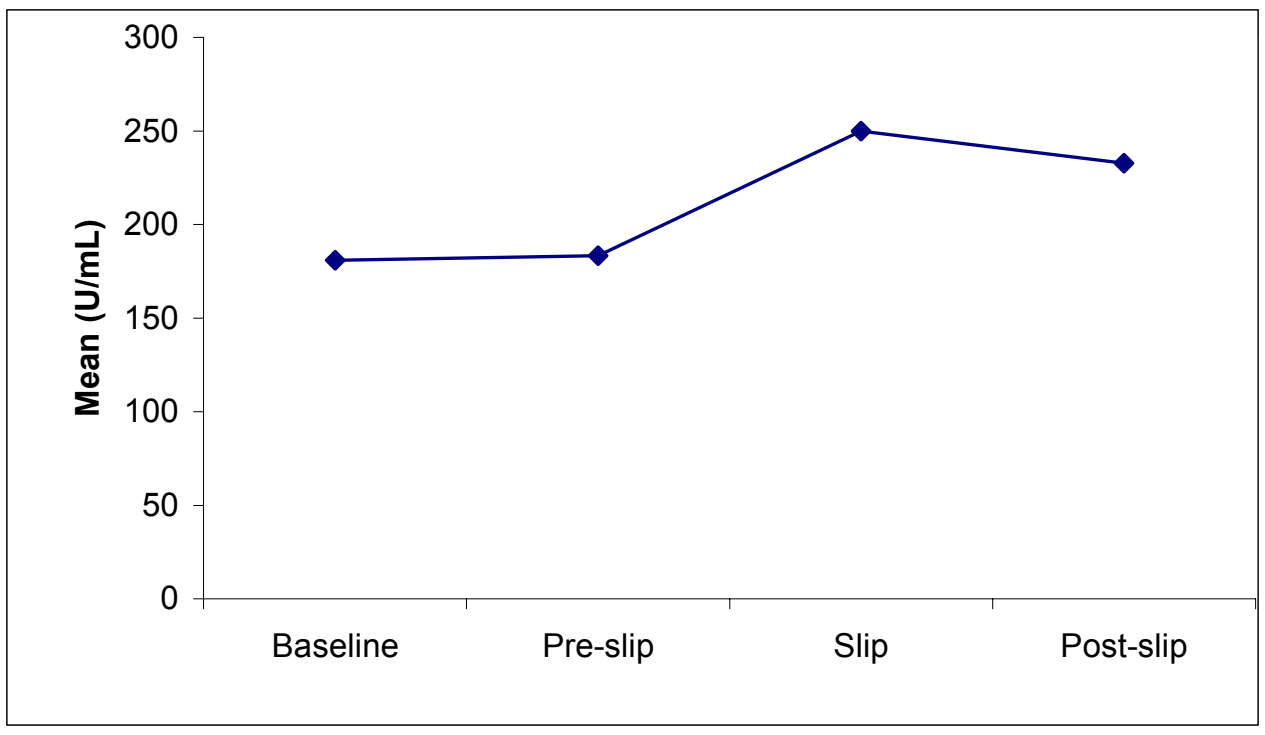

Figure 12. Overall means of salivary amylase levels. 


\section{$\underline{\text { Age Overall Means (MANOVA) }}$}

The results indicated a statistically significant difference $\left(\mathrm{F}_{1,26}=6.0599, \mathrm{p}=\right.$ 0.0208) between older and younger adults (Table 4 and Figure 13). Older adults had a significantly higher SA level than younger adults.

Table 4. Summary of overall SA mean levels for main effect age.

\begin{tabular}{|l|l|l|l|l|}
\hline Age & Baseline & Pre-slip & Slip & Post-slip \\
\hline Young & 157.17 & 172.24 & 193.95 & 181.92 \\
\hline Old & 204.66 & 194.48 & 306.00 & 283.67 \\
\hline
\end{tabular}

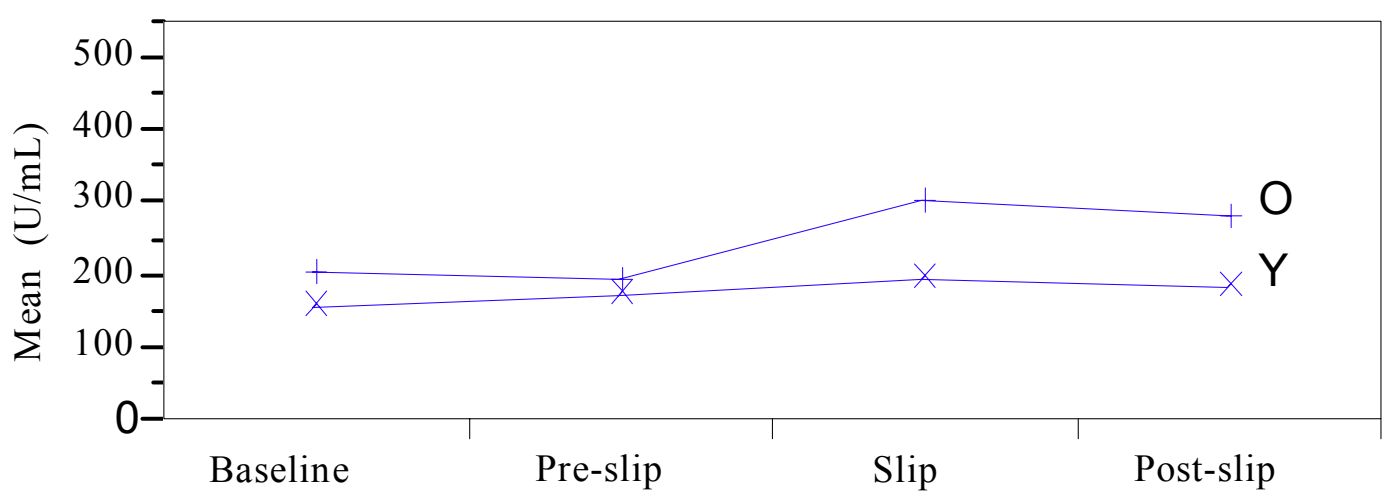

Figure 13. Age effect on overall SA means. 


\section{Results Of Two-Way ANOVA}

\section{Salivary Amylase (SA) Baseline Level}

\section{$\underline{\text { Age Comparison }}$}

The results indicated no statistically significant difference $\left(\mathrm{F}_{3,24}=2.1954, \mathrm{p}=\right.$ 0.1514 ) between older and younger participants. Although not significant, older participants had a higher baseline level than their younger counterparts (Table 5).

Table 5. Descriptive summary of SA baseline level on main effect age.

\begin{tabular}{|c|c|c|c|}
\hline Age & Count & Mean $(\mathrm{U} / \mathrm{mL})$ & Std. Dev. \\
\hline Older Adults & 14 & 204.657 & 89.7833 \\
\hline Younger Adults & 14 & 157.169 & 61.4918 \\
\hline
\end{tabular}

\section{Salivary Amylase (SA) Pre-Slip Level}

\section{Age Comparison}

The results indicated no statistically significant difference $\left(\mathrm{F}_{3,24}=0.5309, \mathrm{p}=\right.$ 0.4733 ) between older and younger participants. Although not significant, older participants had a slightly higher pre-slip SA level than younger participants (Table 6).

Table 6. Descriptive summary of SA pre-slip level on main effect age.

\begin{tabular}{|c|c|c|c|}
\hline Age & Count & Mean $(\mathrm{U} / \mathrm{mL})$ & Std. Dev. \\
\hline Older Adults & 14 & 194.484 & 71.2354 \\
\hline Younger Adults & 14 & 172.244 & 145.6296 \\
\hline
\end{tabular}




\section{Salivary Amylase (SA) Level Slip}

\section{Age Comparison}

The results indicated a statistically significant difference $\left(\mathrm{F}_{3,24}=5.7894, \mathrm{p}=\right.$ 0.0242 ) between older and younger participants. Older participants had a higher SA level after a slip than younger participants (Table 7 and Figure 14).

Table 7. Descriptive summary of SA level after a slip on main effect age.

\begin{tabular}{|c|c|c|c|}
\hline Age & Count & Mean $(\mathrm{U} / \mathrm{mL})$ & Std. Dev. \\
\hline Older Adults & 14 & 305.996 & 107.1807 \\
\hline Younger Adults & 14 & 193.951 & 135.2821 \\
\hline
\end{tabular}

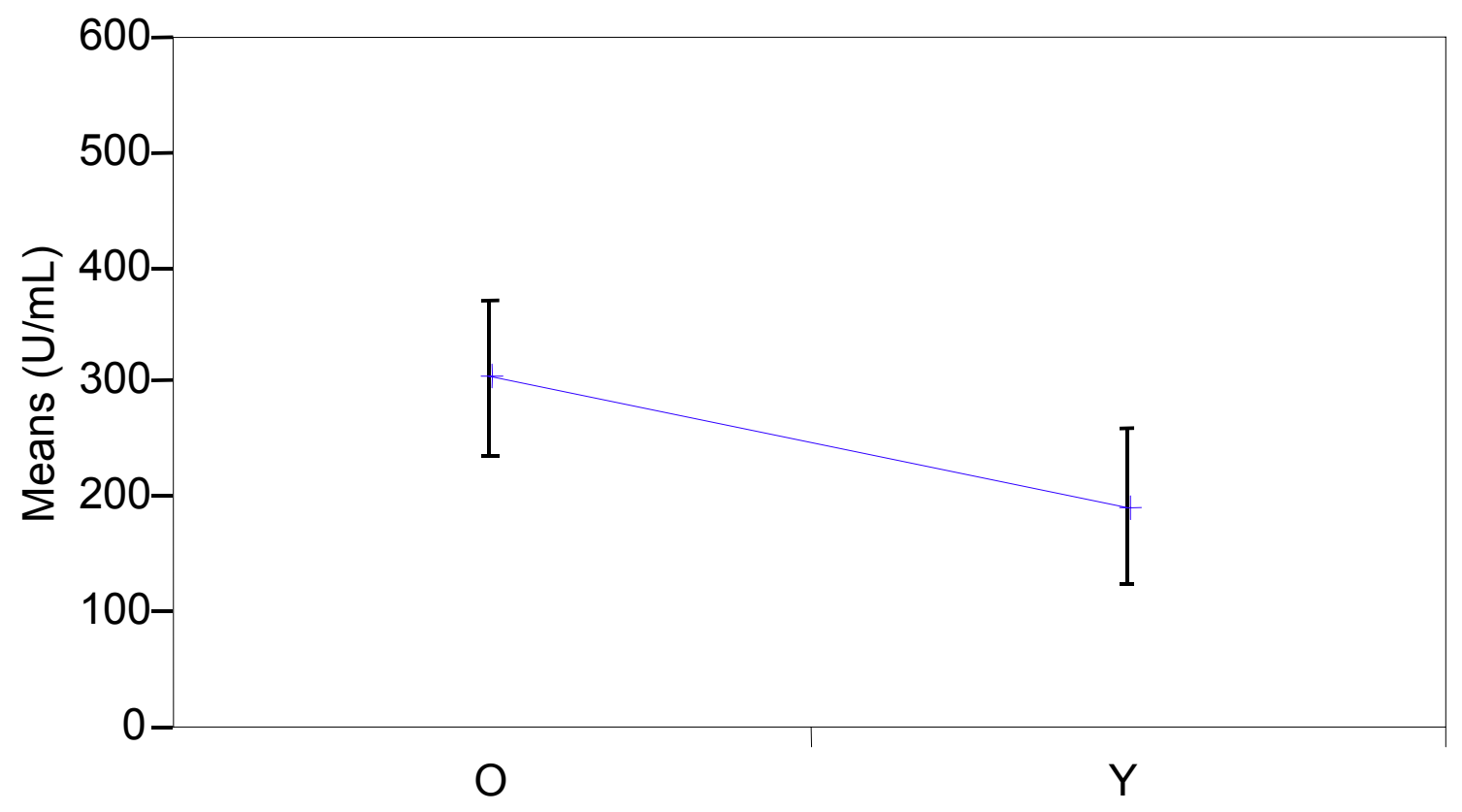

Age

Figure 14. Age effect on SA slip level. 


\section{Salivary Amylase (SA) Post-Slip Level}

\section{Age Comparison}

The results indicated a statistically significant difference $\left(\mathrm{F}_{3,24}=6.4170, \mathrm{p}=\right.$ 0.0183 ) between older and younger participants. Older participants had a higher SA level when standing on the track looking at the slippery surface after a slip than younger participants (Table 8 and Figure 15).

Table 8. Descriptive summary of SA level after a slip on main effect age.

\begin{tabular}{|c|c|c|c|}
\hline Age & Count & Mean $(\mathrm{U} / \mathrm{mL})$ & Std. Dev. \\
\hline Older Adults & 14 & 283.674 & 118.9204 \\
\hline Younger Adults & 14 & 181.916 & 90.4347 \\
\hline
\end{tabular}

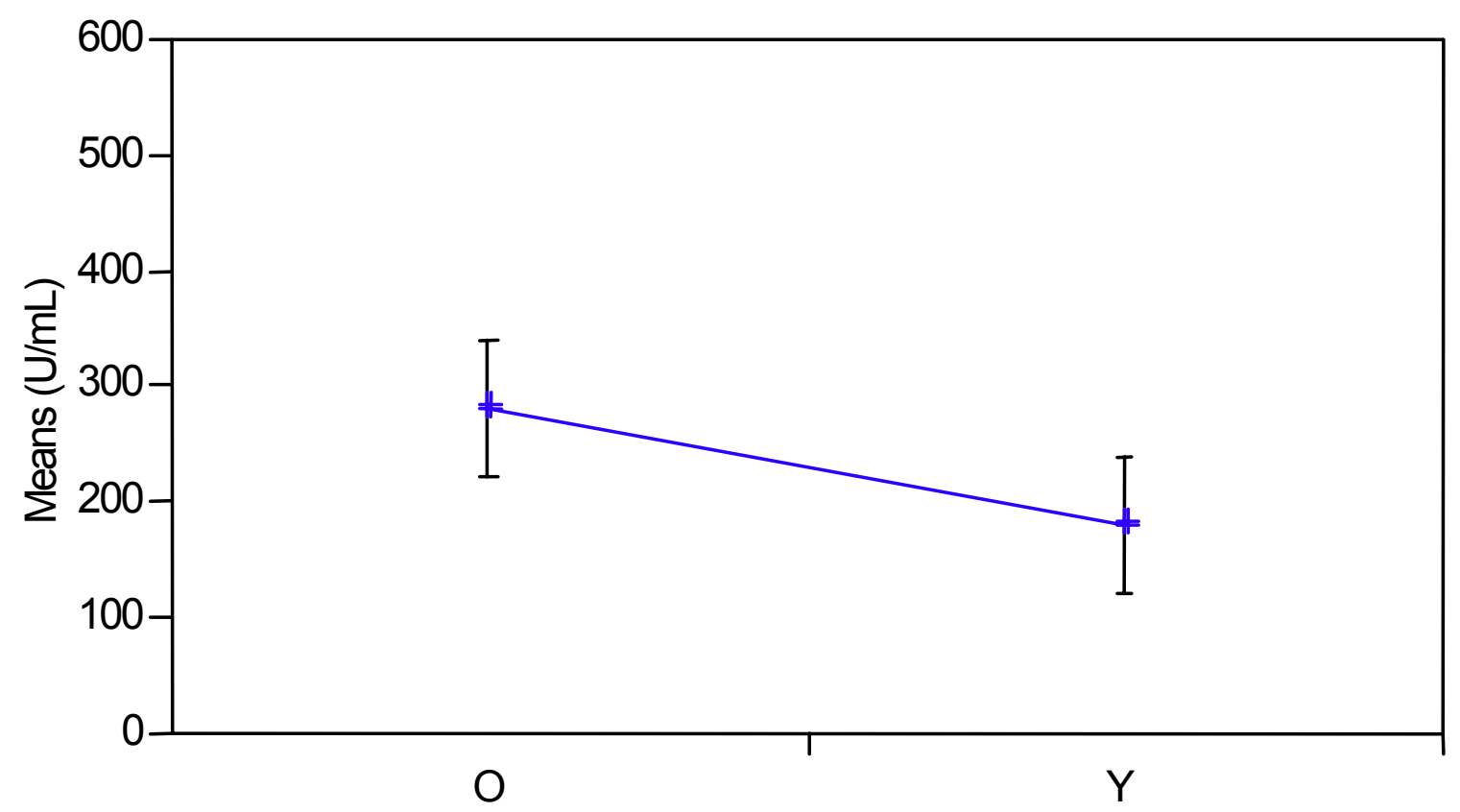

Age

Figure 15. Age effect on SA post-slip level. 


\section{Anxiety Score}

\section{$\underline{\text { Overall Means (MANOVA) }}$}

The results indicated a statistically significant difference $\left(F_{3,106}=7.0368, p=\right.$ 0.0002) between each level: baseline, pre-slip, slip, and post-slip (Table 9 and Figure 16). Furthermore, a Tukey-Kramer post-hoc test indicated that there was a significant difference between baseline mean score and slip mean score, baseline mean score and post-slip mean score, and pre-slip mean score and slip mean score $(\mathrm{p} \leq 0.0005)$. There was a significant increase in the anxiety score after a slip from baseline score and pre-slip score. Also, overall, post-slip mean score was significantly higher than baseline mean score.

Table 9. Summary of overall anxiety level means.

\begin{tabular}{|c|c|c|}
\hline Anxiety Level & Mean (score) & Std. Dev. \\
\hline Baseline & 44.25 & 5.54 \\
\hline Pre-slip & 46.71 & 8.43 \\
\hline Slip & 63.68 & 26.47 \\
\hline Post-slip & 58.46 & 22.19 \\
\hline
\end{tabular}

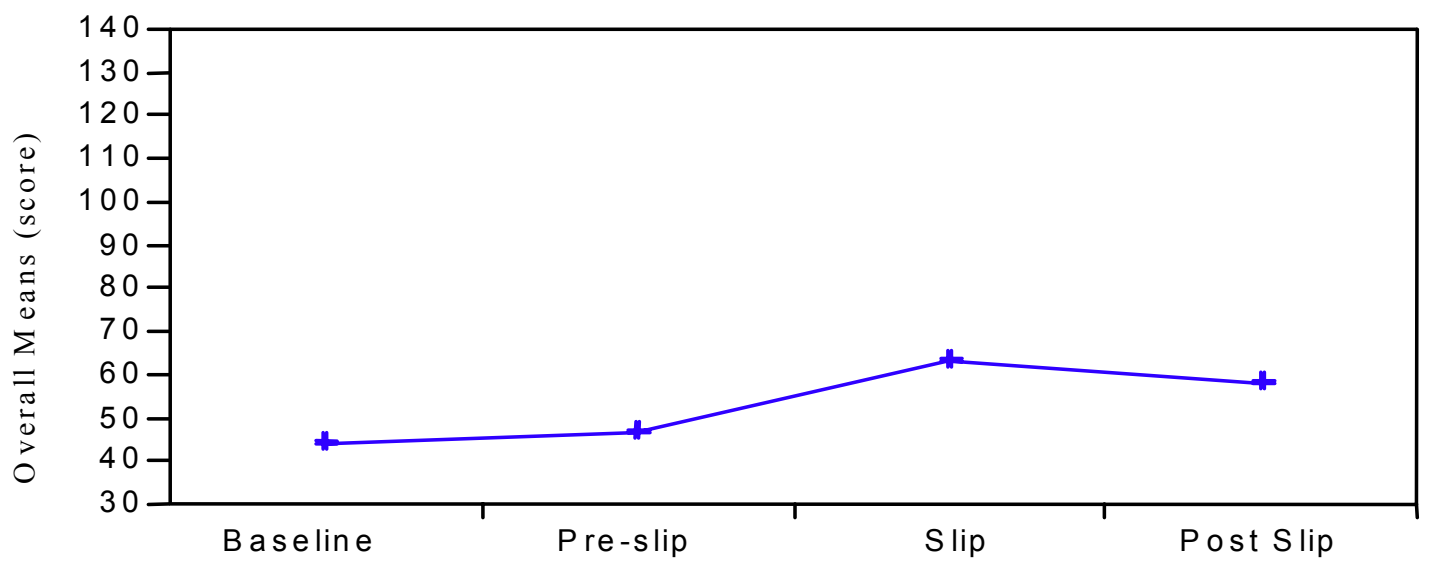

Figure 16. Overall means of anxiety scores. 


\section{$\underline{\text { Age Overall Means (MANOVA) }}$}

The results indicated no statistically significant difference $\left(\mathrm{F}_{1,26}=0.5212, \mathrm{p}=\right.$ 0.4768) between older and younger adults (Table 10 and Figure 17). Although not significant, younger adults had a slightly higher anxiety score than older adults.

Table 10. Summary of overall anxiety means for main effect age.

\begin{tabular}{|c|c|c|c|c|}
\hline Age & Baseline & Pre-slip & Slip & Post-slip \\
\hline Young & 46.15 & 47.31 & 67.69 & 58.31 \\
\hline Old & 43.00 & 46.69 & 61.69 & 57.85 \\
\hline
\end{tabular}

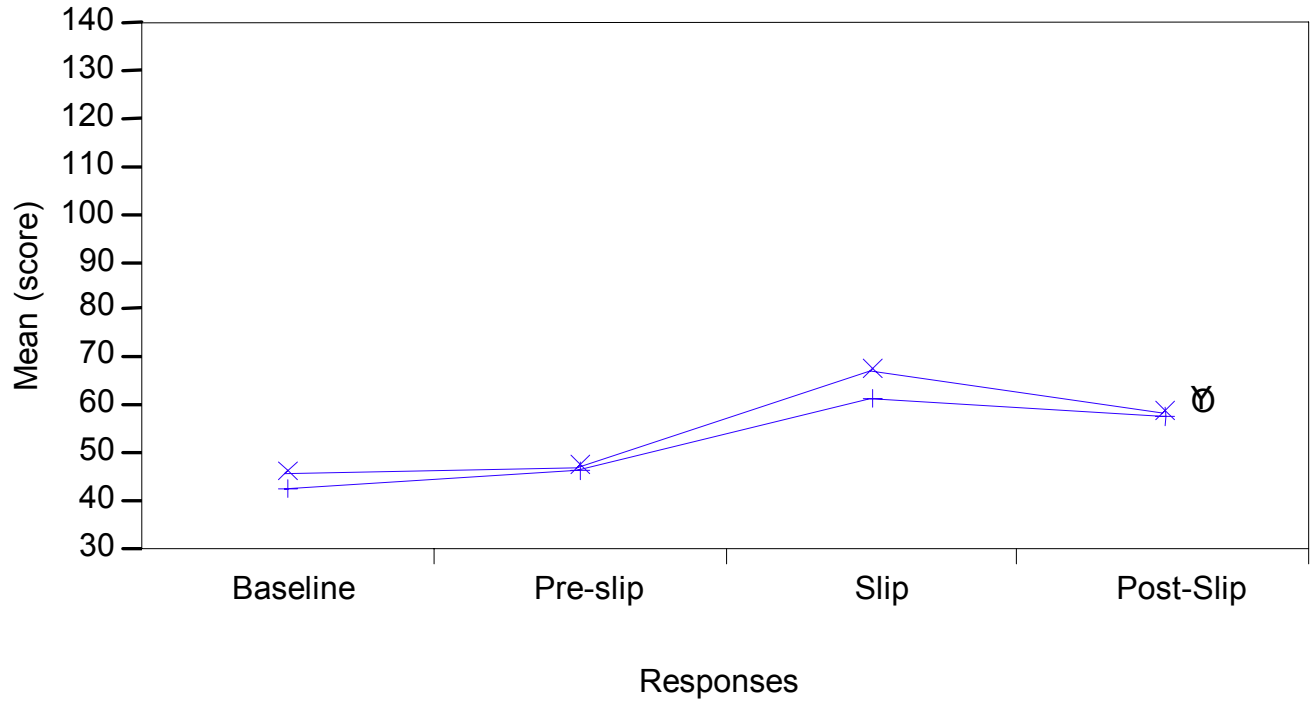

Figure 17. Age effect on overall anxiety score means. 


\section{Results Of Two-Way ANOVA}

\section{Baseline Anxiety Score}

\section{$\underline{\text { Age Comparison }}$}

The results indicated no statistically significant difference $\left(\mathrm{F}_{3,24}=2.9651, \mathrm{p}=\right.$ 0.0979 ) between older and younger participants. Although not significant, younger participants had a slightly higher baseline score than older participants (Table 11 and Figure 18).

Table 11. Descriptive summary of anxiety baseline score on main effect age.

\begin{tabular}{|c|c|c|c|}
\hline Age & Count & Mean (score) & Std. Dev. \\
\hline Older Adults & 14 & 42.5714 & 3.9088 \\
\hline Younger Adults & 14 & 45.9286 & 5.7467 \\
\hline
\end{tabular}

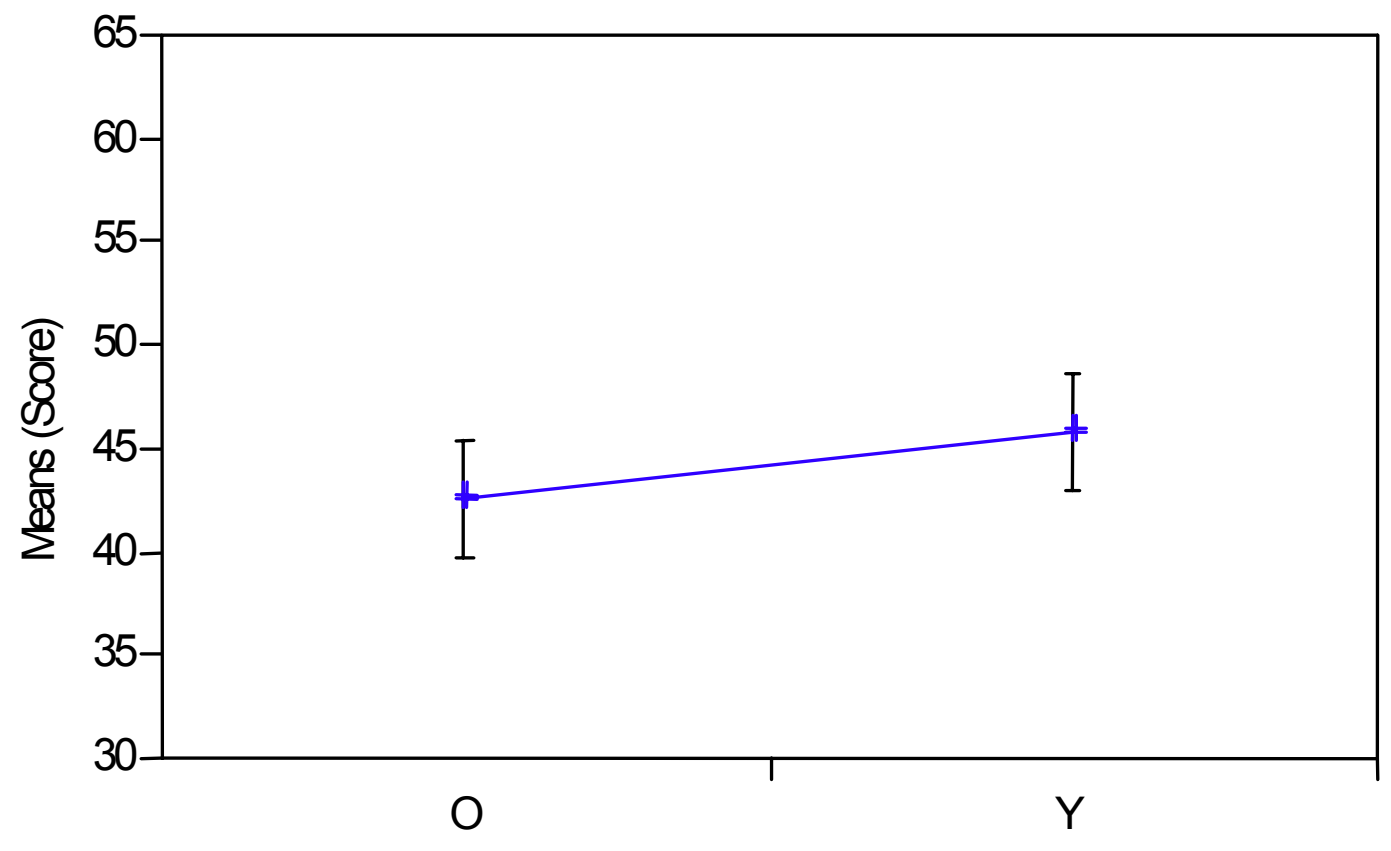

Age

Figure 18. Age effect on baseline anxiety score. 


\section{Pre-Slip Anxiety Score}

\section{Age Comparison}

The results indicated no statistically significant difference $\left(\mathrm{F}_{3,24}=0.0319, \mathrm{p}=\right.$ 0.8597 ) between older and younger participants. Although not significant, younger participants had a slightly higher pre-slip score than older participants (Table 12 and Figure 19).

Table 12. Descriptive summary of anxiety pre-slip score on main effect age.

\begin{tabular}{|c|c|c|c|}
\hline Age & Count & Mean (Score) & Std. Dev. \\
\hline Older Adults & 14 & 46.4286 & 9.0143 \\
\hline Younger Adults & 14 & 47.0000 & 5.7772 \\
\hline
\end{tabular}

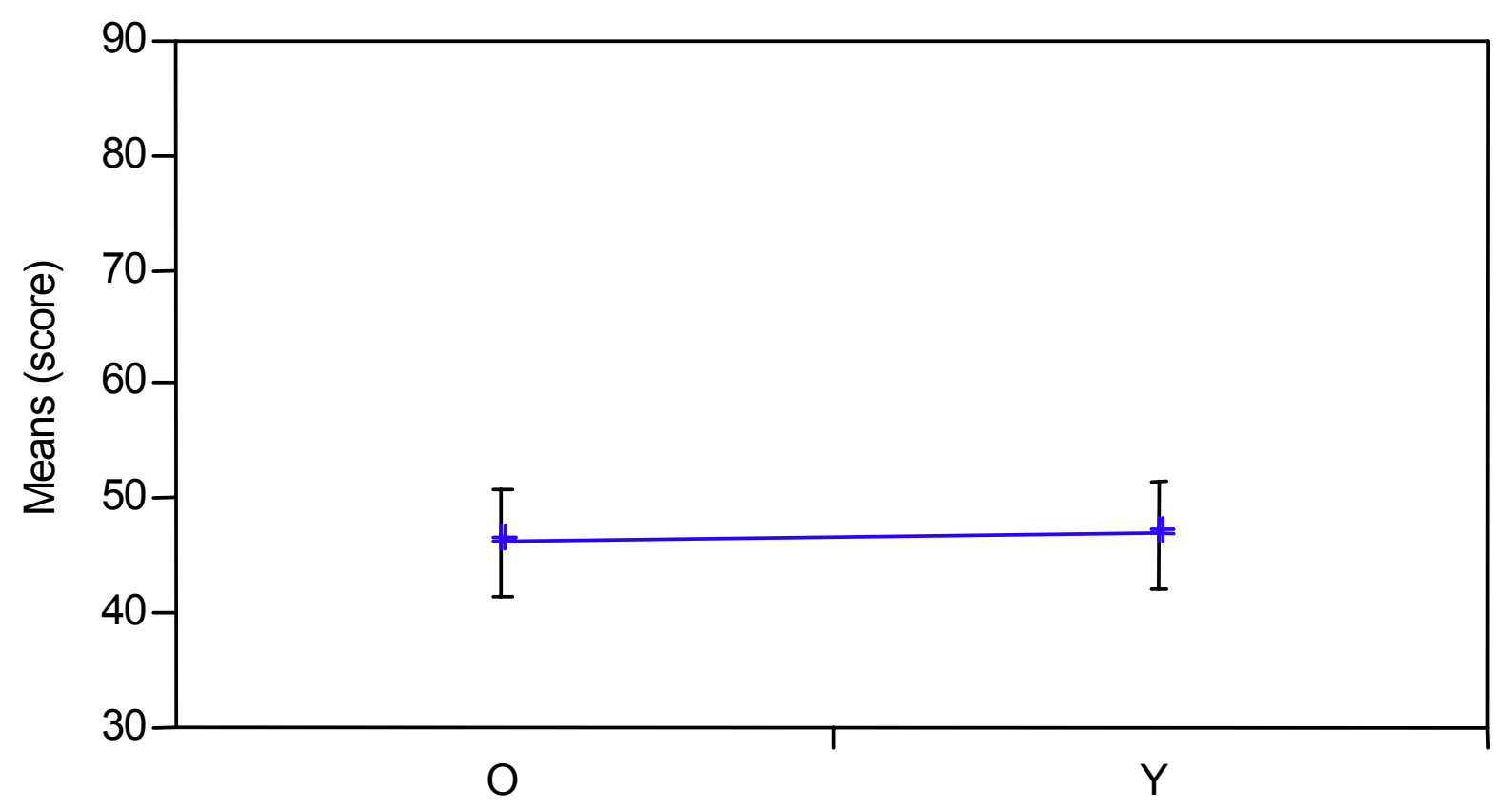

Age

Figure 19. Age effect on pre-slip anxiety score. 


\section{Slip Anxiety Score}

\section{Age Comparison}

The results indicated no statistically significant difference $\left(F_{3,24}=0.4049, p=\right.$ 0.5306) between older and younger participants. Although not significant, younger participants had a slightly higher anxiety score after slip than older participants (Table 13 and Figure 20).

Table 13. Descriptive summary of anxiety score after slip on main effect age.

\begin{tabular}{|c|c|c|c|}
\hline Age & Count & Mean (score) & Std. Dev. \\
\hline Older Adults & 14 & 60.3571 & 29.8589 \\
\hline Younger Adults & 14 & 67.0000 & 24.2608 \\
\hline
\end{tabular}

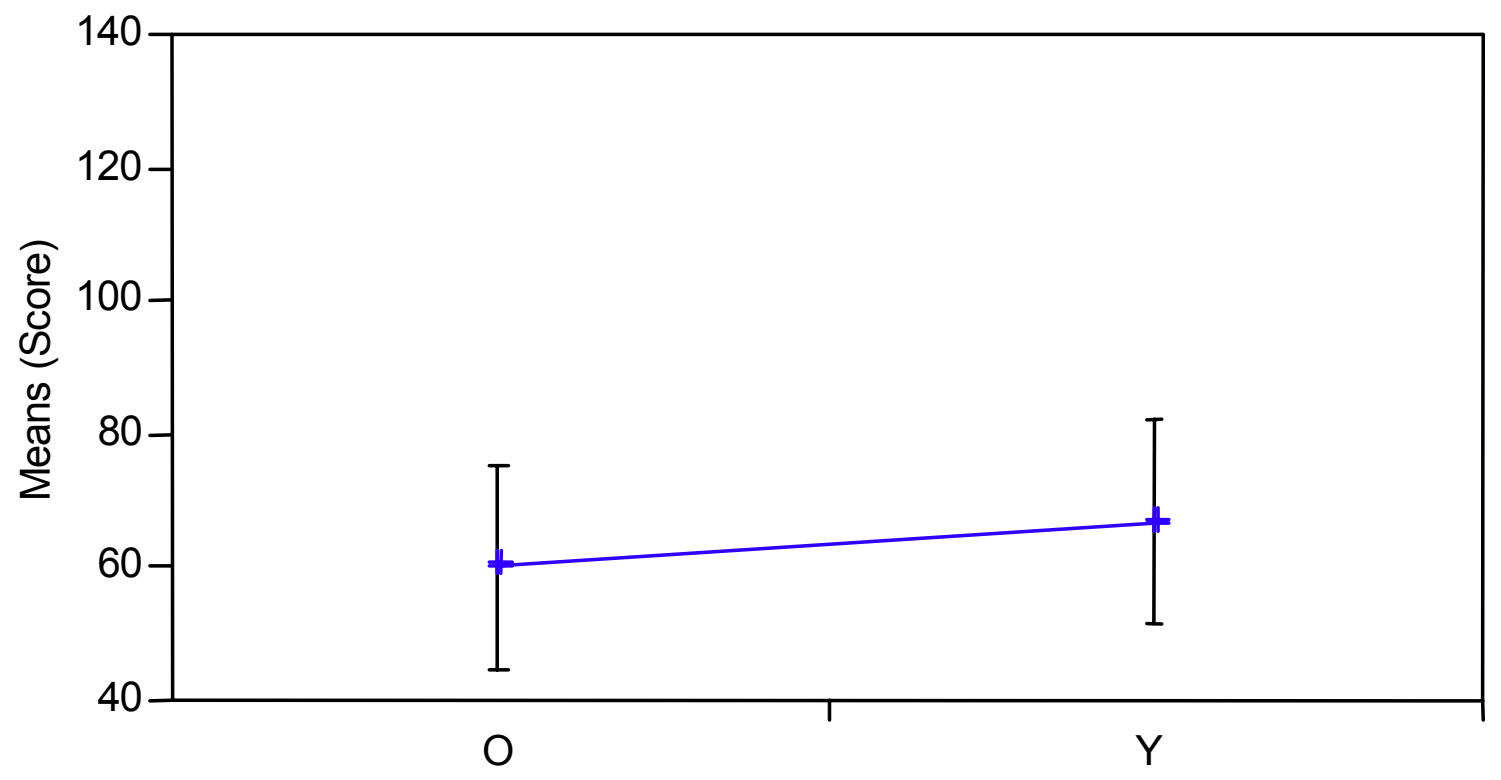

Age

Figure 20. Age effect on slip anxiety score. 


\section{Post-Slip Anxiety Score}

\section{Age Comparison}

The results indicated no statistically significant difference $\left(\mathrm{F}_{3,24}=0.1266, \mathrm{p}=\right.$ 0.7251 ) between older and younger participants. Although not significant, younger participants had a slightly higher anxiety score while standing on the track looking at the slippery floor surface after slipping than older participants (Table 14 and Figure 21).

Table 14. Descriptive summary of post-slip anxiety score on main effect age.

\begin{tabular}{|c|c|c|c|}
\hline Age & Count & Mean (score) & Std. Dev. \\
\hline Older Adults & 14 & 56.9286 & 25.8229 \\
\hline Younger Adults & 14 & 60.0000 & 18.6723 \\
\hline
\end{tabular}

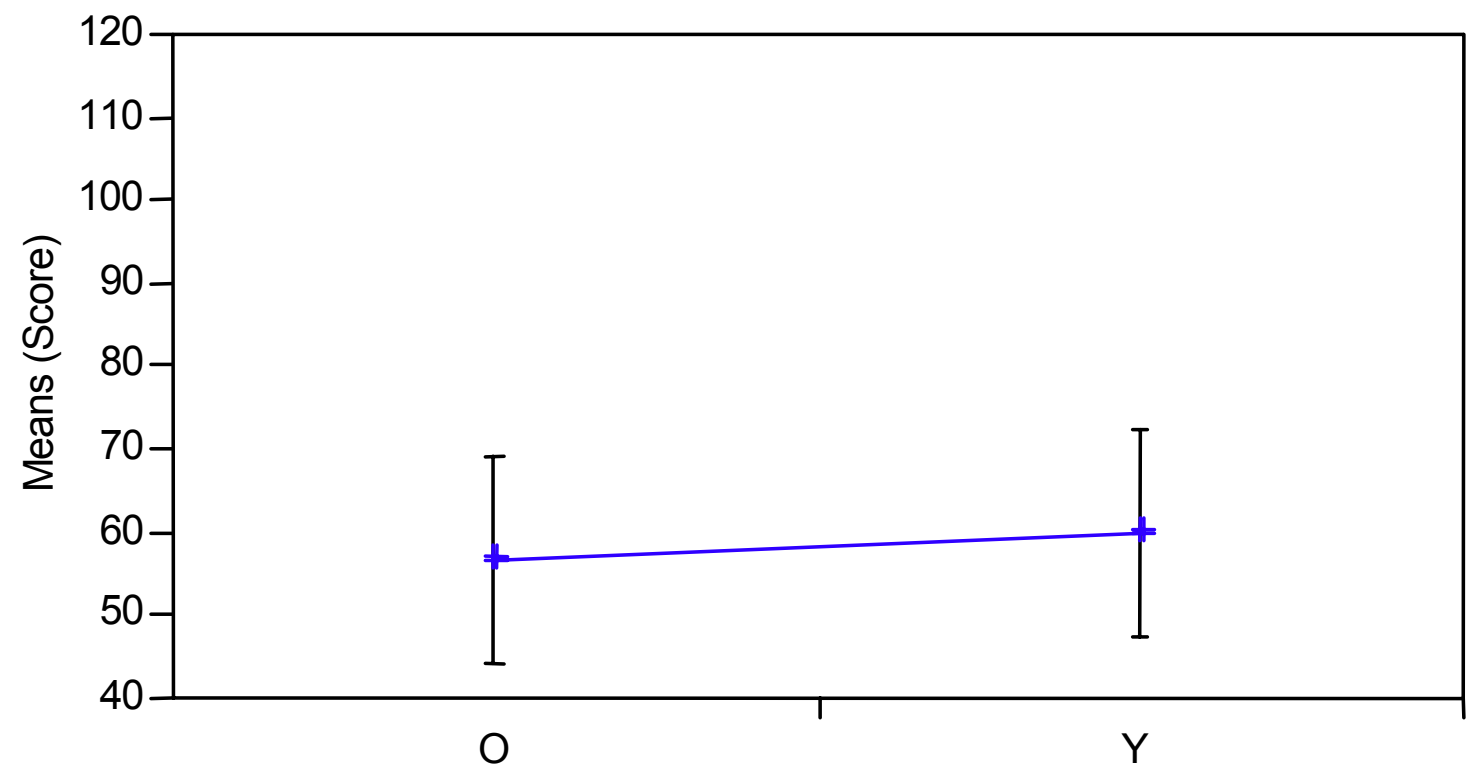

Age

Figure 21. Age effect on post-slip anxiety score. 


\section{ANOVA Results}

The findings from the ANOVA analyses are summarized under the following headings: age comparison, gender comparison, and interactions. All dependent variables in this study were analyzed with $2 \times 2$ two-way repeated measures (age x gender) analysis of variance. Summary of the ANOVA results are listed in Table 15.

Table 15. Summary of ANOVA Means and Standard Deviations.

\begin{tabular}{llc}
\hline $\begin{array}{l}\text { Variables } \\
\text { (unit) }\end{array}$ & $\begin{array}{c}\text { Young } \\
\text { Mean (SD) }\end{array}$ & $\begin{array}{c}\text { Old } \\
\text { Mean (SD) }\end{array}$ \\
\hline${ }^{*}$ Step Length Normal Gait (cm) & $66.98(6.03)$ & $61.43(4.95)$ \\
*Step Length Adjusted Gait (cm) & $64.19(20.00)$ & $51.16(8.76)$ \\
${ }^{*}$ RCOF Normal Gait & $0.18(0.02)$ & $0.15(0.03)$ \\
RCOF Adjusted Gait & $0.07(0.04)$ & $0.06(0.03)$ \\
Heel Velocity Normal Gait (cm/s) & $69.74(13.42)$ & $60.91(13.06)$ \\
Heel Velocity Adjusted Gait (cm/s) & $19.58(16.49)$ & $12.35(12.73)$ \\
Slip Distance 1 (cm) & $1.93(1.49)$ & $1.382(1.54)$ \\
*Slip Distance 2 (cm) & $8.08(5.97)$ & $3.97(4.34)$ \\
Total Slip Distance (cm) & $10.73(7.27)$ & $5.35(5.60)$ \\
\hline
\end{tabular}

*Denotes significant differences between age groups. 


\section{Step Length Normal Gait}

\section{$\underline{\text { Age Comparisons }}$}

The results indicated a statistically significant difference $\left(\mathrm{F}_{3,24}=3.1702, \mathrm{p}=\right.$ 0.0139 ) between the two age groups. Younger individuals step length was longer than their older counterparts (Table 16 and Figure 22).

Table 16. Descriptive summary of normal gait step length on main effect age.

\begin{tabular}{|c|c|c|c|}
\hline Age & Count & Mean $(\mathrm{cm})$ & Std. Dev. \\
\hline Older Adults & 14 & 61.4321 & 4.9454 \\
\hline Younger Adults & 14 & 66.9771 & 6.0256 \\
\hline
\end{tabular}

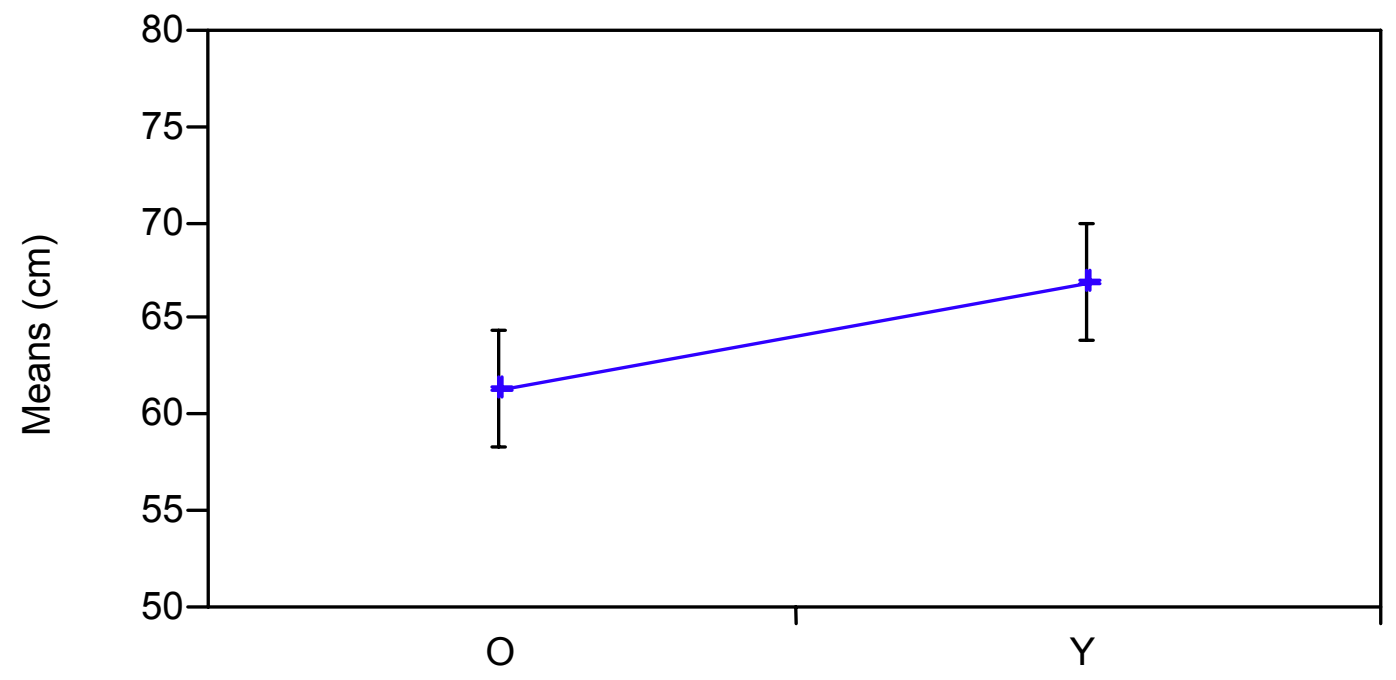

Age

Figure 22. Age effect on step length normal gait. 


\section{Step Length Adjusted Gait}

\section{$\underline{\text { Age Comparison }}$}

The results indicated a statistically significant difference $\left(\mathrm{F}_{3,24}=4.9265, \mathrm{p}=\right.$ 0.0362) between older and younger participants. Younger participants step length was longer than their older counterparts (Table 17 and Figure 23).

Table 17. Descriptive summary of adjusted gait step length on main effect age.

\begin{tabular}{|c|c|c|c|}
\hline Age & Count & Mean $(\mathrm{cm})$ & Std. Dev. \\
\hline Older Adults & 14 & 51.1593 & 8.7644 \\
\hline Younger Adults & 14 & 64.1929 & 20.0004 \\
\hline
\end{tabular}

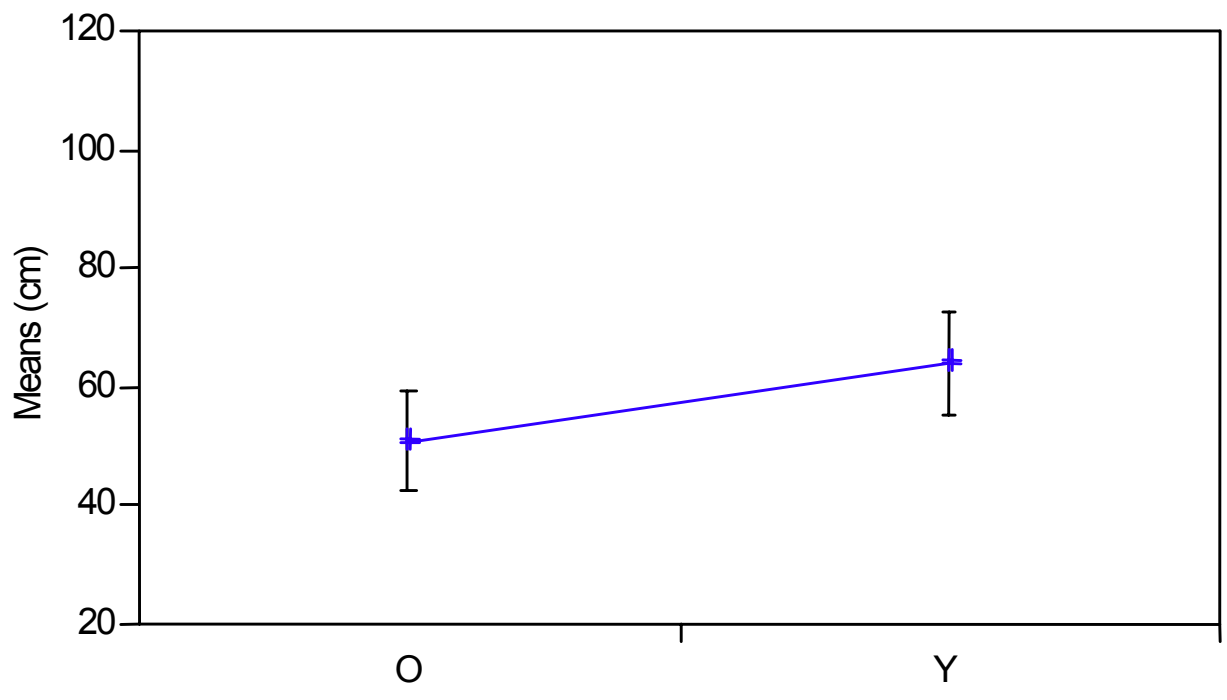

Age

Figure 23. Age effect on step length adjusted gait. 


\section{RCOF Normal Gait}

\section{Age Comparison}

The results indicated a statistically significant difference $\left(\mathrm{F}_{3,24}=11.0666, \mathrm{p}=\right.$ 0.0028 ) between older and younger participants. Younger participants RCOF was higher than their older counterparts (Table 18 and Figure 24).

Table 18. Descriptive summary of normal gait RCOF on main effect age.

\begin{tabular}{|l|l|c|c|}
\hline \multicolumn{1}{|c|}{ Age } & Count & Mean & Std. Dev. \\
\hline Older Adults & 14 & 0.152571 & 0.0261 \\
\hline Younger Adults & 14 & 0.182357 & 0.0210 \\
\hline
\end{tabular}

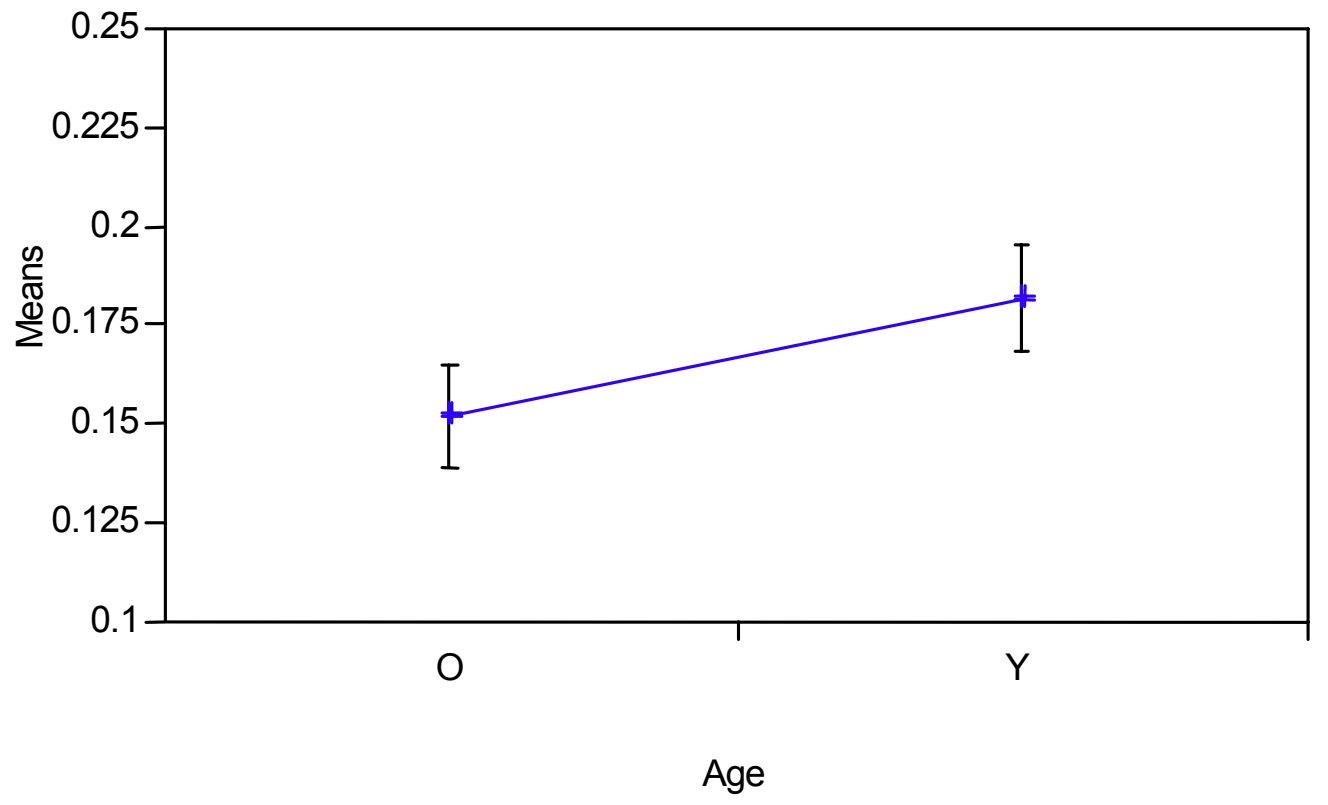

Figure 24. Age effect on RCOF normal gait. 


\section{RCOF Adjusted Gait}

\section{Age Comparison}

The results indicated no statistically significant difference $\left(\mathrm{F}_{3,24}=0.0379, \mathrm{p}=\right.$ 0.8473 ) between older and younger participants. Although not significant, younger participants RCOF was slightly higher than their older counterparts (Table 19 and Figure 25).

Table 19. Descriptive summary of adjusted gait RCOF on main effect age.

\begin{tabular}{|l|c|c|c|}
\hline \multicolumn{1}{|c|}{ Age } & Count & Mean & Std. Dev. \\
\hline Older Adults & 14 & 0.064336 & 0.0313 \\
\hline Younger Adults & 14 & 0.067443 & 0.0432 \\
\hline
\end{tabular}

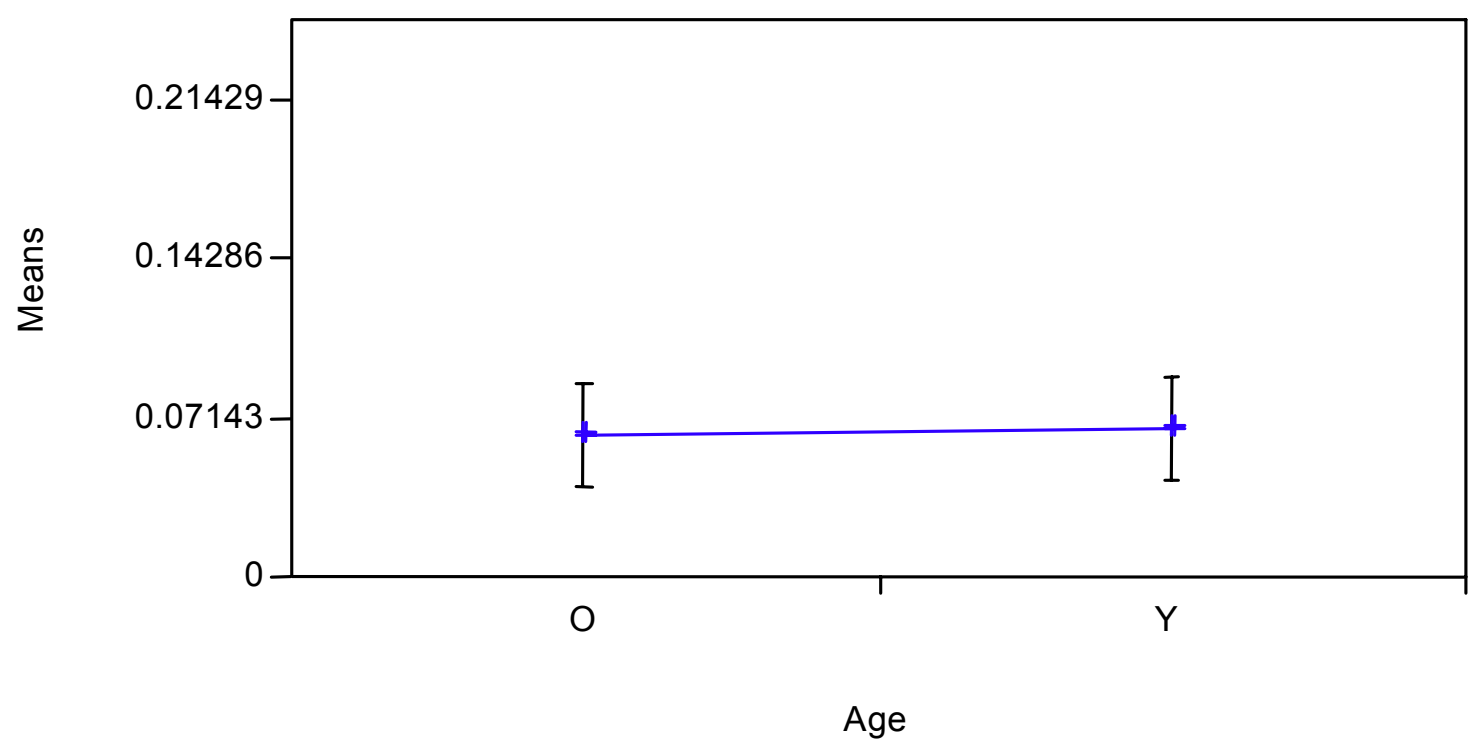

Figure 25. Age effect on RCOF adjusted gait. 


\section{Heel Velocity Normal Gait}

\section{Age Comparison}

The results indicated no statistically significant difference $\left(\mathrm{F}_{3,24}=1.2450, \mathrm{p}=\right.$ 0.2756 ) between older and younger participants. Although not significant, younger participants heel velocity was slightly faster than their older counterparts (Table 20 and Figure 26).

Table 20. Descriptive summary of normal gait heel velocity on main effect age.

\begin{tabular}{|c|c|c|c|}
\hline Age & Count & Mean $(\mathrm{cm} / \mathrm{s})$ & Std. Dev. \\
\hline Older Adults & 14 & 60.9064 & 13.0611 \\
\hline Younger Adults & 14 & 69.7429 & 13.4166 \\
\hline
\end{tabular}

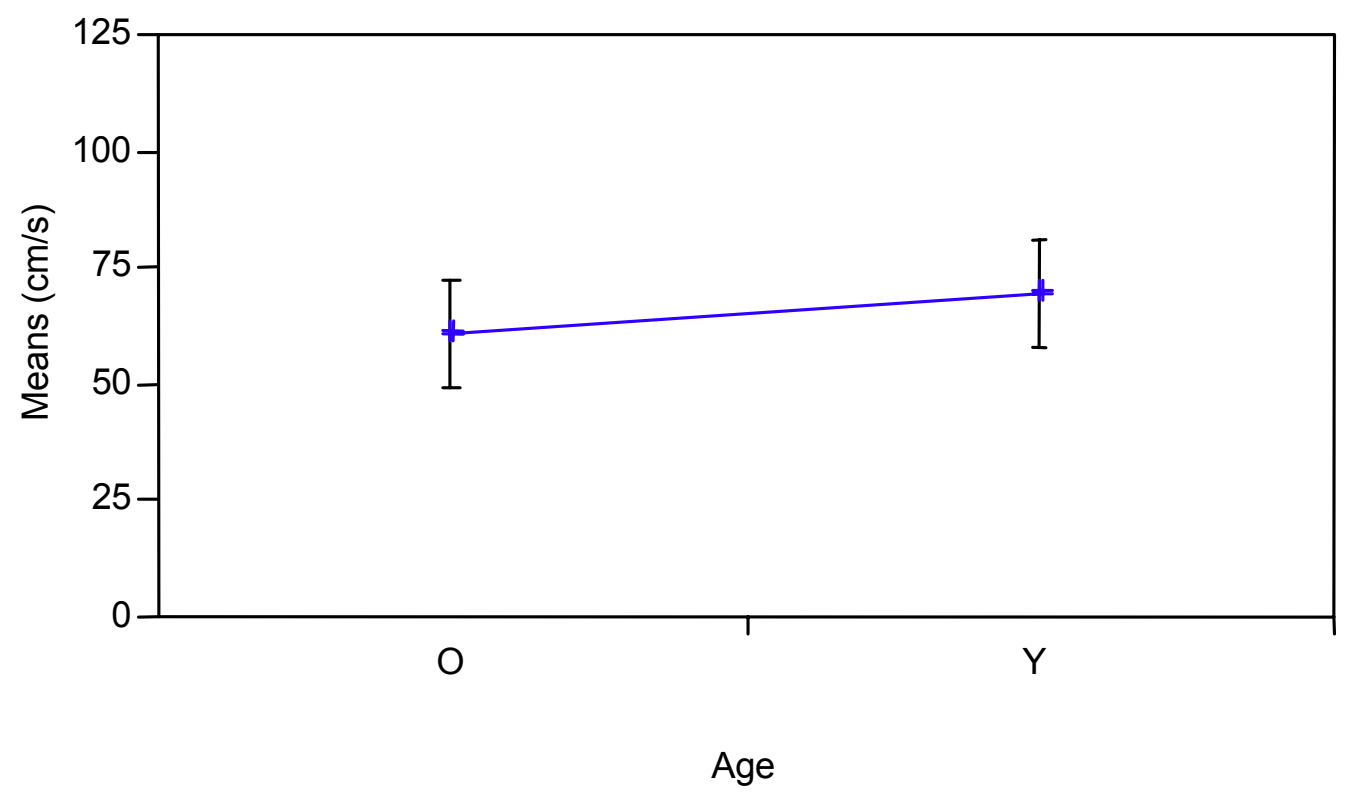

Figure 26. Age effect on heel velocity normal gait. 


\section{Heel Velocity Adjusted Gait}

\section{Age Comparison}

The results indicated no statistically significant difference $\left(\mathrm{F}_{3,24}=1.8841, \mathrm{p}=\right.$ 0.1831 ) between older and younger participants. Although not significant, younger participant's adjusted heel velocity was slightly faster than their older counterparts (Table 21 and Figure 27).

Table 21. Descriptive summary of adjusted gait heel velocity on main effect age.

\begin{tabular}{|c|c|c|c|}
\hline Age & Count & Mean $(\mathrm{cm} / \mathrm{s})$ & Std. Dev. \\
\hline Older Adults & 14 & 12.3477 & 12.7316 \\
\hline Younger Adults & 14 & 19.5760 & 16.4923 \\
\hline
\end{tabular}

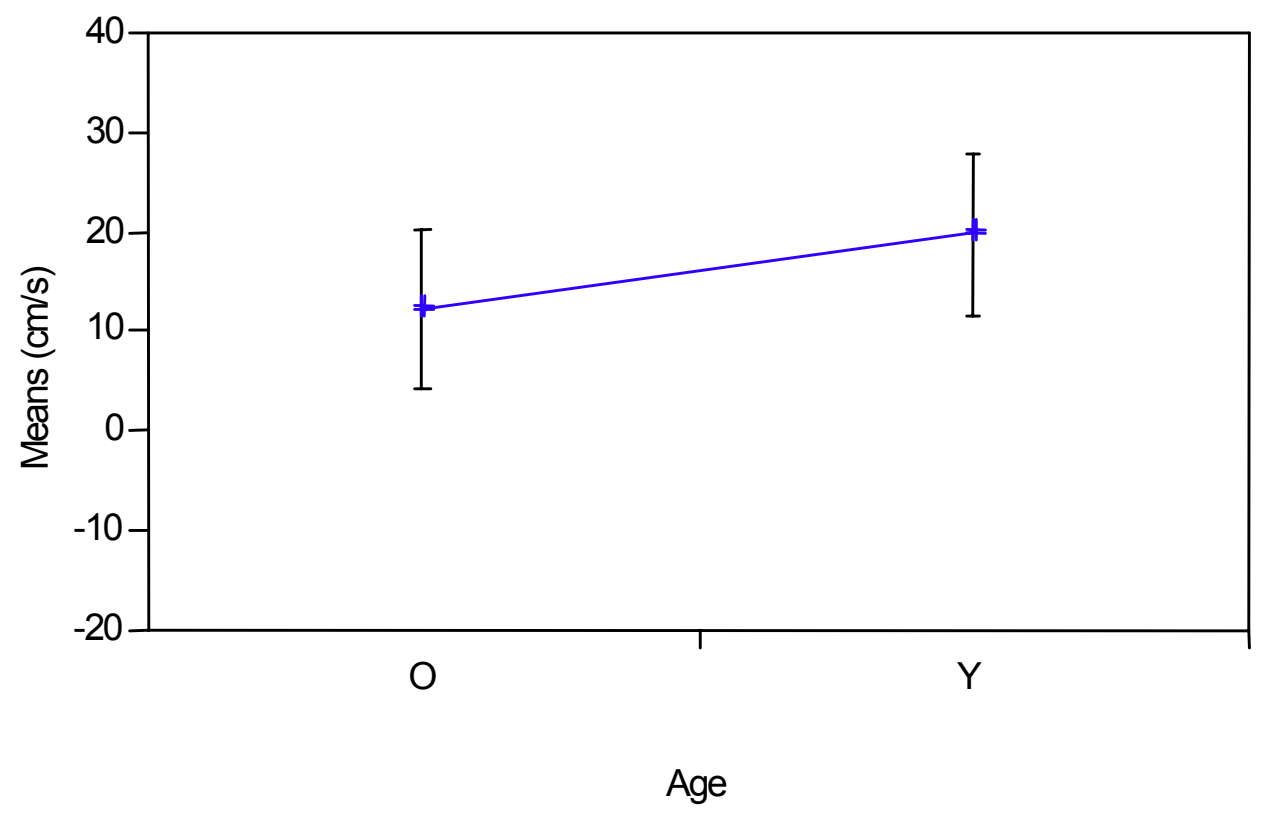

Figure 27. Age effect on heel velocity adjusted gait. 


\section{Slip Distance 1 (SD1)}

\section{Age Comparison}

The results indicated no statistically significant difference $\left(\mathrm{F}_{3,24}=0.8055, \mathrm{p}=\right.$ 0.3784 ) between older and younger participants. Although not significant, younger participant's had a longer forward slip distance than their older counterparts (Table 22 and Figure 28).

Table 22. Descriptive summary of SD1 on main effect age.

\begin{tabular}{|c|c|c|c|}
\hline Age & Count & Mean $(\mathrm{cm})$ & Std. Dev. \\
\hline Older Adults & 14 & 1.38200 & 1.5380 \\
\hline Younger Adults & 14 & 1.93007 & 1.4861 \\
\hline
\end{tabular}

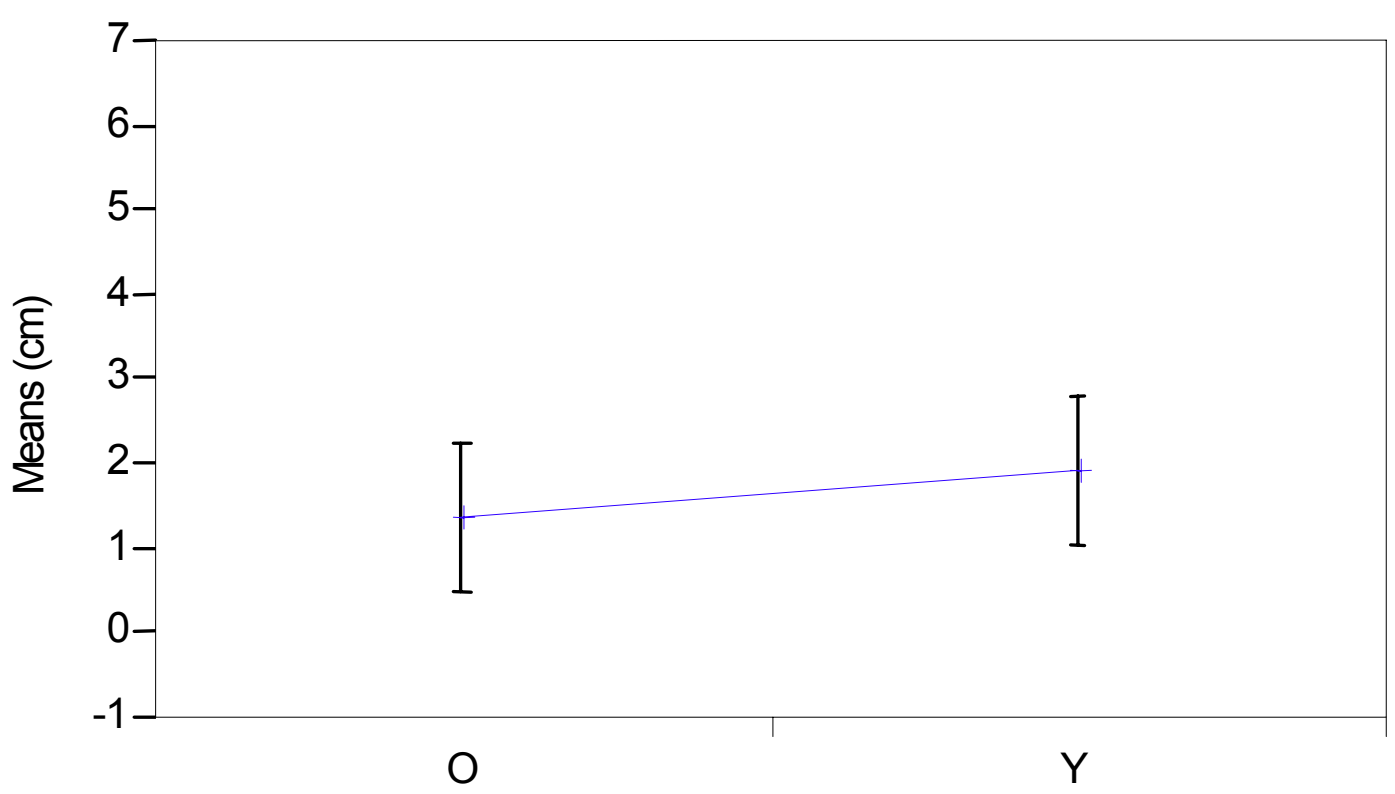

Age

Figure 28. Age effect on SD1. 


\section{Slip Distance 2 (SD2)}

\section{Age Comparison}

The results indicated a statistically significant difference $\left(\mathrm{F}_{3,24}=4.0372, \mathrm{p}=\right.$ $0.0559)$ between older and younger participants. Younger participant's slipped more than their older counterparts (Table 23 and Figure 29).

Table 23. Descriptive summary of SD2 on main effect age.

\begin{tabular}{|c|c|c|c|}
\hline Age & Count & Mean $(\mathrm{cm})$ & Std. Dev. \\
\hline Older Adults & 14 & 3.96538 & 4.3356 \\
\hline Younger Adults & 14 & 8.08173 & 5.9749 \\
\hline
\end{tabular}

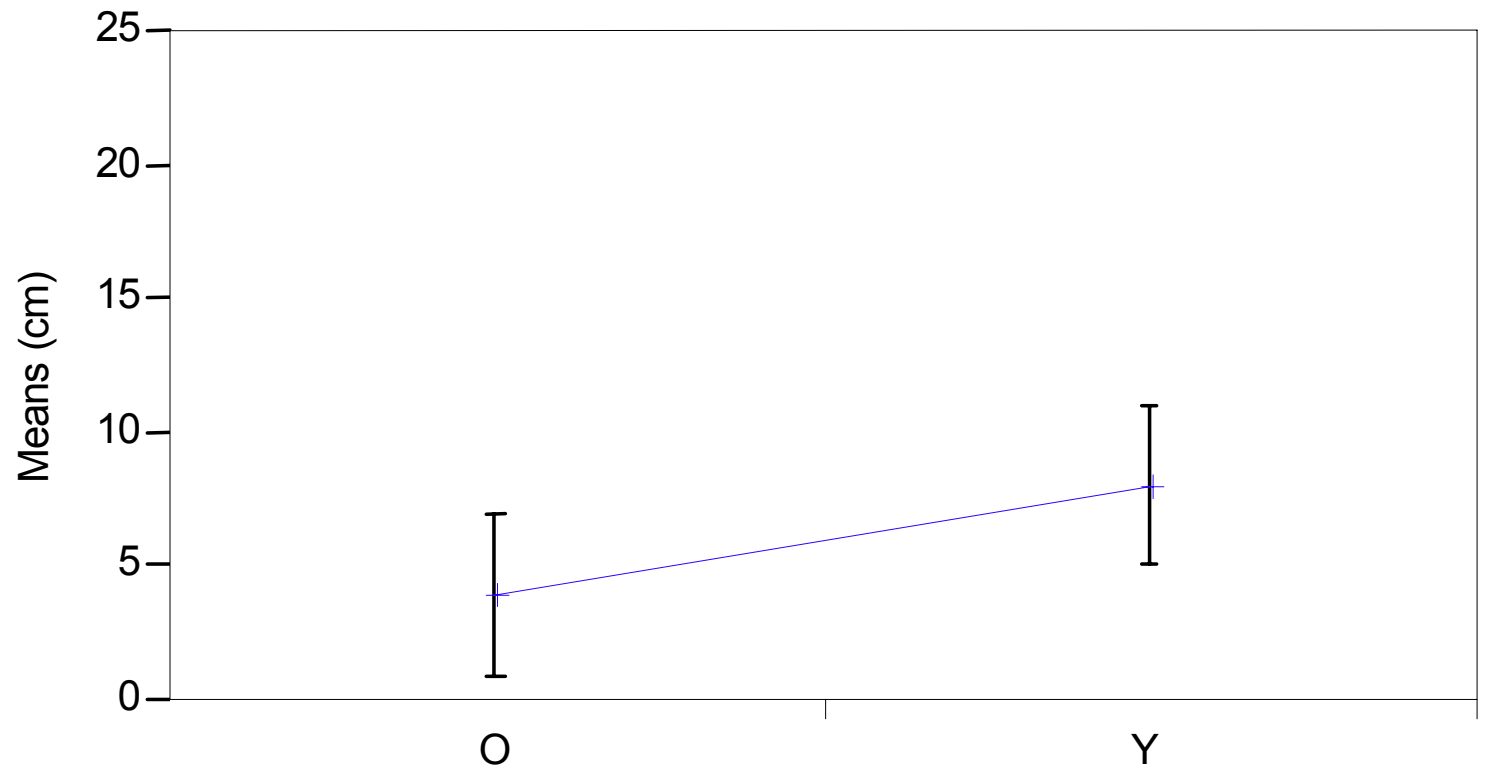

Age

Figure 29. Age effect on SD2. 


\section{Total Slip Distance}

\section{Age Comparison}

The results indicated no statistically significant difference $\left(\mathrm{F}_{3,24}=3.4473, \mathrm{p}=\right.$ 0.0757 ) between older and younger participants. Although not significant, younger participants slipped more than their older counterparts (Table 24 and Figure 30).

Table 24. Descriptive summary of total slip distance on main effect age.

\begin{tabular}{|c|c|c|c|}
\hline Age & Count & Mean $(\mathrm{cm})$ & Std. Dev. \\
\hline Older Adults & 14 & 5.3474 & 5.6029 \\
\hline Younger Adults & 14 & 10.7316 & 7.2739 \\
\hline
\end{tabular}

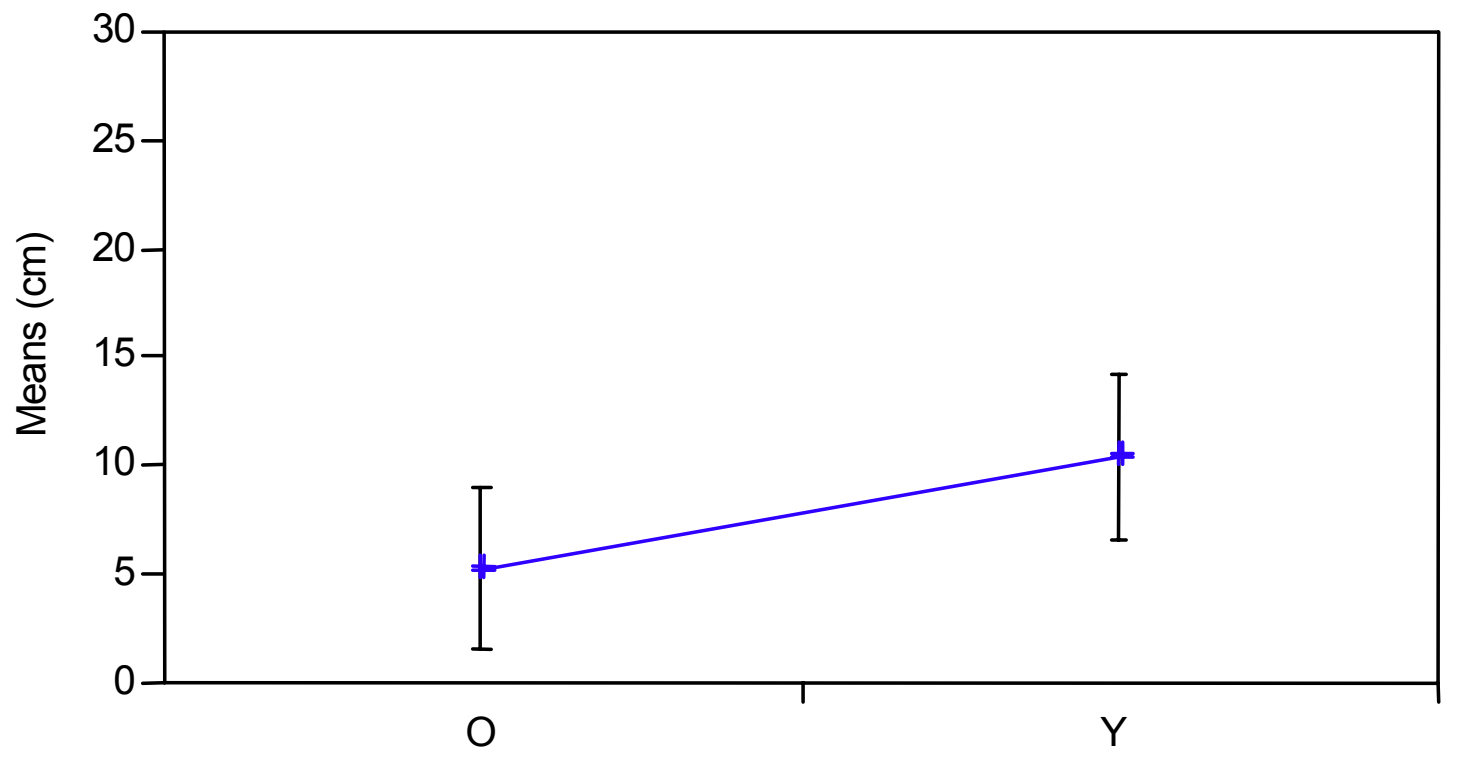

Age

Figure 30. Age effect on total slip distance. 


\section{Older Adults Normal and Adjusted Gait Comparisons}

\section{Older Adults Normal and Adjusted Step Length}

The results indicated a significant difference $\left(F_{2,25}=9.3095, p=0.0053\right)$ between older adults normal gait step length and adjusted gait step length. Older adults normal step length was significantly longer than adjusted step length (Figure 31).

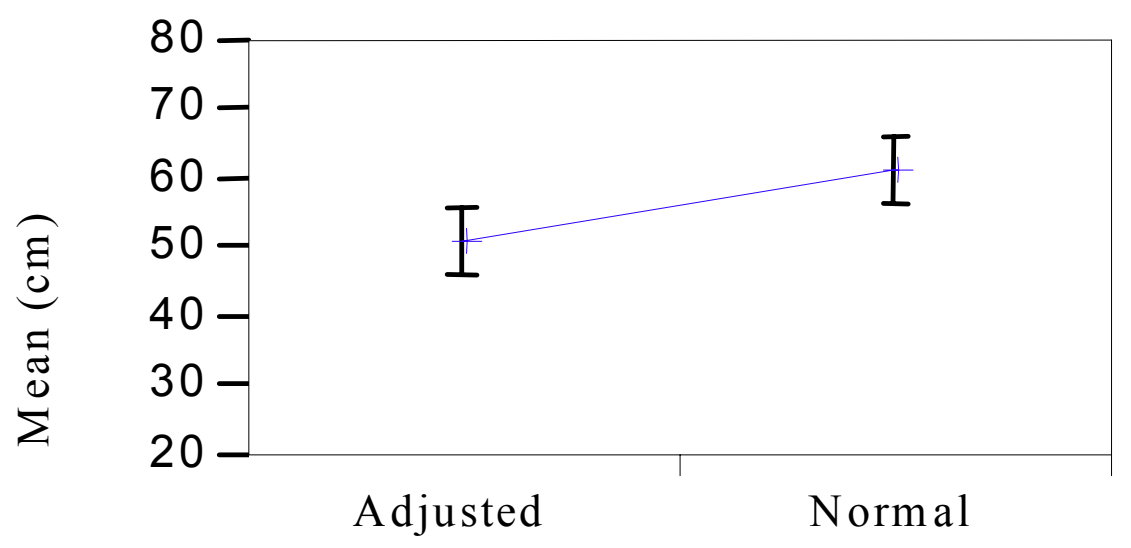

Figure 31. Comparison of older adults normal and adjusted gait Step Length. 


\section{Older Adults Normal and Adjusted Step Length}

There was a significant difference $\left(\mathrm{F}_{2,25}=16.4158, \mathrm{p}=0.0004\right)$ between older adult males and older adult females step length. Overall, males had a longer step length than females (Figure 32).

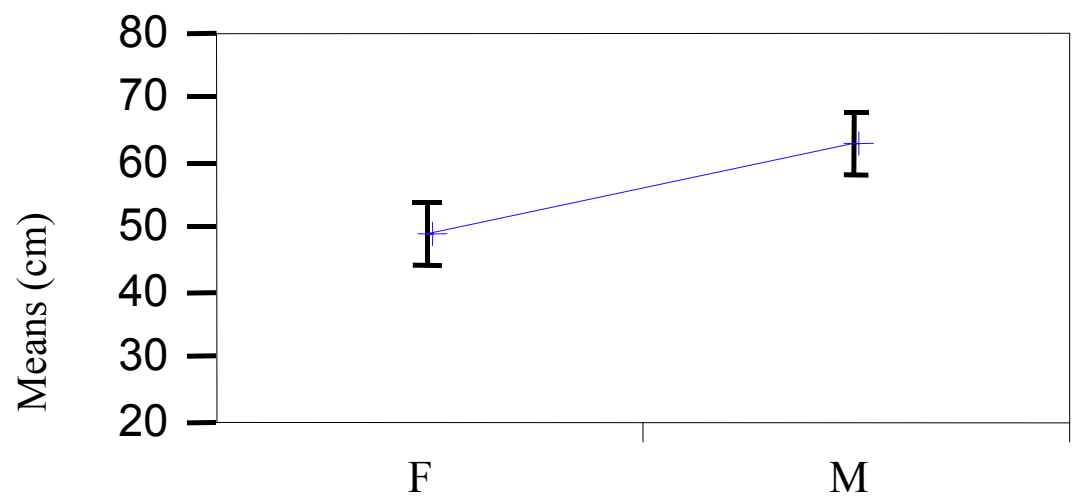

Figure 32. Comparison of older adults normal and adjusted gait Step Length. 


\section{Older Adults Normal and Adjusted RCOF}

The results indicated a significant difference $\left(\mathrm{F}_{2,25}=64.6110, \mathrm{p}=0.001\right)$ between older adults normal gait RCOF and adjusted gait RCOF (Figure 33).

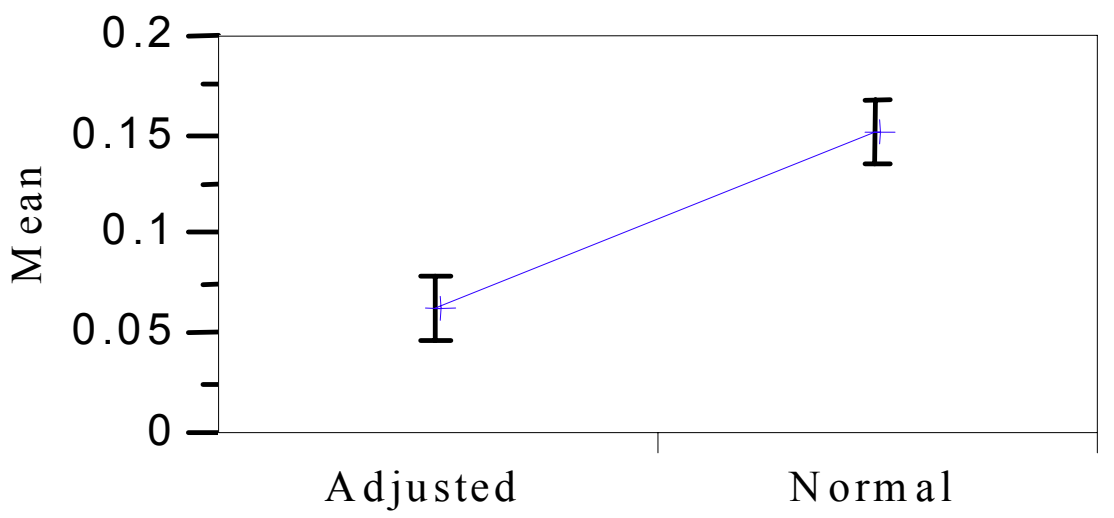

Figure 33. Comparison of older adults normal and adjusted gait RCOF. 


\section{Older Adults Normal HCV and Adjusted HCV}

The results indicated no significant difference $\left(\mathrm{F}_{2,25}=1.9437, \mathrm{p}=0.1755\right)$ between older adults normal HCV and adjusted HCV. Although not significant, older adult's normal HCV was higher than their adjusted HCV (Figure 34).

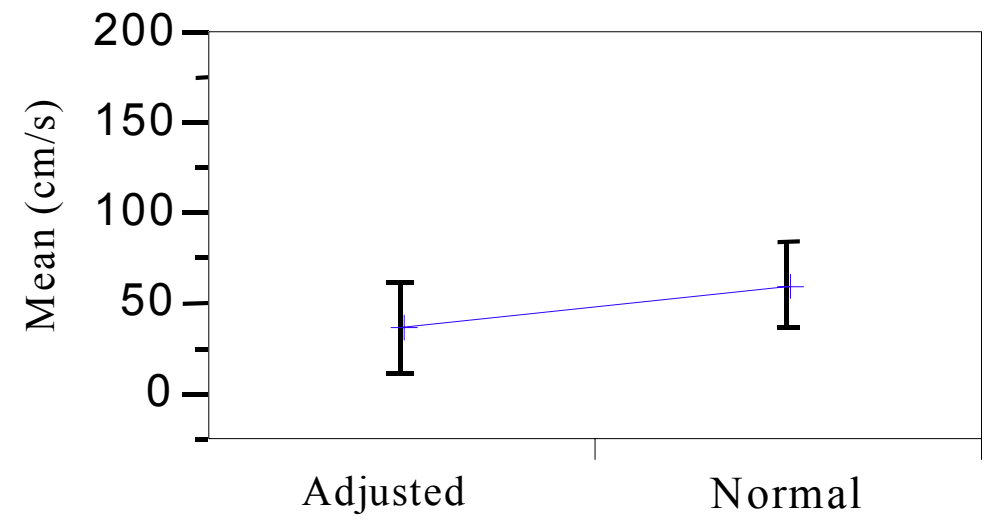

Figure 34. Comparison of older adults normal and adjusted gait HCV. 


\section{Additional Analysis}

The results indicated that older females had a faster heel contact velocity than older males in the normal gait phase of the study. However, older females had a slower heel contact velocity than older males in the adjusted gait phase of the study. Literature indicates that older females fall more often than older males (CDC, 2000). Therefore, further studies should be done to investigate if heel contact velocity may contribute to the increased fall rate of older females.

\section{Correlation Analysis}

Bivariate correlation analyses were used to determine the relationships among all dependent variables: normal gait heel velocity, adjusted gait heel velocity, normal gait RCOF, adjusted gait RCOF, SD1, SD2, total SD, normal gait step length, adjusted gait step length, anxiety score, and salivary amylase level. Summary of Bivariate correlation analysis results are listed in Table 25 . 
Table 25 Summary of Correlation Analysis

\begin{tabular}{ll}
\hline \multicolumn{1}{c}{ Relationships } & \multicolumn{1}{c}{$\mathrm{R}^{2}$} \\
\hline Normal Step Length and Normal RCOF & $\mathrm{R}^{2}=0.22^{*}$ \\
Adjusted Step Length and Adjusted HCV & $\mathrm{R}^{2}=0.16^{*}$ \\
SA Pre-slip and Normal HCV & $\mathrm{R}^{2}=0.31^{*}$ \\
SA Pre-slip and SD2 & $\mathrm{R}^{2}=0.25^{*}$ \\
SA Pre-slip and Total SD & $\mathrm{R}^{2}=0.23^{*}$ \\
SA Slip and Total Slip Distance & $\mathrm{R}^{2}=0.18^{*}$ \\
SA Post-slip and SD1 & $\mathrm{R}^{2}=0.16^{*}$ \\
SA Baseline and Anxiety Baseline & $\mathrm{R}^{2}=0.04$ \\
SA Pre-slip and Anxiety Pre-slip & $\mathrm{R}^{2}=0.01$ \\
SA Slip and Anxiety Slip & $\mathrm{R}^{2}=0.01$ \\
SA Post-slip and Anxiety Post-slip & $\mathrm{R}^{2}=0.01$ \\
\hline
\end{tabular}

*Denotes significant relationship between variables 


\section{Discussion of significant correlations}

\section{Normal Step Length and Normal RCOF}

The results indicated a statistically significant relationship $\left(\mathrm{F}_{1,26}=7.2699, \mathrm{p}=\right.$ 0.0121 ) between normal step length and normal RCOF with $\mathrm{R}^{2}=0.22$. This significant positive relationship indicates that when participants walked across the dry floor surface their RCOF increased as their step length increased.

\section{Adjusted Step Length and Adjusted HCV}

The results indicated a statistically significant relationship $\left(\mathrm{F}_{1,26}=4.8385, \mathrm{p}=\right.$ 0.0369 ) between adjusted step length and adjusted heel contact velocity with $\mathrm{R}^{2}=0.16$. This significant positive relationship indicates that as participants shortened their step length to avoid slipping while walking back across the slippery floor surface their heel contact velocity was slower.

\section{$\underline{\text { SA Pre-slip and Normal HCV }}$}

The results indicated a statistically significant relationship $\left(\mathrm{F}_{1,26}=11.4108, \mathrm{p}=\right.$ 0.0023 ) between SA pre-slip and normal $\mathrm{HCV}$ with $\mathrm{R}^{2}=0.31$. This significant positive relationship indicates that participant's heel contact velocity got faster as their stress level increased.

\section{$\underline{\text { SA Pre-slip and SD2 }}$}

The results indicated a statistically significant relationship $\left(\mathrm{F}_{1,26}=8.4375, \mathrm{p}=\right.$ 0.0074 ) between SA pre-slip and SD2 with $\mathrm{R}^{2}=0.25$. This significant positive 
relationship indicates that an increase in the participant's pre-slip stress level resulted in a longer slip distance in the rewards direction.

\section{$\underline{\text { SA Pre-slip and Total SD }}$}

The results indicated a statistically significant relationship $\left(\mathrm{F}_{1,26}=7.5911, \mathrm{p}=\right.$ 0.0106 ) between SA pre-slip level and total slip distance with $\mathrm{R}^{2}=0.23$. This significant positive relationship indicates that an increase in the participant's pre-slip stress level resulted in a longer total slip distance.

\section{$\underline{\text { SA Slip and Total SD }}$}

The results indicated a statistically significant relationship $\left(\mathrm{F}_{1,26}=4.2974, \mathrm{p}=\right.$ 0.0290 ) between SA slip and total SD with $\mathrm{R}^{2}=0.18$. This significant positive relationship indicates that after initiation of a slip, participant's stress level was related to total SD. An increase in total slip distance resulted in an increase in stress level.

\section{$\underline{\text { SA Post-slip and SD1 }}$}

The results indicated a statistically significant relationship $\left(\mathrm{F}_{1,26}=4.8925, \mathrm{p}=\right.$ 0.0360 ) between SA post-slip and SD1 with $\mathrm{R}^{2}=0.16$. This significant positive relationship indicates that when participants walked back across the known slippery floor surface attempting not to slip (adjusted gait), their stress level was related to SD1. Therefore, a longer slip distance in the forward direction resulted in an increased stress level. 


\section{$\underline{\text { SA and Anxiety }}$}

The results indicated no statistically significant relationship between all levels (e.g., baseline, pre-slip, slip, and post-slip) of SA and all levels of anxiety.

\section{$\underline{\text { Discussion }}$}

\section{Hypothesis and Experimental Findings:}

\section{Hypothesis 1}

Stress level and anxiety score for the older age group will be higher than their younger counterparts after a slip, as measured by salivary amylase test, and

\section{MAACL.}

One objective of the study was to investigate if older adults would have a higher stress level and anxiety score compared to younger adults after an inadvertent slip. The results indicated a statistically significant stress level (as measured by salivary amylase) difference between younger and older adults after slipping. The reason for the older adult's increased SA level compared to younger adults is somewhat unclear. Overall SDII and SA level were positively related; a longer SDII resulted in an increase in SA level. However, older adult's SA level was higher but their SDII was shorter than their younger counter parts. One reason may be due to a fear of falling; previous studies indicated that older adults are more fearful of falling than younger adults (Brown et. Al, 2002; Lachman et. al., 1998; Makei et. al., 1991; Tinetti et. al, 1990). Additionally, anxiety was assessed utilizing the multiple affects adjective checklist (MAACL). The results indicated no significant difference in anxiety score between younger and older 
adults after slipping; younger adults had a higher anxiety score than older adults.

Previous studies have found a relationship between the SA and anxiety (Blewett, et. al, 1990; Fatkin, L., \& Kaufman, J., 2001; Chatterton, R.T., Fatkin, L.T., Hudgens, G.A., King, J.M. 1991). However, Bivariate correlation analyses indicated no significant relationship between SA and anxiety for baseline, pre-slip, slip, or post-slip conditions. This may be due to the differences in the two measures. For salivary amylase test, saliva samples were collected for each condition and analyzed to determine the participant's stress level. However, in assessing anxiety, participants had to select adjectives on the MAACL (Appendix C) that most accurately described how they felt at each condition presented in the experiment (e.g., baseline, pre-slip, slip, post-slip). It was observed that after slipping older participants tended to not check adjectives such as fearful, panicky, nervous, or offended to describe how they felt at the time of slipping. Rather, they checked adjectives such as loving, merry, joyful, or cooperative. Each participant was debriefed at the conclusion of the experiment, and most of the older participants indicated that they were nervous and afraid. Therefore, the anxiety score as indicated by the MAACL may not accurately represent the anxiety of older adults at the time they slipped, and prior to walking back over the slippery floor surface.

In summary, older adults had a significantly higher level of stress, as measured by salivary amylase, after slipping. Stress level may have been affected by slip severity, due to the fact, that salivary amylase level and slip severity were positively related.

Conversely, anxiety score was not related to slip severity; therefore, other factors may have affected anxiety score. 


\section{Hypothesis 2}

The younger age group's and older age group's pre-slip (normal gait) and post-slip (adjusted gait) step length, RCOF and heel contact velocity will be significantly

\section{different.}

A second objective of the study was to explore whether younger and older adult's gait characteristics are different. The results indicated a statistically significant step length difference between older and younger adults while walking across the dry floor surface (pre-slip). Also, These findings are consistent with previous findings (Lockhart, 2000; Lockhart et. al., 2001, Winter, 1991). In addition, the results indicated a statistically significant step length difference between older and younger adults while walking across the slippery floor surface (post-slip). In general, the younger adults adjusted step length was longer than older adults. The results indicated a statistically significant RCOF difference between older and younger participants. In general, younger adult's RCOF was higher than older adults. Previous research (Lockhart, 2000; Lockhart et. al., 2001a;b) found no significant difference between the RCOF of younger and older participants while walking across a dry floor surface. The difference in findings may be due to normal gait step length and normal gait RCOF had a significant relationship in this study [e.g., $\left.\mathrm{R}^{2}=0.22\right]$ versus previous research.

Also, The results indicated no statistically significant RCOF difference between younger and older adults in the adjusted gait phase of the experiment. Also, the adjusted step length and adjusted RCOF was not significantly related. Overall, there was little difference between the adjusted gait RCOF of younger and older adults (means: 
$\mathrm{Y}=0.064336$ and $\mathrm{O}=0.067443$ ). Additionally, the results indicated no statistically significant heel contact velocity difference between younger and older adults in either the normal or adjusted gait phases of the study. In general, younger adults had a faster heel contact velocity than their older counterpart in both the normal and adjusted gait phases. Overall, females had a faster heel contact velocity than males in the normal gait phases.

$\underline{\text { Hypothesis } 3}$

Older adults who slipped after walking condition 1 (normal gait) will have a higher level of stress as measured by salivary Amylase test when standing still on the track looking at the floor surface prior to starting walking condition 2 (adjusted gait) than their younger counterparts.

A third objective of the study was to investigate if older adults would have a higher stress level compared to younger adults while standing on the track, looking at the slippery floor surface prior to walking over it. The results indicated a statistically significant stress level (as measured by salivary amylase level) difference between older and younger adults while standing on the test track looking at the slippery floor surface prior to walking over it. In general, older adults had a higher stress level than younger adults. Also, the results indicated that there was a significant relationship between salivary amylase level and the severity of slip initiation (as measured by SD1) [e.g., $\mathrm{R}^{2}=$ 0.16]. In general, younger adults slip initiation severity was greater than that of older adults. Therefore, it would be expected that younger adults would have a higher stress level than older adults when standing on the test track looking at the slippery surface 
prior to walking over it. Hence, there may be other factors, which contributed to the increased stress level of older adults.

\section{Hypothesis 4}

\section{Older adults who slipped in walking condition 1 will have a higher level of stress as measured by Salivary Amylase test, and will modify their gait characteristics in a way that will adversely affect slip- induced falls (i.e., faster heel contact velocity, higher RCOF and longer step length).}

A final objective of this study was to investigate if older adults stress level would be higher, and if their gait characteristics would change after an inadvertent slip. The results indicated a statistically significant stress level (as measured by salivary amylase test) difference between older adults pre-slip and slip stress levels. In general, older adults stress level after slipping was significantly higher. Additionally, the results indicated a statistically significant difference in stress level between older males and older females. Overall, males had a significantly higher stress level than females.

The results indicated a statistically significant difference between older adults normal and adjusted RCOF. Older adults normal gait RCOF was significantly higher than their adjusted gait RCOF. The results indicated no statically significant difference between older males and older females. Overall, males had a slightly higher RCOF than females.

The results indicated a statically significant difference between older adults normal and adjusted step length. Older adults normal gait step length was significantly longer than adjusted gait step length. Also, the results indicated a statically significant 
difference between older males and females step length. Overall, males step length was longer than females.

The results indicated no statically significant difference between older adults normal gait $\mathrm{HCV}$ and adjusted gait $\mathrm{HCV}$. In general, normal gait $\mathrm{HCV}$ was slightly faster than adjusted gait HCV. Additionally, the results indicated no statically significant difference between older males and older females HCV.

In summary, older adults significantly shortened their step length, and significantly reduced their RCOF after slipping. In addition, their HCV was slightly slower after slipping. These findings suggest that older adults should be less prone to slip or fall when encountering slippery surfaces. However, previous research (Khuvasanont, 2002; Maki et. al, 1991; Tinetti et. al., 1990) found that older adults are more likely to fall than younger adults. Therefore, there may be other factors, which contributes to the higher rate of falls among older adults. Brown et. al. (2002); Lachman et. al., 1998; Tenetti et. al., 1990) indicated that a higher incidence of falls among older adults may be related to an increased fear of falling. 


\section{Summary and Recommendations}

In summary, this study focused on the initiation phase of slips and falls. The findings from this study indicate that both younger and older adults are susceptible to inadvertent slips when a slippery floor surface is randomly introduced. However, older adults had a significantly higher-level of stress as measured by salivary amylase.

Salivary amylase level was significantly related to slip severity, and should increase as slip distance increase. However, this was not the case, older adults slipped less than younger adults, but their salivary amylase level was higher. This may be due to other factors; one factor may be a fear of falling. Previous studies indicated that older adults are more fearful of falling than younger adults (Brown et. al, 2002; Lachman et. al, 1998; Maki et. al, 1991; Tinetti et. al, 1990).

Additionally, older adults significantly shorten their step length while walking across the slippery floor surface compared to younger adults. However, their friction demand characteristics were similar to that of younger adults. This may be due to other factors (e.g., muscle degradation, push off torque, hamstring activation rate,). Lockhart et. al. (2001), indicated that the deterioration of lower extremity muscular strength among elderly adults affected the process of initiation and recovery of inadvertent slips and falls. Winter et. al. (1990), indicated that hamstring activation rate is related to heel contact velocity, and may affect the initiation process of inadvertent slips and falls. Additionally, Khuvasanont and Lockhart (2002), indicated that older adults push off torque was lower than younger adults, and may affect the initiation phase of inadvertent slips and falls.

Additionally, it should be noted that the older adults in this study appeared to be in superb physical condition. Most of them indicated that they exercised daily (i.e., 
walking, jogging, water aerobics, weight lifting). However, they had a significantly higher level of stress after a slip than younger adults. It can be suggested that older adults who are living in assisted living environments would have an even higher level of stress. Therefore, additional studies should be conducted to investigate the effects of stress on the initiation and recovery of inadvertent slips and falls in the population of older adults who are sedentary or less active than the older adults in this study.

In conclusion, the results of this study suggest that some anxiety and stress may be good, in that, it leads to an increased awareness of one's surroundings, and appears to help facilitate appropriate gait adaptation when hazardous conditions are encountered. Also, regular exercise and muscle strengthening may play a vital role in helping older adults prevent slip and fall accidents, or reduce the severity of slip and fall accidents.

\section{$\underline{\text { Recommendations for future research }}$}

1. Research should be conducted to investigate the factors involving the recovery phase of slips and falls, such as, reaction time of lower extremities and, muscle strength.

2. The effects of stress, due to a fear of falling, should be studied further to investigate if there is a relationship with biomechanical factors of the recovery phase of slips and falls.

3. The effects of anxiety due to a fear of falling for those older adults in assisted living communities should be investigated.

\section{Limitations and Assumptions of the Study}

A principal limitation in the study arose from the situation of inadvertency. Unexpected slips and falls were induced utilizing methods described. However, as with 
the case of most laboratory experiments, the tendency to anticipate "complete unexpectedness" was limited by equipment and laboratory settings. In order to veer from such anticipation, participants walked at a natural cadence for 10-15 minutes before the slippery surface was introduced (same color and contrast to the base-line floor surface). Additionally, secondary tasks minimized such anticipation.

Participants in the study, was aware of the fact, that a slip would be induced. The awareness of an impending slip and/or fall may lead to pretension of lower extremity muscles, increased attention, or other heightened reactions that may not accurately reflect participant's nervousness and muscle responses in the event of unexpected loss of balance. There were no critical age-related deficits apparent in fit and healthy participant's responses to expected perturbations of balance; however, it is reasonable to assume that some deficits would be present in less fit members of the older population when experiencing unexpected moments of instability during their activities of daily living.

The second limitation stemmed from a safety harness used to protect participants from falling. According to Lockhart et al., 2001b, this could confound the biomechanical parameters because as the participants slip, the vertical and horizontal force profiles are altered due to the fall arresting rig. To compensate for this, the collection of data was limited to the time before the fall arresting rig begins to support the participant when a slip was initiated. Additionally, a drop of $10 \mathrm{~cm}$ before the fall arresting rig braced the participants ensured that data collection portrayed realistic slip and fall characteristics. 


\section{REFERENCES}

Administration on Aging (2000). Older Americans 2000: Key indicators of well-being. [Web page]. Federal Interagency Forum on Aging Related Statistics: Author. Retrieved August 13, 2001 from the world wide web:http://www.agingstats.gov.

Andres, R.O., \& O’Connor, D.O. (1992). A pratical synthesis of biomechanical results to prevent slip and falls in the workplace. Advances in Industrial Ergonomics and Safety IV, 1001-1006.

ASTM (American Society for Testing and Materials), 1975, designation D 2047-75, Standard method of test for static COF of polish-coated floor surfaces as measured by the James Machine. American Society for Testing and Materials, Philadelphia.

Balaban, C.D., and Thayer, J.F. (2001). Neurological bases for balance-anxiety links. Journal of Anxiety Disorders, 15, 53-79.

Beck, A. T. \& Emery, G. (1979). Anxiety disorders and phobias: A cognitive perspective. New York: Harper Collins.

Blewett, W.K., Ramos, G.A., Redmond, D.P., Cadarette, B.S., Hudgens, G.A., Fatkin, L.T., \& McKiernan, K. (1994). P2NBC test: The effects of microclimate cooling on tactical performance (ERDEC-TR-148). Aberdeen Proving ground, MD: U.S. Army Chemical and Biological Defense Agency.

Brown, B. B. (1984). Between Health and illness: New notion on stress and the nature of well being. Boston: Houghton Mifflin Co.

Brown, B. A., Gage, G. H., Polych, M.A. (2002). Central set influence on gait: Agedependent effects of postural threat. Experimental Brain Research., 145, 286-289.

Brown, L. A., Frank, J. S. (1997). Postural compensations to the potential consequences of instability: kinematics. Gait and Posture, 6, 89-97.

Carlsoo, J. (1962). A method for studying walking on different surfaces, Ergonomics, 5, 271-274.

Carpenter, M.G., Frank, J. S., Silcher, C. P., \& Peyser, G. W. (2001). The influence of postural threat on the control of upright stance. Experimental Brain Research, $138,210-218$.

Center for Disease Control (2000). Falls and hip fractures among older adults. [Web page]. Retrieved August 14, 2001 from the world wide web: http://www.cdc.gov/ ncipc/factsheets/falls.htm. 
Chaffin, D.B., Woldstad, J.C., \& Trujillo, A. (1992). Floor/shoe slip resistance measurement. Am. Ind. Hyg. Assoc. J., 53, 283-289.

Chatterton, R. T, Vogelsong, K. M., Lu, Y., Ellman, A. B. \& Hudgens, G. A. (1996). Salivary amylase as a measure of endogenous adrenergic activity. Clinical Psychology, 16.

Clarkson, P.M. (1978). The effect of age and activity level on simple and choice fractionated response time. Eur. J. Appl. Physiol., 40, 17-25.

Cohen, H.H., \& Cohen, D.M.,1994a, Psychophysical assessment of the perceived slipperiness of floor tile surfaces in a laboratory setting. Journal of Safety Research, 25(1), 19-26.

Cohen, H.H., \& Cohen, D.M. (1994b). Perceptions of walking slipperiness under realistic conditions utilizing a slipperiness rating scale. Journal of Safety Research, 25(1), 27-31.

Cooper, J. M., \& Glassow, R. B. (1963). Kinesiology. New York: Mosby Company, $140-175$.

Crowinshield, R.D., Brand, R.A. \& Johnston, R.C. (1978). The effect of velocity on the kinematics and kinetics of gait. Clinical Orthopedics and Related Research, 132, 140-144.

Do, M.C., Breniere, Y., \& Brenguier, P. (1982). A biomechanical study of balance recovery during the fall forward. J. Biomech., 15, 933-939.

Ekkubus, C.F., \& Killey, W. (1973). Validity of .5 static COF (James Machine) as a measure of safe walkway surfaces. Soap/Cosmetics/Chemical, 49(2), 40-45.

Fatkin, L. T., King, J. M., \& Hudgens, G. A. (1990). Evaluation of stress experienced by Yellowstone Army fire fighters (ARL-TM9-90). Aberdeen Proving Ground, MD: U.S. Army Research Laboratory.

Fatkin, L.T., Hudgens, G.A., Torre, J..P., King, J.M., \& Chatterton, R.T., (1991). Psychological responses to competitive markmanship. In Torre, J.P., Wansack, S., Hudgens, G.A., King, J.M., Fatkin, L.T., Mazurczak, J., \& Breitenbach, J.S. Effects of competition and mode of fire on physiological responses, psychological stress reactions, and shooting performance (HEL TM 11-91). Aberdeen Proving Ground, MD: U.S. Army Human Engineering Laboratory.

Finley, F. R., Karpovich, P.V. (1969). Locomotors patterns in elderly women. Arch. Phys. Med. and Rehab. 50:140-146. 
Gescheider, G. A. (1985). Psychophysics: Method, theory, and application. New Jersey: Lawrence Erlbaum Associates, Inc.

Gottsdanker, R. (1980). Aging and the maintenance of preparation. Exp. Aging Res., 6, 13-27.

Gronqvist, R. (1995). A dynamic method for assessing pedestrian slip resistance. Finnish Institute of Occupational Health, Helsinki 1995, Research Report 2.

Gronqvist, R., Roine, J., Jaroinen, E., \& Korhonen, E. (1989). An apparatus and a method for determining the slip resistance of shoes and floors by simulation of human foot motions. Ergonomics, 32(8), 979-995.

Herman, R., Wirta, R., Bampton, S. \& Finley, F.R. (1976). Human solutions for locomotion. I. Single limb analysis. In: Herman, R., Grillner, S., Stein, P.S.G. and Stuart, D.G. (eds.), Neural control of locomotion. Advances in behavioral Biology, 18, New York: Plenum Press.

Inman, V.T., Ralston H.J. and Todd F. (1981). Human Walking. Williams and Wilkins, Baltimore.

Kaufman, J., \& Fatkin, L. (2001). Assessment of advanced personal cooling systems for use with chemical protective outer garments. (Tech. Report). Patuxent River, MD: Naval Air Warfare Center Aircraft Division, Human Performance Technology.

Kroll, W., \& Clarkson, P.M., (1978). Age, isometric knee extension strength, and fractionated resisted response time. Exp. Aging Res., 4, 389-409.

Khuvasanont, T. (2002). The relationship between ankle strength and the gait characteristics, M.S. Thesis, Virginia Tech University,

Lachman, M. E., Howland, J., Tennstedt, S., Jette, A., Assmann, S., Peterson, E. W. (1998). Fear of falling and activity restriction: The survey of activities and fear of falling in the elderly. Psychol Sci Soc Sci., 53B, 43-50.

Lazarus, R. S., (1991). Emotion and adaptation. New York: Oxford University Press.

Levit, E. E. (1967). The psychology of anxiety. New York: Howard W. Sams \& Co., Inc.

Lishman, J.R. (1981). Vision and the Optic flow field. Nature, 293, 263-264.

Llewellyn, M. G. A. \& Nevola, V. R. (1992). Strategies for walking on low-friction surfaces, in W. A. Lotens, G. Havenith (eds.), Proceedings of the Fifth 
International Conference on Environmental Ergonomics (The Netherlands: Maastricht), pp. 156-157.

Lockhart, T.E. (1997). The ability of elderly people to traverse slippery walking surfaces. Proceedings of the Human Factors and Ergonomics Society 41 st Annual Meeting. 1: 125-129.

Lockhart, T.E. (2000). Effects of musculoskeletal and sensory degradation due to aging on the biomechanics of slips and falls, Ph.D. Dissertation, Texas Tech University.

Lockhart, T.E., Smith, J.L., Woldstad, J.C., \& Lee, P.S. (2000a). Effects of Musculoskeletal and Sensory degradation due to Aging on the Biomechanics of Slips and Falls. Proceedings of the IEA/HFES Conference, 2000. 5: 83-86.

Lockhart, T.E., Woldstad, J.C., Smith, J. L., \& Hsiang, S.M. (2000b). Prediction of Falls Using a Robust Definition of Slip Distance and Adjusted Required Coefficient of Friction. Proceedings of the IEA/HFES Conference, 2000. 4: 506-509.

Loveless, N.E. (1980). Aging effects in simple RT and voluntary movement paradigms. Prog. Brain Res., 54, 547-551.

McGuigan, F. J. (1999). Encyclopedia of stress. Boston: Joseph E. Burns.

Meserlain, E. (1995). The effects of walking cadence on static COF required by the elderly. Professional Safety, 100-110.

Michelson, L., \& Ascher, L. M. (1987). Anxiety and stress disorders: Cognitivebehavioral assessment and treatment. New York: Guildford Press.

Murray, M.P., Kory, R.C., Clarkson, B.H., \& Sepic, S.B. (1966). Comparison of slow and fast speed walking patterns of normal men. American Journal of Physical Medicine, 45, 8-24.

Murray, M.P., Kory, R.C., Clarkson, B.H. (1969). Walking patterns in healthy old men. J. Geront. 24:169-178.

National Center for Injury Prevention and control (2001). Falls: Fact Book. [Web page]. Retrieved August 13, 2001 from the world wide web:http://www.cdc.gov/ncipc/pubres/FactBook/fkfalls.htm.

Ohmichi, H., \& Miyashita, M. (1983). Relationship between step length and selected parameters in human gait. Biomechanics, VIII, Champaign, IL: Human Kinetics Publishers, 480-484. 
Perkins, P.J. (1978). Measurement of slip between the shoe and ground during walking. American Society of Testing and Materials, Special Technical Publication 649, 71-87.

Perkins, P.J., \& Wilson, M.P. (1983). Slip resistance testing of shoes - New developments. Ergonomics, 26(1), 73-82.

Prince, F., Corriveau, H., Herbert, R., Winter, D. (1997). Gait in the elderly. Gait Posture, 5, 128-135.

Rice, P. L. (1987). Stress and health: Principles and practices for coping and wellness. California: Books/Cole publishing Co.

Stachowiak, G. W., \& Batcher, A. W. (2001). Engineering tribology. Boston: Butterworth - Heinemann

Stelmach, G.E., \& Worringham, G.J. (1985). Sensor motor deficits related to postural stability: Implication for falling in elderly. Clin. Geriatr. Med., 1, 1679.

Strandberg, L., and Lanshammar, H. (1981). The dynamics of slipping accidents. Journal of Occupational Accidents, 3, 153-162.

Swensen, E., Purswell, J., Schlegel, R., and Stanevich, R. (1992). Coefficient of friction and subjective assessment of slippery work surfaces, Human Factors, 34, 67-77.

Tinnetti, M.E., Speechley M., \& Ginter, S.F., 1988, Risk factors for falls among elderly persons living in the community. N. Engl. J. Med., 319, 17011707.

Winer, B. J., Brown, D. R., and Michels, K. M. (1991). statistical Principles in Experimental Design ( ${ }^{\text {rd }}$. ed.). New York, NY: McGraw-Hill.

Winter, D. A., Patla, A. E., Frank, J. S., and Walt, S. E. (1990). Biomechanical walking pattern changes in the fit and healthy elderly. Phys. Ther. 70: 340-347.

Winter, D.A. (1990). Biomechanics and Motor Control of Human Movement. 2nd Edit. John Wiley \& Sons, Inc. 


\author{
APPENDIX A: Informed Consent Form \\ Informed Consent for Participants of Investigative Projects \\ Grado Department of Industrial and Systems Engineering \\ Virginia Polytechnic Institute and State University
}

TITLE: Effects of Aging on the Biomechanics of Slips and Falls

PRINCIPAL INVESTIGATOR: Thurmon E. Lockhart Ph.D.

\title{
PURPOSE
}

This is an experiment to investigate the changes in biomechanical parameters and ground reaction forces due to an increase in age. The objective of this experiment is to measure the aging effect on different conditions with or without contaminant (oil).

\section{PROCEDURE}

This study will last two days consisting of a familiarization session and body composition measurements, and a 20-minute walking experiment. Prior to this experiment, you will be given an opportunity to walk around the laboratory wearing a harness to familiarize yourself with the equipment (fall arresting harness), and floor surfaces. Next, you will be asked to walk across the oily or dry floor surface for 20 minutes. While you are walking along the path, please keep your eyes looking straight ahead and try to maintain the speed that you practiced.

After the familiarization session, an initial saliva sample will be collected and three other samples will be collected during the walking experiment. The saliva samples will be sent to Northwestern University to be analyzed. Next, you will be asked to walk on specially prepared floor surfaces. The floor surface that you will walk across may or may not be slippery. As you experienced in the familiarization session, the harness system will protect you and only allow you to "fall or slip" 3 or 4 inches.

Postural sway will be measured by having you stand on a force platform with your feet comfortably shoulder width apart. Movement of the feet while on the platform is not required. For your safety and confidence, you will be asked to wear a safety harness. These testing procedures are not designed to make you lose your balance. One of the procedures requires you to close your eyes while attempting to remain as still as possible, and the next procedure will have you remain as still as possible with your eyes open. You can move your feet between measurements and use the grab bars to maintain your balance between tasks.

Additionally, a strength test will be performed using a dynamometer. To test the leg strength, you will be asked to sit on Biodex chair with backrest. The vertical height of the chair will be adjusted to accommodate your popliteal height. The speed selector will be set at 30,60, and 90 degrees per second. The tests will be performed for the range of 0 to $90^{\circ}$ of flexion. The leg will begin in the neutral, $0^{\circ}$ position corresponding to a straight, 
extended leg, and proceed to trace out a bending motion until the upper and lower portions of the leg forms a $90^{\circ}$ angle. You will be asked to apply three maximal torques at each velocity as suggested by the Biodex Dynamometer Exercise Manual.

\section{RISKS OF PARTICIPATION}

Minor muscle sprain if you lose your balance while walking on the floor surface.

\section{BENEFITS AND COMPENSATION}

The benefits to you are a better understanding of floor surface slipperiness, which could lead to preventing slips and falls in the elderly. Additionally, monetary compensation will be provided at a rate of $\$ 10.00$ per hour.

\section{ANOYNMITY AND CONFIDENTIALITY}

The data from this study will be kept strictly confidential. No data will be released to anyone but the principal investigator and graduate students involved in the project without written consent of the participant. Participant numbers will be used to identify data.

\section{FREEDOM TO WITHDRAW}

You are free to withdraw from the study at any time and for any reason. Also, circumstances may arise, which might cause the researcher to conclude that you should not continue as a participant in the study. For example, an illness could be a reason to terminate your participation in the study.

\section{APPROVAL OF RESEARCH}

This research has been approved, as required, by the Institutional Review Board for Research Involving Human Participants at Virginia Tech, and by the Grado Department of Industrial and Systems Engineering. You will receive a copy of this from to take with you.

\section{PARTICIPANT PERMISSION}

I have read the informed consent and fully understand the procedures and conditions of the study. I have had all my questions answered, and I hereby give my voluntary consent to be a participant in this research study. I agree to abide by the rules of the study. I understand that I may withdraw from the study at any time.

If I have questions, I will contact:

Pricipal Investigator: Thurmon E. Lockhart, Assistant Professor, Grado Department of Industrial and Systems Engineering, 231-9088.

Chairman, Institutional Review Board for Research Involving Human Subjects: David Moore, 231-4991.

Signature of Participant:

Date 
Signature of Project Director or his Authorized Representative:

Date

Signature of Witness to Oral Presentation:

Date 


\section{APPENDIX B: Personal Data and Medical History}

Personal Data and Medical History

Grado Department of Industrial and Systems Engineering

Virginia Polytechnic Institute and State University

Effects of Aging on the Biomechanics of Slips and Falls Date

\section{Personal Data}

Name

Age

Sex

Height (cm)

Weight $(\mathrm{kg})$

In case of emergency contact: Name Phone

\section{Medical History}

1. Please check if susceptible to Shortness of breath Dizziness

Fatigue

Pain in arm, shoulder or chest

If you checked any of the items above, please explain:

2. Please answer these questions (Yes or No)

2.1 Have you ever had a heart attack?

If so, please explain

2.2 Are you currently taking any type of medication? explain

if so, please

2.3 Have you had or do you now have any problems with your blood pressure?

If so, please explain

2.4 In the last 6 month, have you had any back pain?

If so, please explain

2.5 Have you had or do you now have a hernia? If so, please explain 
2.6 Have you had or do you now have any problems with ankle, knee, or hip (surgery, injuries, replacements)? if so, please explain

2.7 Have you currently had osteoporosis or treated with osteoporosis? If so, please explain

2.8 Have you had or do you now have any inner ear or balance problems? If so, please explain

2.9 Have you experienced slips and falls? If so, how long ago? $\overline{\text { Please explain }}$

2.10 Have you had visual problems? if so, please explain 
APPENDIX C: Multiple Affects Adjective Check List (MAACL)

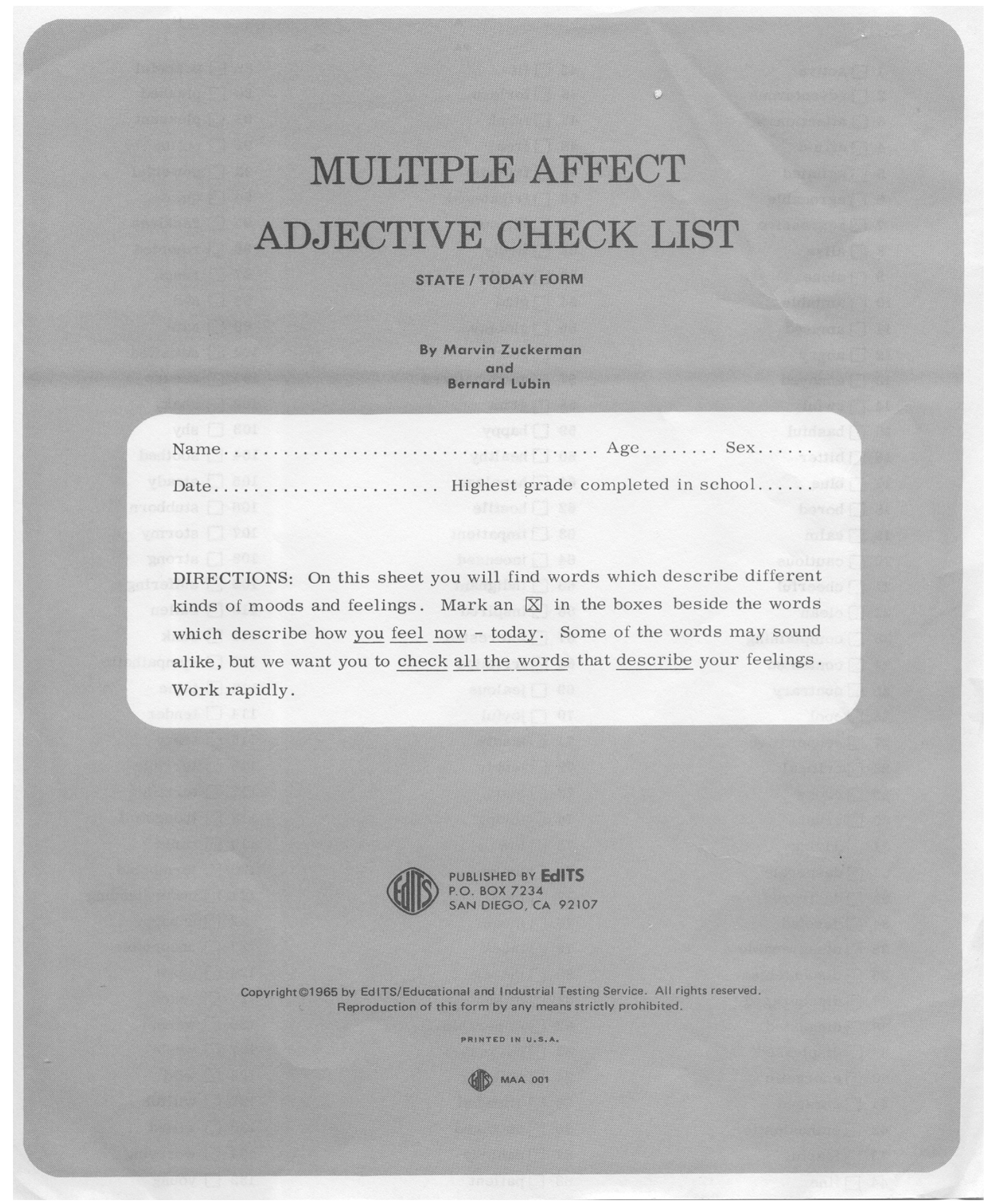




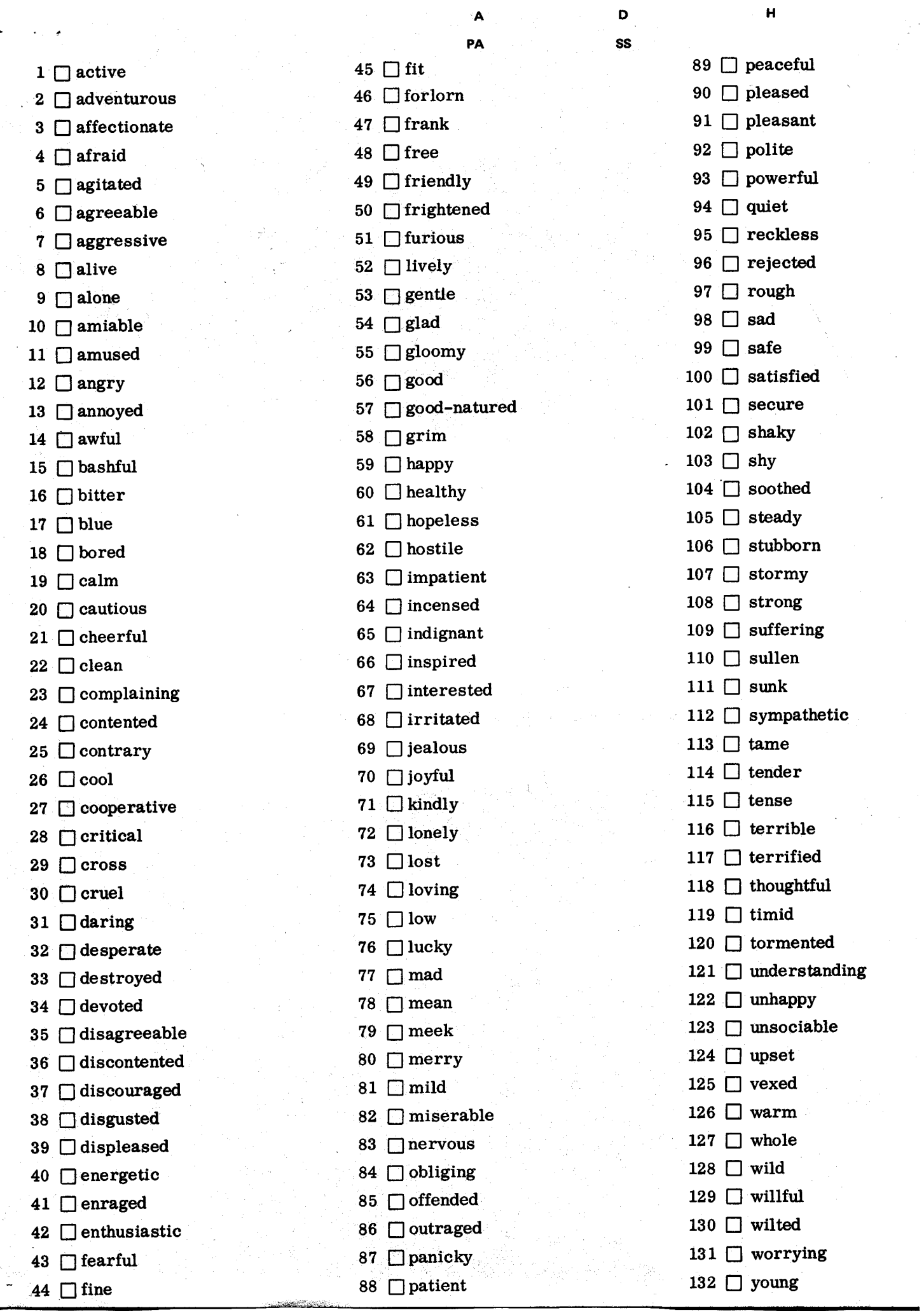




\section{VITA}

Thomas W. Davis

Upon graduation from High School in 1979, Mr. Davis joined the U.S. Army and served on active duty for nine years. After leaving the military in 1988, Mr. Davis became a Federal Civil Servant and has over 22 years of Federal service. He is currently an Engineer (Human Factors) with the U. S. Army Research Laboratory. Prior to accepting a position with the Army Research laboratory, Mr. Davis worked for the U.S. Army Test Measurement and Diagnostic Equipment Support Center as chief of the Physical Standards Laboratory. Mr. Davis earned a Bachelor of Science degree from North Carolina Agricultural and Technical State University (NC A\&T State University) in December 1999. In 1998, Mr. Davis was selected for "Who’s Who Among Students In American Universities and Colleges" for outstanding merit and accomplishment while at NC A\&T State University. Also, in 1998, Mr. Davis was selected as an "Outstanding Young Man of America" by the office of Outstanding Young Americans in recognition of his leadership ability, professional achievement, and service to his community. Mr. Davis is a member of several professional societies to include: Psi Chi, the National Honor Society in Psychology, Alpha Pi Mu, the National Honor Society for Industrial Engineering, and the Human Factors and Ergonomics Society. 